\title{
Global Carbon Budget 2019
}

Pierre Friedlingstein ${ }^{1,2}$, Matthew W. Jones ${ }^{3}$, Michael O'Sullivan ${ }^{1}$, Robbie M. Andrew ${ }^{4}$, Judith Hauck ${ }^{5}$, Glen P. Peters ${ }^{4}$, Wouter Peters ${ }^{6,7}$, Julia Pongratz ${ }^{8,9}$, Stephen Sitch ${ }^{10}$, Corinne Le Quéré ${ }^{3}$,

Dorothee C. E. Bakker ${ }^{3}$, Josep G. Canadell ${ }^{11}$, Philippe Ciais ${ }^{12}$, Robert B. Jackson ${ }^{13}$, Peter Anthoni ${ }^{14}$, Leticia Barbero $^{15,16}$, Ana Bastos ${ }^{8}$, Vladislav Bastrikov ${ }^{12}$, Meike Becker ${ }^{17,18}$, Laurent Bopp ${ }^{2}$, Erik Buitenhuis $^{3}$, Naveen Chandra ${ }^{19}$, Frédéric Chevallier ${ }^{12}$, Louise P. Chini ${ }^{20}$, Kim I. Currie ${ }^{21}$, Richard A. Feely ${ }^{22}$, Marion Gehlen ${ }^{12}$, Dennis Gilfillan ${ }^{23}$, Thanos Gkritzalis ${ }^{24}$, Daniel S. Goll ${ }^{25}$, Nicolas Gruber ${ }^{26}$, Sören Gutekunst ${ }^{27}$, Ian Harris ${ }^{28}$, Vanessa Haverd ${ }^{11}$, Richard A. Houghton ${ }^{29}$, George Hurtt $^{20}$, Tatiana Ilyina ${ }^{9}$, Atul K. Jain ${ }^{30}$, Emilie Joetzjer ${ }^{31}$, Jed O. Kaplan ${ }^{32}$, Etsushi Kato ${ }^{33}$, Kees Klein Goldewijk ${ }^{34,35}$, Jan Ivar Korsbakken ${ }^{4}$, Peter Landschützer ${ }^{9}$, Siv K. Lauvset ${ }^{36,18}$, Nathalie Lefèvre $^{37}$, Andrew Lenton ${ }^{38,39}$, Sebastian Lienert ${ }^{40}$, Danica Lombardozzi ${ }^{41}$, Gregg Marland ${ }^{23}$, Patrick C. McGuire ${ }^{42}$, Joe R. Melton ${ }^{43}$, Nicolas Metzl ${ }^{37}$, David R. Munro ${ }^{44}$, Julia E. M. S. Nabel ${ }^{9}$, Shin-Ichiro Nakaoka ${ }^{45}$, Craig Neill ${ }^{38}$, Abdirahman M. Omar ${ }^{38,18}$, Tsuneo Ono ${ }^{46}$, Anna Peregon ${ }^{12,47}$, Denis Pierrot ${ }^{15,16}$, Benjamin Poulter ${ }^{48}$, Gregor Rehder ${ }^{49}$, Laure Resplandy ${ }^{50}$, Eddy Robertson ${ }^{51}$, Christian Rödenbeck $^{52}$, Roland Séférian ${ }^{53}$, Jörg Schwinger ${ }^{34,18}$, Naomi Smith ${ }^{6,54}$, Pieter P. Tans ${ }^{55}$, Hanqin Tian ${ }^{56}$, Bronte Tilbrook ${ }^{38,57}$, Francesco N. Tubiello ${ }^{58}$, Guido R. van der Werf ${ }^{59}$, Andrew J. Wiltshire ${ }^{51}$, and Sönke Zaehle ${ }^{52}$

${ }^{1}$ College of Engineering, Mathematics and Physical Sciences, University of Exeter, Exeter EX4 4QF, UK

${ }^{2}$ Laboratoire de Meteorologie Dynamique, Institut Pierre-Simon Laplace, CNRS-ENS-UPMC-X, Departement de Geosciences, Ecole Normale Superieure, 24 rue Lhomond, 75005 Paris, France

${ }^{3}$ Tyndall Centre for Climate Change Research, School of Environmental Sciences, University of East Anglia, Norwich Research Park, Norwich NR4 7TJ, UK

${ }^{4}$ CICERO Center for International Climate Research, Oslo 0349, Norway

${ }^{5}$ Alfred Wegener Institute Helmholtz Centre for Polar and Marine Research, Postfach 120161, 27515 Bremerhaven, Germany

${ }^{6}$ Wageningen University, Environmental Sciences Group, P.O. Box 47, 6700AA, Wageningen, the Netherlands

${ }^{7}$ University of Groningen, Centre for Isotope Research, Groningen, the Netherlands

${ }^{8}$ Ludwig-Maximilians-Universität München, Luisenstr. 37, 80333 Munich, Germany

${ }^{9}$ Max Planck Institute for Meteorology, Hamburg, Germany

${ }^{10}$ College of Life and Environmental Sciences, University of Exeter, Exeter EX4 4RJ, UK

${ }^{11}$ CSIRO Oceans and Atmosphere, G.P.O. Box 1700, Canberra, ACT 2601, Australia

${ }^{12}$ Laboratoire des Sciences du Climat et de l'Environnement, Institut Pierre-Simon Laplace,

CEA-CNRS-UVSQ, CE Orme des Merisiers, 91191 Gif-sur-Yvette CEDEX, France

${ }^{13}$ Department of Earth System Science, Woods Institute for the Environment, and Precourt Institute for Energy, Stanford University, Stanford, CA 94305-2210, USA

${ }^{14}$ Karlsruhe Institute of Technology, Institute of Meteorology and Climate,

Research/Atmospheric Environmental Research, 82467 Garmisch-Partenkirchen, Germany

${ }^{15}$ Cooperative Institute for Marine and Atmospheric Studies, Rosenstiel School for Marine and Atmospheric Science, University of Miami, Miami, FL 33149, USA

${ }^{16}$ National Oceanic \& Atmospheric Administration/Atlantic Oceanographic \& Meteorological Laboratory (NOAA/AOML), Miami, FL 33149, USA

${ }^{17}$ Geophysical Institute, University of Bergen, Bergen, Norway

${ }^{18}$ Bjerknes Centre for Climate Research, Allegaten 70, 5007 Bergen, Norway

${ }^{19}$ Earth Surface System Research Center (ESS), Japan Agency for Marine-Earth Science and Technology (JAMSTEC), Yokohama, 236-0001, Japan 
${ }^{20}$ Department of Geographical Sciences, University of Maryland, College Park, Maryland 20742, USA

${ }^{21}$ NIWA/UoO Research Centre for Oceanography, P.O. Box 56, Dunedin 9054, New Zealand

${ }^{22}$ Pacific Marine Environmental Laboratory, National Oceanic and Atmospheric Administration, 7600 Sand Point Way NE, Seattle, WA 98115-6349, USA

${ }^{23}$ Research Institute for Environment, Energy, and Economics, Appalachian State University, Boone, North Carolina, USA

${ }^{24}$ Flanders Marine Institute (VLIZ), InnovOceanSite, Wandelaarkaai 7, 8400 Ostend, Belgium

${ }^{25}$ Lehrstuhl fur Physische Geographie mit Schwerpunkt Klimaforschung, Universität Augsburg, Augsburg, Germany

${ }^{26}$ Environmental Physics Group, ETH Zurich, Institute of Biogeochemistry and Pollutant Dynamics and Center for Climate Systems Modeling (C2SM), Zurich, Switzerland

${ }^{27}$ GEOMAR Helmholtz Centre for Ocean Research Kiel, Dusternbrooker Weg 20, 24105 Kiel, Germany

${ }^{28}$ NCAS-Climate, Climatic Research Unit, School of Environmental Sciences,

University of East Anglia, Norwich Research Park, Norwich NR4 7TJ, UK

${ }^{29}$ Woods Hole Research Center (WHRC), Falmouth, MA 02540, USA

${ }^{30}$ Department of Atmospheric Sciences, University of Illinois, Urbana, IL 61821, USA

${ }^{31}$ Centre National de Recherche Meteorologique, Unite mixte de recherche 3589 Meteo-France/CNRS, 42 Avenue Gaspard Coriolis, 31100 Toulouse, France

${ }^{32}$ Department of Earth Sciences, University of Hong Kong, Pokfulam Road, Hong Kong

${ }^{33}$ Institute of Applied Energy (IAE), Minato-ku, Tokyo 105-0003, Japan

${ }^{34}$ PBL Netherlands Environmental Assessment Agency, Bezuidenhoutseweg 30, P.O. Box 30314, $2500 \mathrm{GH}$, The Hague, the Netherlands

${ }^{35}$ Faculty of Geosciences, Department IMEW, Copernicus Institute of Sustainable Development, Heidelberglaan 2, P.O. Box 80115, 3508 TC, Utrecht, the Netherlands

${ }^{36}$ NORCE Norwegian Research Centre, NORCE Climate, Jahnebakken 70, 5008 Bergen, Norway

${ }^{37}$ LOCEAN/IPSL laboratory, Sorbonne Université, CNRS/IRD/MNHN, Paris, France

${ }^{38}$ CSIRO Oceans and Atmosphere, Hobart, Tasmania, Australia

${ }^{39}$ Institute for Marine and Antarctic Studies, University of Tasmania, Hobart, Tasmania, Australia

${ }^{40}$ Climate and Environmental Physics, Physics Institute and Oeschger Centre for

Climate Change Research, University of Bern, Bern, Switzerland

${ }^{41}$ National Center for Atmospheric Research, Climate and Global Dynamics,

Terrestrial Sciences Section, Boulder, CO 80305, USA

${ }^{42}$ Department of Meteorology, Department of Geography \& Environmental Science,

National Centre for Atmospheric Science, University of Reading, Reading, UK

${ }^{43}$ Climate Research Division, Environment and Climate Change Canada, Victoria, BC, Canada

${ }^{44}$ Cooperative Institute for Research in Environmental Sciences, University of Colorado, Boulder, CO, USA

${ }^{45}$ Center for Global Environmental Research, National Institute for Environmental Studies (NIES), 16-2 Onogawa, Tsukuba, Ibaraki, 305-8506, Japan

${ }^{46}$ Japan Fisheries Research and Education Agency, 2-12-4 Fukuura, Kanazawa-Ku, Yokohama 236-8648, Japan

${ }^{47}$ Institute of Soil Science and Agrochemistry, Siberian Branch Russian Academy of Sciences (SB RAS), Pr. Akademika Lavrentyeva, 8/2, 630090, Novosibirsk, Russia

${ }^{48}$ NASA Goddard Space Flight Center, Biospheric Sciences Laboratory, Greenbelt, Maryland 20771, USA

${ }^{49}$ Leibniz Institute for Baltic Sea Research Warnemuende (IOW), Seestrasse 15, 18119 Rostock, Germany

${ }^{50}$ Princeton University, Department of Geosciences and Princeton Environmental Institute, Princeton, NJ, USA

${ }^{51}$ Met Office Hadley Centre, FitzRoy Road, Exeter EX1 3PB, UK

${ }^{52}$ Max Planck Institute for Biogeochemistry, P.O. Box 600164, Hans-Knöll-Str. 10, 07745 Jena, Germany

${ }^{53}$ CNRM (Météo-France/CNRS)-UMR, 3589, Toulouse, France

${ }^{54}$ ICOS Carbon Portal, Lund University, Lund, Sweden

${ }^{55}$ National Oceanic \& Atmospheric Administration, Earth System Research Laboratory

(NOAA ESRL), Boulder, CO 80305, USA

${ }^{56}$ International Center for Climate and Global Change Research, School of Forestry and Wildlife Sciences,

Auburn University, 602 Ducan Drive, Auburn, AL 36849, USA

${ }^{57}$ Australian Antarctic Partnership Program, University of Tasmania, Hobart, Tasmania, Australia

${ }^{58}$ Statistics Division, Food and Agriculture Organization of the United Nations, Via Terme di Caracalla, Rome 00153, Italy 
${ }^{59}$ Faculty of Science, Vrije Universiteit, Amsterdam, the Netherlands

Correspondence: Pierre Friedlingstein (p.friedlingstein@exeter.ac.uk)

Received: 1 October 2019 - Discussion started: 10 October 2019

Revised: 10 October 2019 - Accepted: 28 October 2019 - Published: 4 December 2019

\begin{abstract}
Accurate assessment of anthropogenic carbon dioxide $\left(\mathrm{CO}_{2}\right)$ emissions and their redistribution among the atmosphere, ocean, and terrestrial biosphere - the "global carbon budget" - is important to better understand the global carbon cycle, support the development of climate policies, and project future climate change. Here we describe data sets and methodology to quantify the five major components of the global carbon budget and their uncertainties. Fossil $\mathrm{CO}_{2}$ emissions $\left(E_{\mathrm{FF}}\right)$ are based on energy statistics and cement production data, while emissions from land use change $\left(E_{\mathrm{LUC}}\right)$, mainly deforestation, are based on land use and land use change data and bookkeeping models. Atmospheric $\mathrm{CO}_{2}$ concentration is measured directly and its growth rate $\left(G_{\text {ATM }}\right)$ is computed from the annual changes in concentration. The ocean $\mathrm{CO}_{2}$ sink $\left(S_{\text {OCEAN }}\right)$ and terrestrial $\mathrm{CO}_{2}$ sink $\left(S_{\text {LAND }}\right)$ are estimated with global process models constrained by observations. The resulting carbon budget imbalance $\left(B_{\mathrm{IM}}\right)$, the difference between the estimated total emissions and the estimated changes in the atmosphere, ocean, and terrestrial biosphere, is a measure of imperfect data and understanding of the contemporary carbon cycle. All uncertainties are reported as $\pm 1 \sigma$. For the last decade available (2009-2018), $E_{\mathrm{FF}}$ was $9.5 \pm 0.5 \mathrm{GtC} \mathrm{yr}^{-1}, E_{\mathrm{LUC}} 1.5 \pm 0.7 \mathrm{GtC} \mathrm{yr}^{-1}, G_{\mathrm{ATM}} 4.9 \pm 0.02 \mathrm{GtC} \mathrm{yr}^{-1}\left(2.3 \pm 0.01 \mathrm{ppm} \mathrm{yr}^{-1}\right), S_{\text {OCEAN }}$ $2.5 \pm 0.6 \mathrm{GtC} \mathrm{yr}^{-1}$, and $S_{\mathrm{LAND}} 3.2 \pm 0.6 \mathrm{GtC} \mathrm{yr}^{-1}$, with a budget imbalance $B_{\mathrm{IM}}$ of $0.4 \mathrm{GtC} \mathrm{yr}^{-1}$ indicating overestimated emissions and/or underestimated sinks. For the year 2018 alone, the growth in $E_{\mathrm{FF}}$ was about $2.1 \%$ and fossil emissions increased to $10.0 \pm 0.5 \mathrm{GtC} \mathrm{yr}^{-1}$, reaching $10 \mathrm{GtC} \mathrm{yr}^{-1}$ for the first time in history, $E_{\mathrm{LUC}}$ was $1.5 \pm 0.7 \mathrm{GtC} \mathrm{yr}^{-1}$, for total anthropogenic $\mathrm{CO}_{2}$ emissions of $11.5 \pm 0.9 \mathrm{GtC} \mathrm{yr}^{-1}\left(42.5 \pm 3.3 \mathrm{GtCO}_{2}\right)$. Also for $2018, G_{\text {ATM }}$ was $5.1 \pm 0.2 \mathrm{GtC} \mathrm{yr}^{-1}\left(2.4 \pm 0.1 \mathrm{ppm} \mathrm{yr}^{-1}\right), S_{\text {OCEAN }}$ was $2.6 \pm 0.6 \mathrm{GtC} \mathrm{yr}^{-1}$, and $S_{\text {LAND }}$ was $3.5 \pm 0.7 \mathrm{GtC} \mathrm{yr}^{-1}$, with a $B_{\mathrm{IM}}$ of $0.3 \mathrm{GtC}$. The global atmospheric $\mathrm{CO}_{2}$ concentration reached $407.38 \pm 0.1 \mathrm{ppm}$ averaged over 2018. For 2019, preliminary data for the first 6-10 months indicate a reduced growth in $E_{\mathrm{FF}}$ of $+0.6 \%$ (range of $-0.2 \%$ to $1.5 \%$ ) based on national emissions projections for China, the USA, the EU, and India and projections of gross domestic product corrected for recent changes in the carbon intensity of the economy for the rest of the world. Overall, the mean and trend in the five components of the global carbon budget are consistently estimated over the period 1959-2018, but discrepancies of up to $1 \mathrm{GtC} \mathrm{yr}^{-1}$ persist for the representation of semi-decadal variability in $\mathrm{CO}_{2}$ fluxes. A detailed comparison among individual estimates and the introduction of a broad range of observations shows (1) no consensus in the mean and trend in land use change emissions over the last decade, (2) a persistent low agreement between the different methods on the magnitude of the land $\mathrm{CO}_{2}$ flux in the northern extra-tropics, and (3) an apparent underestimation of the $\mathrm{CO}_{2}$ variability by ocean models outside the tropics. This living data update documents changes in the methods and data sets used in this new global carbon budget and the progress in understanding of the global carbon cycle compared with previous publications of this data set (Le Quéré et al., 2018a, b, 2016, 2015a, b, 2014, 2013). The data generated by this work are available at https://doi.org/10.18160/gcp-2019 (Friedlingstein et al., 2019).
\end{abstract}

\section{Introduction}

The concentration of carbon dioxide $\left(\mathrm{CO}_{2}\right)$ in the atmosphere has increased from approximately 277 parts per million (ppm) in 1750 (Joos and Spahni, 2008), the beginning of the Industrial Era, to $407.38 \pm 0.1 \mathrm{ppm}$ in 2018 (Dlugokencky and Tans, 2019; Fig. 1 from this paper). The atmospheric $\mathrm{CO}_{2}$ increase above pre-industrial levels was, initially, primarily caused by the release of carbon to the atmosphere from deforestation and other land use change activities (Ciais et al., 2013). While emissions from fossil fuels started before the Industrial Era, they only became the dominant source of anthropogenic emissions to the atmosphere from around
1950 and their relative share has continued to increase until present. Anthropogenic emissions occur on top of an active natural carbon cycle that circulates carbon between the reservoirs of the atmosphere, ocean, and terrestrial biosphere on timescales from sub-daily to millennia, while exchanges with geologic reservoirs occur at longer timescales (Archer et al., 2009).

The global carbon budget presented here refers to the mean, variations, and trends in the perturbation of $\mathrm{CO}_{2}$ in the environment, referenced to the beginning of the Industrial Era (defined here as 1750). This paper describes the components of the global carbon cycle over the historical period with a stronger focus on the recent period (since 1958, onset 


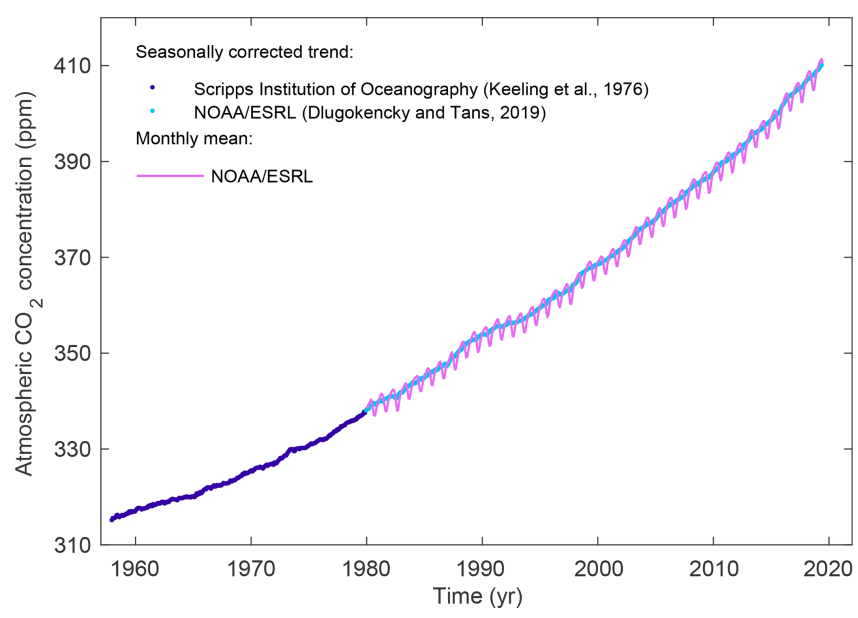

Figure 1. Surface average atmospheric $\mathrm{CO}_{2}$ concentration (ppm). The 1980-2018 monthly data are from NOAA ESRL (Dlugokencky and Tans, 2019) and are based on an average of direct atmospheric $\mathrm{CO}_{2}$ measurements from multiple stations in the marine boundary layer (Masarie and Tans, 1995). The 1958-1979 monthly data are from the Scripps Institution of Oceanography, based on an average of direct atmospheric $\mathrm{CO}_{2}$ measurements from the Mauna Loa and South Pole stations (Keeling et al., 1976). To take into account the difference of mean $\mathrm{CO}_{2}$ and seasonality between the NOAA ESRL and the Scripps station networks used here, the Scripps surface average (from two stations) was deseasonalised and harmonised to match the NOAA ESRL surface average (from multiple stations) by adding the mean difference of $0.542 \mathrm{ppm}$, calculated here from overlapping data during 1980-2012.

of atmospheric $\mathrm{CO}_{2}$ measurements), the last decade (20092018), and the current year (2019). We quantify the input of $\mathrm{CO}_{2}$ to the atmosphere by emissions from human activities, the growth rate of atmospheric $\mathrm{CO}_{2}$ concentration, and the resulting changes in the storage of carbon in the land and ocean reservoirs in response to increasing atmospheric $\mathrm{CO}_{2}$ levels, climate change and variability, and other anthropogenic and natural changes (Fig. 2). An understanding of this perturbation budget over time and the underlying variability and trends in the natural carbon cycle is necessary to also understand the response of natural sinks to changes in climate, $\mathrm{CO}_{2}$ and land use change drivers, and the permissible emissions for a given climate stabilisation target. Note that this paper does not estimate the remaining future carbon emissions consistent with a given climate target (often referred to as the remaining carbon budget; Millar et al., 2017; Rogelj et al., 2016, 2019).

The components of the $\mathrm{CO}_{2}$ budget that are reported annually in this paper include separate estimates for the $\mathrm{CO}_{2}$ emissions from (1) fossil fuel combustion and oxidation from all energy and industrial processes and cement production

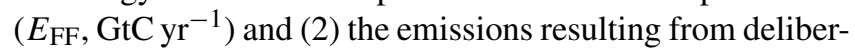
ate human activities on land, including those leading to land use change ( $E_{\mathrm{LUC}}, \mathrm{GtC}_{\mathrm{yr}^{-1}}$ ), as well as their partitioning among (3) the growth rate of atmospheric $\mathrm{CO}_{2}$ concentration
$\left(G_{\mathrm{ATM}}, \mathrm{GtC} \mathrm{yr}^{-1}\right)$, and the uptake of $\mathrm{CO}_{2}$ (the "CO 2 sinks") in (4) the ocean $\left(S_{\text {OCEAN }}, \mathrm{GtC} \mathrm{yr}^{-1}\right)$ and $(5)$ on land $\left(S_{\text {LAND, }}\right.$,

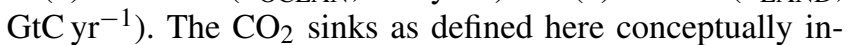
clude the response of the land (including inland waters and estuaries) and ocean (including coasts and territorial sea) to elevated $\mathrm{CO}_{2}$ and changes in climate, rivers, and other environmental conditions, although in practice not all processes are fully accounted for (see Sect. 2.7). The global emissions and their partitioning among the atmosphere, ocean, and land are in reality in balance; however due to imperfect spatial and/or temporal data coverage, errors in each estimate, and smaller terms not included in our budget estimate (discussed in Sect. 2.7), their sum does not necessarily add up to zero. We estimate a budget imbalance $\left(B_{\mathrm{IM}}\right)$, which is a measure of the mismatch between the estimated emissions and the estimated changes in the atmosphere, land, and ocean, with the full global carbon budget as follows:

$E_{\mathrm{FF}}+E_{\mathrm{LUC}}=G_{\mathrm{ATM}}+S_{\mathrm{OCEAN}}+S_{\mathrm{LAND}}+B_{\mathrm{IM}}$.

$G_{\mathrm{ATM}}$ is usually reported in parts per million per year, which

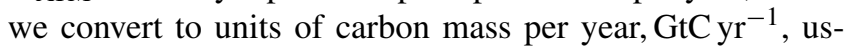
ing $1 \mathrm{ppm}=2.124 \mathrm{GtC}$ (Ballantyne et al., 2012; Table 1). We also include a quantification of $E_{\mathrm{FF}}$ by country, computed with both territorial and consumption-based accounting (see Sect. 2), and we discuss missing terms from sources other than the combustion of fossil fuels (see Sect. 2.7).

The $\mathrm{CO}_{2}$ budget has been assessed by the Intergovernmental Panel on Climate Change (IPCC) in all assessment reports (Prentice et al., 2001; Schimel et al., 1995; Watson et al., 1990; Denman et al., 2007; Ciais et al., 2013), and by others (e.g. Ballantyne et al., 2012). The IPCC methodology has been revised and used by the Global Carbon Project (GCP, https://www.globalcarbonproject.org, last access: 27 September 2019), which has coordinated this cooperative community effort for the annual publication of global carbon budgets for the year 2005 (Raupach et al., 2007; including fossil emissions only), year 2006 (Canadell et al., 2007), year 2007 (published online; GCP, 2007), year 2008 (Le Quéré et al., 2009), year 2009 (Friedlingstein et al., 2010), year 2010 (Peters et al., 2012b), year 2012 (Le Quéré et al., 2013; Peters et al., 2013), year 2013 (Le Quéré et al., 2014), year 2014 (Le Quéré et al., 2015a; Friedlingstein et al., 2014), year 2015 (Jackson et al., 2016; Le Quéré et al., 2015b), year 2016 (Le Quéré et al., 2016), year 2017 (Le Quéré et al., 2018a; Peters et al., 2017), and most recently year 2018 (Le Quéré et al., 2018b; Jackson et al., 2018). Each of these papers updated previous estimates with the latest available information for the entire time series.

We adopt a range of \pm 1 standard deviation $(\sigma)$ to report the uncertainties in our estimates, representing a likelihood of $68 \%$ that the true value will be within the provided range if the errors have a Gaussian distribution and no bias is assumed. This choice reflects the difficulty of characterising the uncertainty in the $\mathrm{CO}_{2}$ fluxes between the atmosphere and the ocean and land reservoirs individually, particularly 


\section{The global carbon cycle}

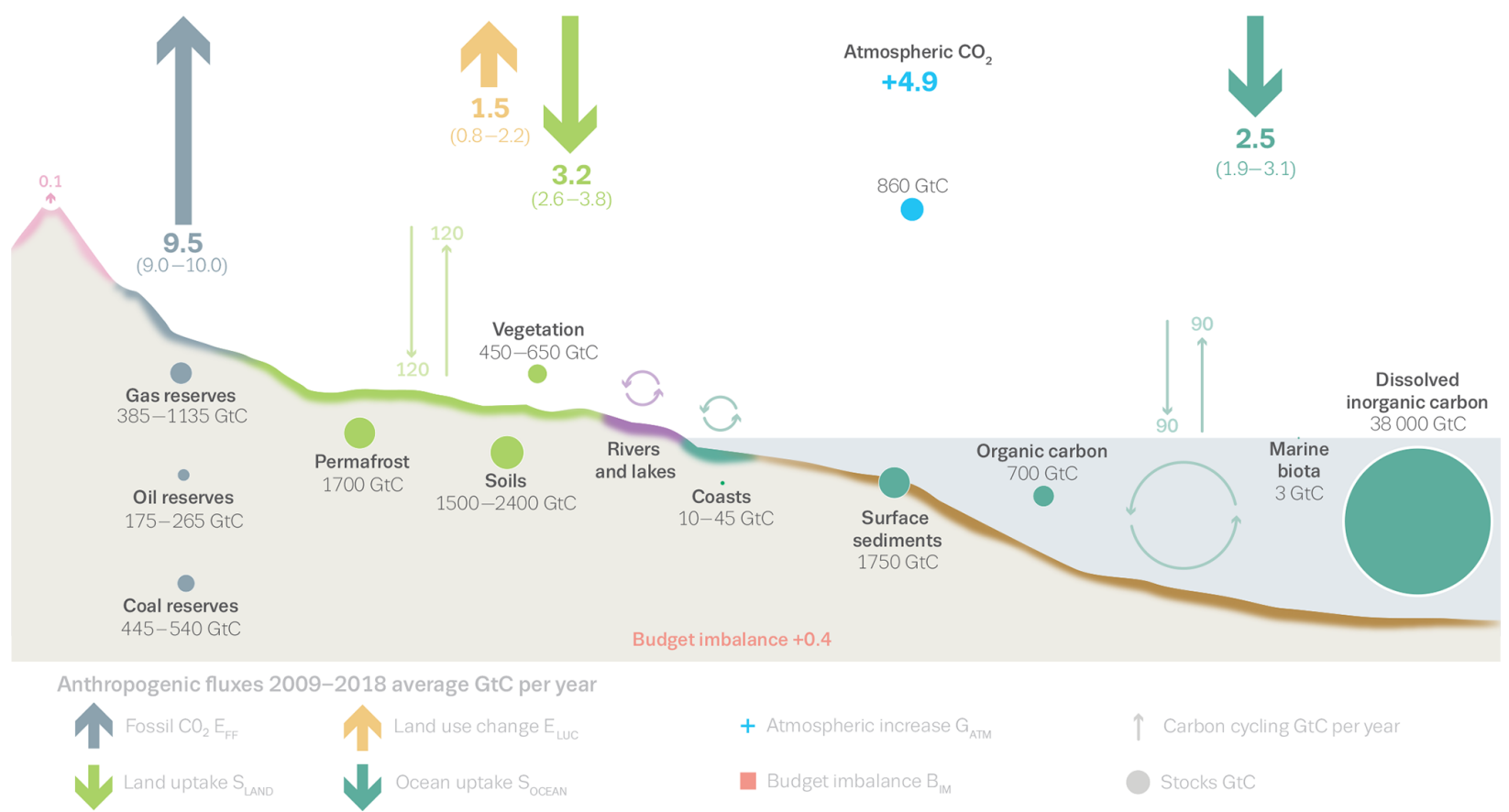

Figure 2. Schematic representation of the overall perturbation of the global carbon cycle caused by anthropogenic activities, averaged globally for the decade 2009-2018. See legends for the corresponding arrows and units. The uncertainty in the atmospheric $\mathrm{CO}_{2}$ growth rate is very small $\left( \pm 0.02 \mathrm{GtC} \mathrm{yr}^{-1}\right)$ and is neglected for the figure. The anthropogenic perturbation occurs on top of an active carbon cycle, with fluxes and stocks represented in the background and taken from Ciais et al. (2013) for all numbers, with the ocean gross fluxes updated to $90 \mathrm{GtC} \mathrm{yr}^{-1}$ to account for the increase in atmospheric $\mathrm{CO}_{2}$ since publication, and except for the carbon stocks in coasts, which are from a literature review of coastal marine sediments (Price and Warren, 2016).

Table 1. Factors used to convert carbon in various units (by convention, unit $1=$ unit $2 \times$ conversion).

\begin{tabular}{llrl}
\hline Unit 1 & Unit 2 & Conversion & Source \\
\hline $\mathrm{GtC}$ (gigatonnes of carbon) & ppm (parts per million) & $2.124^{\mathrm{b}}$ & Ballantyne et al. (2012) \\
$\mathrm{GtC}$ (gigatonnes of carbon) & $\mathrm{PgC}$ (petagrams of carbon) & 1 & SI unit conversion \\
$\mathrm{GtCO}_{2}$ (gigatonnes of carbon dioxide) & $\mathrm{GtC}$ (gigatonnes of carbon) & 3.664 & $44.01 / 12.011$ in mass equivalent \\
$\mathrm{GtC}$ (gigatonnes of carbon) & $\mathrm{MtC}$ (megatonnes of carbon) & 1000 & SI unit conversion \\
\hline
\end{tabular}

a Measurements of atmospheric $\mathrm{CO}_{2}$ concentration have units of dry-air mole fraction. "ppm" is an abbreviation for $\mu \mathrm{m}$ mol ${ }^{-1}$, dry air. ${ }^{\mathrm{b}}$ The use of a factor of 2.124 assumes that the whole atmosphere is well mixed within 1 year. In reality, only the troposphere is well mixed and the growth rate of $\mathrm{CO}_{2}$ concentration in the less well-mixed stratosphere is not measured by sites from the NOAA network. Using a factor of 2.124 makes the approximation that the growth rate of $\mathrm{CO}_{2}$ concentration in the stratosphere equals that of the troposphere on a yearly basis.

on an annual basis, as well as the difficulty of updating the $\mathrm{CO}_{2}$ emissions from land use change. A likelihood of $68 \%$ provides an indication of our current capability to quantify each term and its uncertainty given the available information. For comparison, the Fifth Assessment Report of the IPCC (AR5) generally reported a likelihood of $90 \%$ for large data sets whose uncertainty is well characterised, or for long time intervals less affected by year-to-year variability. Our $68 \%$ uncertainty value is near the $66 \%$ which the IPCC characterises as "likely" for values falling into the $\pm 1 \sigma$ interval. The uncertainties reported here combine statistical analysis of the underlying data and expert judgement of the likelihood of results lying outside this range. The limitations of current information are discussed in the paper and have been examined in detail elsewhere (Ballantyne et al., 2015; Zscheischler et al., 2017). We also use a qualitative assessment of confidence level to characterise the annual estimates from each term based on the type, amount, quality, and consistency of the evidence as defined by the IPCC (Stocker et al., 2013).

All quantities are presented in units of gigatonnes of carbon $\left(\mathrm{GtC}, 10^{15} \mathrm{gC}\right)$, which is the same as petagrams of carbon (PgC; Table 1). Units of gigatonnes of $\mathrm{CO}_{2}$ (or billion 
tonnes of $\mathrm{CO}_{2}$ ) used in policy are equal to 3.664 multiplied by the value in units of gigatonnes of $\mathrm{CO}_{2}$.

This paper provides a detailed description of the data sets and methodology used to compute the global carbon budget estimates for the industrial period, from 1750 to 2018, and in more detail for the period since 1959. It also provides decadal averages starting in 1960 including the last decade (2009-2018), results for the year 2018, and a projection for the year 2019. Finally it provides cumulative emissions from fossil fuels and land use change since the year 1750 (the pre-industrial period), and since the year 1850 , the reference year for historical simulations in IPCC (AR6). This paper is updated every year using the format of "living data" to keep a record of budget versions and the changes in new data, revision of data, and changes in methodology that lead to changes in estimates of the carbon budget. Additional materials associated with the release of each new version will be posted at the Global Carbon Project (GCP) website (http://www.globalcarbonproject.org/ carbonbudget, last access: 27 September 2019), with fossil fuel emissions also available through the Global Carbon Atlas (http://www.globalcarbonatlas.org, last access: 4 December 2019). With this approach, we aim to provide the highest transparency and traceability in the reporting of $\mathrm{CO}_{2}$, the key driver of climate change.

\section{Methods}

Multiple organisations and research groups around the world generated the original measurements and data used to complete the global carbon budget. The effort presented here is thus mainly one of synthesis, where results from individual groups are collated, analysed, and evaluated for consistency. We facilitate access to original data with the understanding that primary data sets will be referenced in future work (see Table 2 for how to cite the data sets). Descriptions of the measurements, models, and methodologies follow below and detailed descriptions of each component are provided elsewhere.

This is the 14th version of the global carbon budget and the eighth revised version in the format of a living data update in Earth System Science Data. It builds on the latest published global carbon budget of Le Quéré et al. (2018b). The main changes are (1) the inclusion of data up to the year 2018 (inclusive) and a projection for the global carbon budget for the year 2019; (2) further developments to the metrics that evaluate components of the individual models used to estimate $S_{\text {OCEAN }}$ and $S_{\text {LAND }}$ using observations, as an effort to document, encourage, and support model improvements through time; (3) a projection of the "rest of the world" emissions by fuel type; (4) a changed method for projecting currentyear global atmospheric $\mathrm{CO}_{2}$ concentration increment; and (5) global emissions calculated as the sum of countries' emissions and bunker fuels rather than taken directly from the
Carbon Dioxide Information Analysis Center (CDIAC). The main methodological differences between recent annual carbon budgets (2015-2018) are summarised in Table 3, and changes since 2005 are provided in Table A7.

\subsection{Fossil $\mathrm{CO}_{2}$ emissions $\left(E_{\mathrm{FF}}\right)$}

\subsubsection{Emissions estimates}

The estimates of global and national fossil $\mathrm{CO}_{2}$ emissions $\left(E_{\mathrm{FF}}\right)$ include the combustion of fossil fuels through a wide range of activities (e.g. transport, heating and cooling, industry, fossil industry own use, and natural gas flaring), the production of cement, and other process emissions (e.g. the production of chemicals and fertilisers). The estimates of $E_{\mathrm{FF}}$ rely primarily on energy consumption data, specifically data on hydrocarbon fuels, collated and archived by several organisations (Andres et al., 2012). We use four main data sets for historical emissions (1750-2018).

1. We use global and national emission estimates for coal, oil, natural gas, and peat fuel extraction from CDIAC for the time period 1750-2016 (Gilfillan et al., 2019), as it is the only data set that extends back to 1750 by country.

2. We use official UNFCCC national inventory reports annually for 1990-2017 for the 42 Annex I countries in the UNFCCC (UNFCCC, 2019). We assess these to be the most accurate estimates because they are compiled by experts within countries that have access to the most detailed data, and they are periodically reviewed.

3. We use the BP Statistical Review of World Energy (BP, 2019), as these are the most up-to-date estimates of national energy statistics.

4. We use global and national cement emissions updated from Andrew (2018) following Andrew (2019) to include the latest estimates of cement production and clinker ratios.

In the following section we provide more details for each data set and describe the additional modifications that are required to make the data set consistent and usable.

CDIAC. The CDIAC estimates have been updated annually to the year 2016, derived primarily from energy statistics published by the United Nations (UN, 2018). Fuel masses and volumes are converted to fuel energy content using country-level coefficients provided by the UN and then converted to $\mathrm{CO}_{2}$ emissions using conversion factors that take into account the relationship between carbon content and energy (heat) content of the different fuel types (coal, oil, natural gas, natural gas flaring) and the combustion efficiency (Marland and Rotty, 1984).

UNFCCC. Estimates from the UNFCCC national inventory reports follow the IPCC guidelines (IPCC, 2006), but 
Table 2. How to cite the individual components of the global carbon budget presented here.

\begin{tabular}{|c|c|}
\hline Component & Primary reference \\
\hline Global fossil $\mathrm{CO}_{2}$ emissions ( $\left.E_{\mathrm{FF}}\right)$, total and by fuel type & Gilfillan et al. (2019) \\
\hline National territorial fossil $\mathrm{CO}_{2}$ emissions $\left(E_{\mathrm{FF}}\right)$ & $\begin{array}{l}\text { CDIAC source: Gilfillan et al. (2019) } \\
\text { UNFCCC (2019) }\end{array}$ \\
\hline $\begin{array}{l}\text { National consumption-based fossil } \mathrm{CO}_{2} \text { emissions }\left(E_{\mathrm{FF}}\right) \text { by } \\
\text { country (consumption) }\end{array}$ & Peters et al. (2011b) updated as described in this paper \\
\hline Land use change emissions ( $\left.E_{\mathrm{LUC}}\right)$ & $\begin{array}{l}\text { Average from Houghton and Nassikas (2017) and Hansis et } \\
\text { al. (2015), both updated as described in this paper }\end{array}$ \\
\hline Growth rate in atmospheric $\mathrm{CO}_{2}$ concentration $\left(G_{\mathrm{ATM}}\right)$ & Dlugokencky and Tans (2019) \\
\hline Ocean and land $\mathrm{CO}_{2}$ sinks ( $S_{\text {OCEAN }}$ and $\left.S_{\text {LAND }}\right)$ & $\begin{array}{l}\text { This paper for } S_{\text {OCEAN }} \text { and } S_{\text {LAND }} \text { and references in Table } 4 \\
\text { for individual models. }\end{array}$ \\
\hline
\end{tabular}

they have a slightly larger system boundary than CDIAC by including emissions coming from carbonates other than in cement manufacturing. We reallocate the detailed UNFCCC estimates to the CDIAC definitions of coal, oil, natural gas, cement, and others to allow more consistent comparisons over time and between countries.

Specific country updates. For China and Saudi Arabia, the most recent version of CDIAC introduces what appear to be spurious interannual variations for these two countries (IEA, 2018); therefore we use data from the 2018 global carbon budget (Le Quéré et al., 2018b). For Norway, the CDIAC's method of apparent consumption results in large errors for Norway, and we therefore overwrite emissions before 1990 with estimates based on official Norwegian statistics.

$B P$. For the most recent period when the UNFCCC and CDIAC estimates are not available, we generate preliminary estimates using energy consumption data from the BP Statistical Review of World Energy (Andres et al., 2014; BP, 2019; Myhre et al., 2009). We apply the BP growth rates by fuel type (coal, oil, natural gas) to estimate 2018 emissions based on 2017 estimates (UNFCCC Annex I countries) and to estimate 2017-2018 emissions based on 2016 estimates (remaining countries). BP's data set explicitly covers about 70 countries (96\% of global energy emissions), and for the remaining countries we use growth rates from the subregion the country belongs to. For the most recent years, natural gas flaring is assumed constant from the most recent available year of data (2017 for Annex I countries, 2016 for the remainder).

Cement. Estimates of emissions from cement production are taken directly from Andrew (2019). Additional calcination and carbonation processes are not included explicitly here, except in national inventories provided by Annex I countries, but are discussed in Sect. 2.7.2.

Country mappings. The published CDIAC data set includes 257 countries and regions. This list includes countries that no longer exist, such as the USSR and Yugoslavia.
We reduce the list to 214 countries by reallocating emissions to currently defined territories, using mass-preserving aggregation or disaggregation. Examples of aggregation include merging former East and West Germany into the currently defined Germany. Examples of disaggregation include reallocating the emissions from the former USSR to the resulting independent countries. For disaggregation, we use the emission shares when the current territories first appeared (e.g. USSR in 1992), and thus historical estimates of disaggregated countries should be treated with extreme care. In the case of the USSR, we were able to disaggregate 1990 and 1991 using data from the IEA. In addition, we aggregate some overseas territories (e.g. Réunion, Guadeloupe) into their governing nations (e.g. France) to align with UNFCCC reporting.

Global total. The global estimate is the sum of the individual countries' emissions and international aviation and marine bunkers. This is different to last year, where we used the independent global total estimated by CDIAC (combined with cement from Andrew, 2018). The CDIAC global total differs from the sum of the countries and bunkers since (1) the sum of imports in all countries is not equal to the sum of exports because of reporting inconsistencies, (2) changes in stocks, and (3) the share of non-oxidised carbon (e.g. as solvents, lubricants, feedstocks) at the global level is assumed to be fixed at the 1970's average while it varies in the country level data based on energy data (Andres et al., 2012). From the 2019 edition CDIAC now includes changes in stocks in the global total (Dennis Gilfillan, personal communication, 2019), removing one contribution to this discrepancy. The discrepancy has grown over time from around zero in 1990 to over $500 \mathrm{MtCO}_{2}$ in recent years, consistent with the growth in non-oxidised carbon (IEA, 2018). To remove this discrepancy we now calculate the global total as the sum of the countries and international bunkers. 
Table 3. Main methodological changes in the global carbon budget since 2015. Methodological changes introduced in one year are kept for the following years unless noted. Empty cells mean there were no methodological changes introduced that year. Table A7 lists methodological changes from the first global carbon budget publication up to 2014 .

\begin{tabular}{|c|c|c|c|c|c|c|c|c|}
\hline \multirow{2}{*}{$\begin{array}{l}\text { Publication } \\
\text { year }\end{array}$} & \multicolumn{3}{|c|}{ Fossil fuel emissions } & \multirow[t]{2}{*}{ LUC emissions } & \multicolumn{3}{|c|}{ Reservoirs } & \multirow{2}{*}{$\begin{array}{l}\text { Uncertainty \& } \\
\text { other changes }\end{array}$} \\
\hline & Global & $\begin{array}{l}\text { Country } \\
\text { (territorial) }\end{array}$ & $\begin{array}{l}\text { Country } \\
\text { (consumption) }\end{array}$ & & Atmosphere & Ocean & Land & \\
\hline 2015 & $\begin{array}{l}\text { Projection for } \\
\text { current year } \\
\text { based on } \\
\text { January- } \\
\text { August data }\end{array}$ & $\begin{array}{l}\begin{array}{l}\text { National emis- } \\
\text { sions from }\end{array} \\
\text { UNFCCC ex- } \\
\text { tended to } 2014 \\
\text { also provided }\end{array}$ & $\begin{array}{l}\text { Detailed } \\
\text { estimates in- } \\
\text { troduced for } \\
2011 \text { based on } \\
\text { GTAP9 }\end{array}$ & & & $\begin{array}{l}\text { Based on eight } \\
\text { models }\end{array}$ & $\begin{array}{l}\text { Based on } 10 \\
\text { models with } \\
\text { assessment of } \\
\text { minimum } \\
\text { realism }\end{array}$ & $\begin{array}{l}\text { The decadal un- } \\
\text { certainty for the } \\
\text { DGVM ensemble } \\
\text { mean now uses } \\
\pm 1 \sigma \text { of the decadal } \\
\text { spread across } \\
\text { models }\end{array}$ \\
\hline \multicolumn{9}{|l|}{$\begin{array}{l}\text { Le Quéré et } \\
\text { al. (2015a) } \\
\text { Jackson et } \\
\text { al. (2016) }\end{array}$} \\
\hline 2016 & $\begin{array}{l}2 \text { years of } \mathrm{BP} \\
\text { data }\end{array}$ & $\begin{array}{l}\text { Added three } \\
\text { small countries; } \\
\text { China's (RMA) } \\
\text { emissions from } \\
1990 \text { from } \\
\text { BP data (this } \\
\text { release only) }\end{array}$ & & $\begin{array}{l}\text { Preliminary } \\
E_{\text {LUC }} \text { using } \\
\text { FRA-2015 } \\
\text { shown for com- } \\
\text { parison; use of } \\
\text { five DGVMs }\end{array}$ & & $\begin{array}{l}\text { Based on seven } \\
\text { models }\end{array}$ & $\begin{array}{l}\text { Based on } \\
14 \text { models }\end{array}$ & $\begin{array}{l}\text { Discussion of pro- } \\
\text { jection for full bud- } \\
\text { get for current year }\end{array}$ \\
\hline \multicolumn{9}{|l|}{$\begin{array}{l}\text { Le Quéré et } \\
\text { al. (2016) }\end{array}$} \\
\hline 2017 & $\begin{array}{l}\text { Projection } \\
\text { includes India- } \\
\text { specific data }\end{array}$ & & & $\begin{array}{l}\text { Average of two } \\
\text { bookkeeping } \\
\text { models; use of } \\
12 \text { DGVMs }\end{array}$ & & $\begin{array}{l}\text { Based on eight } \\
\text { models that } \\
\text { match the } \\
\text { observed sink } \\
\text { for the 1990s; } \\
\text { no longer nor- } \\
\text { malised }\end{array}$ & $\begin{array}{l}\text { Based on } \\
15 \text { models } \\
\text { that meet } \\
\text { observation- } \\
\text { based criteria } \\
\text { (see Sect. 2.5) }\end{array}$ & $\begin{array}{l}\text { Land multi-model } \\
\text { average now used } \\
\text { in main carbon } \\
\text { budget, with the } \\
\text { carbon imbalance } \\
\text { presented sepa- } \\
\text { rately; new table of } \\
\text { key uncertainties }\end{array}$ \\
\hline \multicolumn{9}{|l|}{$\begin{array}{l}\text { Le Quéré et } \\
\text { al. (2018a) } \\
\text { GCB2017 }\end{array}$} \\
\hline 2018 & $\begin{array}{l}\text { Revision } \\
\text { in cement } \\
\text { emissions; pro- } \\
\text { jection includes } \\
\text { EU-specific } \\
\text { data }\end{array}$ & \begin{tabular}{l}
\multicolumn{2}{l}{ Aggregation of } \\
overseas ter- \\
ritories into \\
governing \\
nations for \\
total of 213 \\
countries
\end{tabular} & & $\begin{array}{l}\text { Use of } 16 \\
\text { DGVMs }\end{array}$ & $\begin{array}{l}\text { Use of four } \\
\text { atmospheric in- } \\
\text { versions }\end{array}$ & $\begin{array}{l}\text { Based on seven } \\
\text { models }\end{array}$ & $\begin{array}{l}\text { Based on } 16 \\
\text { models; revised } \\
\text { atmospheric } \\
\text { forcing from } \\
\text { CRUNCEP to } \\
\text { CRU-JRA-55 }\end{array}$ & $\begin{array}{l}\text { Introduction of } \\
\text { metrics for evalu- } \\
\text { ation of individual } \\
\text { models using ob- } \\
\text { servations }\end{array}$ \\
\hline \multicolumn{9}{|l|}{$\begin{array}{l}\text { Le Quéré et } \\
\text { al. (2018b) } \\
\text { GCB2018 }\end{array}$} \\
\hline (this study) & $\begin{array}{l}\text { Global emis- } \\
\text { sions calculated } \\
\text { as sum of all } \\
\text { countries plus } \\
\text { bunkers, rather } \\
\text { than taken } \\
\text { directly from } \\
\text { CDIAC }\end{array}$ & & & $\begin{array}{l}\text { Use of } 15 \\
\text { DGVMs* }\end{array}$ & $\begin{array}{l}\text { Use of three } \\
\text { atmospheric in- } \\
\text { versions }\end{array}$ & $\begin{array}{l}\text { Based on nine } \\
\text { models }\end{array}$ & $\begin{array}{l}\text { Based on } 16 \\
\text { models }\end{array}$ & \\
\hline
\end{tabular}

* $E_{\mathrm{LUC}}$ is still estimated based on bookkeeping models, as in 2018 (Le Quéré et al., 2018b), but the number of DGVMs used to characterise the uncertainty has changed.

\subsubsection{Uncertainty assessment for $E_{\mathrm{FF}}$}

We estimate the uncertainty of the global fossil $\mathrm{CO}_{2}$ emissions at $\pm 5 \%$ (scaled down from the published $\pm 10 \%$ at $\pm 2 \sigma$ to the use of $\pm 1 \sigma$ bounds reported here; Andres et al., 2012). This is consistent with a more detailed analysis of uncertainty of $\pm 8.4 \%$ at $\pm 2 \sigma$ (Andres et al., 2014) and at the high end of the range of $\pm 5 \%-10 \%$ at $\pm 2 \sigma$ reported by Ballantyne et al. (2015). This includes an assessment of uncertainties in the amounts of fuel consumed, the carbon and heat contents of fuels, and the combustion efficiency. While we consider a fixed uncertainty of $\pm 5 \%$ for all years, the uncertainty as a percentage of the emissions is growing with 
time because of the larger share of global emissions from emerging economies and developing countries (Marland et al., 2009). Generally, emissions from mature economies with good statistical processes have an uncertainty of only a few per cent (Marland, 2008), while emissions from developing countries such as China have uncertainties of around $\pm 10 \%$ (for $\pm 1 \sigma$; Gregg et al., 2008). Uncertainties of emissions are likely to be mainly systematic errors related to underlying biases of energy statistics and to the accounting method used by each country.

We assign a medium confidence to the results presented here because they are based on indirect estimates of emissions using energy data (Durant et al., 2011). There is only limited and indirect evidence for emissions, although there is high agreement among the available estimates within the given uncertainty (Andres et al., 2012, 2014), and emission estimates are consistent with a range of other observations (Ciais et al., 2013), even though their regional and national partitioning is more uncertain (Francey et al., 2013).

\subsubsection{Emissions embodied in goods and services}

CDIAC, UNFCCC, and BP national emission statistics "include greenhouse gas emissions and removals taking place within national territory and offshore areas over which the country has jurisdiction" (Rypdal et al., 2006) and are called territorial emission inventories. Consumption-based emission inventories allocate emissions to products that are consumed within a country and are conceptually calculated as the territorial emissions minus the "embodied" territorial emissions to produce exported products plus the emissions in other countries to produce imported products (consumption $=$ territorial - exports + imports). Consumption-based emission attribution results (e.g. Davis and Caldeira, 2010) provide additional information to territorial-based emissions that can be used to understand emission drivers (Hertwich and Peters, 2009) and quantify emission transfers by the trade of products between countries (Peters et al., 2011b). The consumption-based emissions have the same global total, but they reflect the trade-driven movement of emissions across the Earth's surface in response to human activities.

We estimate consumption-based emissions from 1990 to 2016 by enumerating the global supply chain using a global model of the economic relationships between economic sectors within and between every country (Andrew and Peters, 2013; Peters et al., 2011a). Our analysis is based on the economic and trade data from the Global Trade Analysis Project (GTAP; Narayanan et al., 2015), and we make detailed estimates for the years 1997 (GTAP version 5), 2001 (GTAP6), 2004, 2007, and 2011 (GTAP9.2), covering 57 sectors and 141 countries and regions. The detailed results are then extended into an annual time series from 1990 to the latest year of the gross domestic product (GDP) data (2016 in this budget), using GDP data by expenditure in the current exchange rate of US dollars (USD; from the UN National Accounts
Main Aggregates Database; UN, 2017) and time series of trade data from GTAP (based on the methodology in Peters et al., 2011b). We estimate the sector-level $\mathrm{CO}_{2}$ emissions using the GTAP data and methodology, include flaring and cement emissions from CDIAC, and then scale the national totals (excluding bunker fuels) to match the emission estimates from the carbon budget. We do not provide a separate uncertainty estimate for the consumption-based emissions, but based on model comparisons and sensitivity analysis, they are unlikely to be significantly different than for the territorial emission estimates (Peters et al., 2012a).

\subsubsection{Growth rate in emissions}

We report the annual growth rate in emissions for adjacent years (in per cent per year) by calculating the difference between the two years and then normalising to the emissions in the first year: $\left(E_{\mathrm{FF}}\left(t_{0+1}\right)-E_{\mathrm{FF}}\left(t_{0}\right)\right) / E_{\mathrm{FF}}\left(t_{0}\right) \times 100 \%$. We apply a leap-year adjustment where relevant to ensure valid interpretations of annual growth rates. This affects the growth rate by about $0.3 \% \mathrm{yr}^{-1}(1 / 365)$ and causes growth rates to go up approximately $0.3 \%$ if the first year is a leap year and down $0.3 \%$ if the second year is a leap year.

The relative growth rate of $E_{\mathrm{FF}}$ over time periods of greater than 1 year can be rewritten using its logarithm equivalent as follows:

$$
\frac{1}{E_{\mathrm{FF}}} \frac{\mathrm{d} E_{\mathrm{FF}}}{\mathrm{d} t}=\frac{\mathrm{d}\left(\ln E_{\mathrm{FF}}\right)}{\mathrm{d} t} .
$$

Here we calculate relative growth rates in emissions for multi-year periods (e.g. a decade) by fitting a linear trend to $\ln \left(E_{\mathrm{FF}}\right)$ in Eq. (2), reported in per cent per year.

\subsubsection{Emissions projections}

To gain insight into emission trends for 2019, we provide an assessment of global fossil $\mathrm{CO}_{2}$ emissions, $E_{\mathrm{FF}}$, by combining individual assessments of emissions for China, the USA, the EU, India (the four countries/regions with the largest emissions), and the rest of the world.

Our 2019 estimate for China uses (1) the sum of monthly domestic production of raw coal, crude oil, natural gas and cement from the National Bureau of Statistics (NBS, 2019c), (2) monthly net imports of coal, coke, crude oil, refined petroleum products and natural gas from the General Administration of Customs of the People's Republic of China (2019); and (3) annual energy consumption data by fuel type and annual production data for cement from the NBS, using final data for 2000-2017 (NBS, 2019c) and preliminary data for 2018 (NBS, 2019b). We estimate the full-year growth rate for 2019 using a Bayesian regression for the ratio between the annual energy consumption data ( 3 above) from 2014 through 2018 and monthly production plus net imports through September of each year $(1+2$ above). The uncertainty range uses the standard deviations of the resulting posteriors. Sources of uncertainty and deviations between the 
monthly and annual growth rates include lack of monthly data on stock changes and energy density, variance in the trend during the last 3 months of the year, and partially unexplained discrepancies between supply-side and consumption data even in the final annual data. Note that in recent years, the absolute value of the annual growth rate for coal energy consumption, and hence total $\mathrm{CO}_{2}$ emissions, has been consistently lower (closer to zero) than the growth suggested by the monthly, tonnage-based production and import data, and this is reflected in the projection. This pattern is only partially explained by stock changes and changes in energy content. It is therefore not possible to be certain that it will continue in the current year, but it is made plausible by a separate statement by the National Bureau of Statistics on energy consumption growth in the first half of 2019, which suggests no significant growth in energy consumption from coal for January-June (NBS, 2019a). Results and uncertainties are discussed further in Sect. 3.4.1.

For the USA, we use the forecast of the U.S. Energy Information Administration (EIA) for emissions from fossil fuels (EIA, 2019). This is based on an energy forecasting model which is updated monthly (last update with data through October 2019) and takes into account heating-degree days, household expenditures by fuel type, energy markets, policies, and other effects. We combine this with our estimate of emissions from cement production using the monthly US cement data from USGS for January-July 2019, assuming changes in cement production over the first part of the year apply throughout the year. While the EIA's forecasts for current full-year emissions have on average been revised downwards, only 10 such forecasts are available, so we conservatively use the full range of adjustments following revision, and additionally we assume symmetrical uncertainty to give $\pm 2.3 \%$ around the central forecast.

For India, we use (1) monthly coal production and sales data from the Ministry of Mines (2019), Coal India Limited (CIL, 2019), and Singareni Collieries Company Limited (SCCL, 2019), combined with import data from the Ministry of Commerce and Industry (MCI, 2019) and power station stock data from the Central Electricity Authority (CEA, 2019a); (2) monthly oil production and consumption data from the Ministry of Petroleum and Natural Gas (PPAC, 2019b); (3) monthly natural gas production and import data from the Ministry of Petroleum and Natural Gas (PPAC, 2019a); and (4) monthly cement production data from the Office of the Economic Advisor (OEA, 2019). All data were available for January to September or October 2019. We use Holt-Winters exponential smoothing with multiplicative seasonality (Chatfield, 1978) on each of these four emissions series to project to the end of India's current financial year (March 2020). This iterative method produces estimates of both trend and seasonality at the end of the observation period that are a function of all prior observations, weighted most strongly to more recent data, while maintaining some smoothing effect. The main source of uncertainty in the pro- jection of India's emissions is the assumption of continued trends and typical seasonality.

For the EU, we use (1) monthly coal supply data from Eurostat for the first 6-9 months of 2019 (Eurostat, 2019) crosschecked with more recent data on coal-generated electricity from ENTSO-E for January through October 2019 (ENTSOE, 2019); (2) monthly oil and gas demand data for January through August from the Joint Organisations Data Initiative (JODI, 2019); and (3) cement production assumed to be stable. For oil and natural gas emissions we apply the HoltWinters method separately to each country and energy carrier to project to the end of the current year, while for coal - which is much less strongly seasonal because of strong weather variations - we assume the remaining months of the year are the same as the previous year in each country.

For the rest of the world, we use the close relationship between the growth in GDP and the growth in emissions (Raupach et al., 2007) to project emissions for the current year. This is based on a simplified Kaya identity, whereby $E_{\mathrm{FF}}\left(\mathrm{GtC} \mathrm{yr}^{-1}\right)$ is decomposed by the product of GDP (USD yr ${ }^{-1}$ ) and the fossil fuel carbon intensity of the economy $\left(I_{\mathrm{FF}} ; \mathrm{GtC} \mathrm{USD}^{-1}\right)$ as follows:

$E_{\mathrm{FF}}=\mathrm{GDP} \times I_{\mathrm{FF}}$.

Taking a time derivative of Eq. (3) and rearranging gives

$\frac{1}{E_{\mathrm{FF}}} \frac{\mathrm{d} E_{\mathrm{FF}}}{\mathrm{d} t}=\frac{1}{\mathrm{GDP}} \frac{\mathrm{dGDP}}{\mathrm{d} t}+\frac{1}{I_{\mathrm{FF}}} \frac{\mathrm{d} I_{\mathrm{FF}}}{\mathrm{d} t}$,

where the left-hand term is the relative growth rate of $E_{\mathrm{FF}}$, and the right-hand terms are the relative growth rates of GDP and $I_{\mathrm{FF}}$, respectively, which can simply be added linearly to give the overall growth rate.

As preliminary estimates of annual change in GDP are made well before the end of a calendar year, making assumptions on the growth rate of $I_{\mathrm{FF}}$ allows us to make projections of the annual change in $\mathrm{CO}_{2}$ emissions well before the end of a calendar year. The $I_{\mathrm{FF}}$ is based on GDP in constant PPP (purchasing power parity) from the International Energy Agency (IEA) up to 2016 (IEA/OECD, 2018) and extended using the International Monetary Fund (IMF) growth rates through 2018 (IMF, 2019a). Interannual variability in $I_{\mathrm{FF}}$ is the largest source of uncertainty in the GDP-based emissions projections. We thus use the standard deviation of the annual $I_{\mathrm{FF}}$ for the period 2009-2018 as a measure of uncertainty, reflecting a $\pm 1 \sigma$ as in the rest of the carbon budget. In this year's budget, we have extended the rest-of-the-world method to fuel type to get separate projections for coal, oil, natural gas, cement, flaring, and other components. This allows, for the first time, consistent projections of global emissions by both countries and fuel type.

The 2019 projection for the world is made of the sum of the projections for China, the USA, the EU, India, and the rest of the world, where the sum is consistent if done by fuel type (coal, oil, natural gas) or based on total emissions. The 
uncertainty is added in quadrature among the five regions. The uncertainty here reflects the best of our expert opinion.

\section{2 $\mathrm{CO}_{2}$ emissions from land use, land use change, and forestry ( $\left.E_{\mathrm{LUC}}\right)$}

The net $\mathrm{CO}_{2}$ flux from land use, land use change, and forestry ( $E_{\mathrm{LUC}}$, called land use change emissions in the rest of the text) include $\mathrm{CO}_{2}$ fluxes from deforestation, afforestation, logging and forest degradation (including harvest activity), shifting cultivation (cycle of cutting forest for agriculture, then abandoning), and regrowth of forests following wood harvest or abandonment of agriculture. Only some land management activities are included in our land use change emissions estimates (Table A1). Some of these activities lead to emissions of $\mathrm{CO}_{2}$ to the atmosphere, while others lead to $\mathrm{CO}_{2}$ sinks. $E_{\mathrm{LUC}}$ is the net sum of emissions and removals due to all anthropogenic activities considered. Our annual estimate for 1959-2018 is provided as the average of results from two bookkeeping models (Sect. 2.2.1): the estimate published by Houghton and Nassikas (2017; hereafter H\&N2017) updated to 2018a and an estimate using the Bookkeeping of Land Use Emissions model (Hansis et al., 2015; hereafter BLUE). Both data sets are then extrapolated to provide a projection for 2019 (Sect. 2.2.4). In addition, we use results from dynamic global vegetation models (DGVMs; see Sect. 2.2.2 and Table 4) to help quantify the uncertainty in $E_{\mathrm{LUC}}$ (Sect. 2.2.3) and thus better characterise our understanding.

\subsubsection{Bookkeeping models}

Land use change $\mathrm{CO}_{2}$ emissions and uptake fluxes are calculated by two bookkeeping models. Both are based on the original bookkeeping approach of Houghton (2003) that keeps track of the carbon stored in vegetation and soils before and after a land use change (transitions between various natural vegetation types, croplands, and pastures). Literaturebased response curves describe decay of vegetation and soil carbon, including transfer to product pools of different lifetimes, as well as carbon uptake due to regrowth. In addition, the bookkeeping models represent long-term degradation of primary forest as lowered standing vegetation and soil carbon stocks in secondary forests, and they also include forest management practices such as wood harvests.

The bookkeeping models do not include land ecosystems' transient response to changes in climate, atmospheric $\mathrm{CO}_{2}$, and other environmental factors, and the carbon densities are based on contemporary data reflecting stable environmental conditions at that time. Since carbon densities remain fixed over time in bookkeeping models, the additional sink capacity that ecosystems provide in response to $\mathrm{CO}_{2}$ fertilisation and some other environmental changes is not captured by these models (Pongratz et al., 2014; see Sect. 2.7.4).
The H\&N2017 and BLUE models differ in (1) computational units (country-level vs. spatially explicit treatment of land use change), (2) processes represented (see Table A1), and (3) carbon densities assigned to vegetation and soil of each vegetation type. A notable change of H\&N2017 over the original approach by Houghton (2003) used in earlier budget estimates is that no shifting cultivation or other back-andforth transitions at a level below country are included. Only a decline in forest area in a country as indicated by the Forest Resource Assessment of the FAO that exceeds the expansion of agricultural area as indicated by the FAO is assumed to represent a concurrent expansion and abandonment of cropland. In contrast, the BLUE model includes sub-grid-scale transitions at the grid level between all vegetation types as indicated by the harmonised land use change data (LUH2) data set (https://doi.org/10.22033/ESGF/input4MIPs.1127; Hurtt et al., 2011, 2019). Furthermore, H\&N2017 assume conversion of natural grasslands to pasture, while BLUE allocates pasture proportionally on all natural vegetation that exists in a grid cell. This is one reason for generally higher emissions in BLUE. For both H\&N2017 and BLUE, we add carbon emissions from peat burning based on the Global Fire Emission Database (GFED4s; van der Werf et al., 2017) and peat drainage based on estimates by Hooijer et al. (2010) to the output of their bookkeeping model for the countries of Indonesia and Malaysia. Peat burning and emissions from the organic layers of drained peat soils, which are not captured by bookkeeping methods directly, need to be included to represent the substantially larger emissions and interannual variability due to synergies of land use and climate variability in Southeast Asia, in particular during El Niño events.

The two bookkeeping estimates used in this study differ with respect to the land use change data used to drive the models. H\&N2017 base their estimates directly on the Forest Resource Assessment of the FAO, which provides statistics on forest area change and management at intervals of 5 years currently updated until 2015 (FAO, 2015). The data are based on countries reporting to the FAO and may include remotesensing information in more recent assessments. Changes in land use other than forests are based on annual, national changes in cropland and pasture areas reported by the FAO (FAOSTAT, 2015). H\&N2017 was extended here for 2016 to 2018 by adding the annual change in total tropical emissions to the H\&N2017 estimate for 2015, including estimates of peat drainage and peat burning as described above as well as emissions from tropical deforestation and degradation fires from GFED4.1s (van der Werf et al., 2017). On the other hand, BLUE uses the harmonised land use change data LUH2 covering the entire $850-2018$ period (https://doi.org/10.22033/ESGF/input4MIPs.1127; Hurtt et al., 2011, 2019), which describes land use change, also based on the FAO data as well as the HYDE data set (Klein Goldewijk et al., 2017; Goldewijk et al., 2017), but downscaled at a quarter-degree spatial resolution, considering sub-gridscale transitions between primary forest, secondary forest, 
Table 4. References for the process models, $p \mathrm{CO}_{2}$-based ocean flux products, and atmospheric inversions included in Figs. 6-8. All models and products are updated with new data to the end of the year 2018, and the atmospheric forcing for the DGVMs has been updated as described in Sect. 2.2.2.

\begin{tabular}{|c|c|c|}
\hline Model/data name & Reference & Change from Global Carbon Budget 2018 (Le Quéré et al., 2018b) \\
\hline \multicolumn{3}{|c|}{ Bookkeeping models for land use change emissions } \\
\hline $\begin{array}{l}\text { BLUE } \\
\text { H\&N2017 }\end{array}$ & $\begin{array}{l}\text { Hansis et al. (2015) } \\
\text { Houghton and Nassikas } \\
(2017)\end{array}$ & $\begin{array}{l}\text { No change. } \\
\text { No change. }\end{array}$ \\
\hline \multicolumn{3}{|l|}{ Dynamic global vegetation models } \\
\hline CABLE-POP & Haverd et al. (2018) & $\begin{array}{l}\text { Thermal acclimation of photosynthesis; residual stomatal conductance }(g 0) \text { now non-zero; stomatal } \\
\text { conductance set to maximum of } g 0 \text { and vapour-pressure-deficit-dependent term }\end{array}$ \\
\hline CLASS-CTEM & $\begin{array}{l}\text { Melton and Arora } \\
(2016)\end{array}$ & 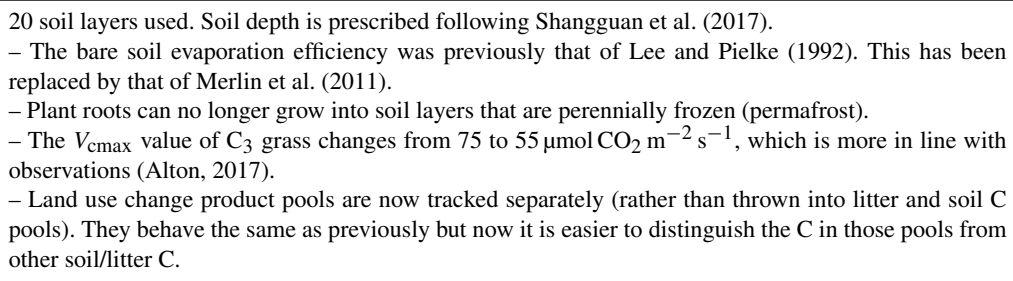 \\
\hline CLM5.0 & Lawrence et al. (2019) & $\begin{array}{l}\text { Added representation of shifting cultivation, fixed a bug in the fire model, used updated \& higher- } \\
\text { resolution lightening strike data set. }\end{array}$ \\
\hline DLEM & Tian et al. $(2015)^{\mathrm{a}}$ & No change. \\
\hline ISAM & Meiyappan et al. (2015) & No change. \\
\hline ISBA-CTRIP & $\begin{array}{l}\text { Decharme et } \\
\text { al. }(2019)^{b}\end{array}$ & Updated spin-up protocol + model name updated (SURFEXv8 in GCB2017). \\
\hline JSBACH & Mauritsen et al. (2019) & No change. \\
\hline JULES-ES & Sellar et al. $(2019)^{\mathrm{c}}$ & $\begin{array}{l}\text { Major update. Model configuration is now JULES-ES v1.0, the land surface and vegetation component } \\
\text { of the UK Earth System Model (UKESM1). Includes interactive nitrogen scheme, extended number of } \\
\text { plant functional types represented, trait based physiology and crop harvest. }\end{array}$ \\
\hline LPJ-GUESS & Smith et al. $(2014)^{\mathrm{d}}$ & $\begin{array}{l}\text { Using daily climate forcing instead of monthly forcing. Using nitrogen inputs from NMIP. Adjustment } \\
\text { in the spin-up procedure. Growth suppression mortality parameter of PFT IBS changed to } 0.12 \text {. }\end{array}$ \\
\hline LPJ & Poulter et al. $(2011)^{\mathrm{e}}$ & No change. \\
\hline LPX-Bern & Lienert and Joos (2018) & Using nitrogen input from NMIP. \\
\hline $\mathrm{OCN}$ & $\begin{array}{l}\text { Zaehle and Friend } \\
(2010)^{f}\end{array}$ & No change (uses r294). \\
\hline ORCHIDEE-CNP & Goll et al. $(2017)^{\mathrm{g}}$ & Refinement of parameterisation (r6176); change in $\mathrm{N}$ forcing (different $\mathrm{N}$ deposition, no (N\&P) manure) \\
\hline ORCHIDEE-Trunk & $\begin{array}{l}\text { Krinner et } \\
\text { al. }(2005)^{\mathrm{h}}\end{array}$ & $\begin{array}{l}\text { No major changes, except some small bug corrections linked to the implementation of land cover } \\
\text { changes. }\end{array}$ \\
\hline SDGVM & Walker et al. $(2017)^{\mathrm{i}}$ & $\begin{array}{l}\text { (1) Changed the multiplicative scale parameters of these diagnostic output variables from } \\
\text { - evapotranspft, evapo, transpft } 2.257 \times 10^{6} \text { to } 2.257 \times 10^{6} /(30 \times 24 \times 3600) \\
\text { - swepft from NA to } 0.001 \text {. } \\
\text { (2) The autotrophic respiration diagnostic output variable is now properly initialised to zero for bare } \\
\text { ground. } \\
\text { (3) A very minor change that prevents the soil water limitation scalar (often called beta) being applied } \\
\text { to } g 0 \text { in the stomatal conductance }\left(g_{\mathrm{s}}\right) \text { equation. Previously it was applied to both } g 0 \text { and } g 1 \text { in the } g_{\mathrm{s}} \\
\text { equation. Now beta is applied only to } g 1 \text { in the } g_{\mathrm{s}} \text { equation. } \\
\text { (4) The climate driving data and land cover data are in } 0.5^{\circ} \text { resolution. }\end{array}$ \\
\hline VISIT & Kato et al. $(2013)^{\mathrm{j}}$ & No change. \\
\hline \multicolumn{3}{|l|}{ Global ocean biogeochemistry models } \\
\hline NEMO-PlankTOM5 & Buitenhuis et al. (2013) & No change. \\
\hline MICOM-HAMOCC (NorESM-OC) & Schwinger et al. (2016) & Flux calculation improved to take into account correct land-sea mask after interpolation. \\
\hline MPIOM-HAMOCC6 & Paulsen et al. (2017) & No change. \\
\hline NEMO3.6-PISCESv2-gas (CNRM) & Berthet et al. (2019) & No change. \\
\hline CSIRO & Law et al. (2017) & No change. \\
\hline MITgcm-REcoM2 & $\begin{array}{l}\text { Hauck et } \\
\text { al. (2018) }\end{array}$ & No change. \\
\hline MOM6-COBALT (Princeton) & Adcroft et al. (2019) & New this year. \\
\hline CESM-ETHZ & Doney et al. (2009) & New this year. \\
\hline NEMO-PISCES (IPSL) & Aumont et al. (2015) & Updated spin-up procedure. \\
\hline
\end{tabular}


Table 4. Continued.

\begin{tabular}{|c|c|c|}
\hline Model/data name & Reference & Change from Global Carbon Budget 2018 (Le Quéré et al., 2018b) \\
\hline \multicolumn{3}{|l|}{$p \mathrm{CO}_{2}$-based flux ocean products } \\
\hline Landschützer (MPI-SOMFFN) & $\begin{array}{l}\text { Landschützer et } \\
\text { al. (2016) }\end{array}$ & Update to SOCATv2019 measurements. \\
\hline Rödenbeck (Jena-MLS) & $\begin{array}{l}\text { Rödenbeck et } \\
\text { al. (2014) }\end{array}$ & $\begin{array}{l}\text { Update to SOCATv } 2019 \text { measurements. Interannual net ecosystem exchange (NEE) variability } \\
\text { estimated through a regression to air temperature anomalies. Using } 89 \text { atmospheric stations. } \\
\text { Fossil fuel emissions taken from Jones et al. (2019) consistent with country totals of this study. }\end{array}$ \\
\hline CMEMS & $\begin{array}{l}\text { Denvil-Sommer et } \\
\text { al. (2019) }\end{array}$ & New this year. \\
\hline \multicolumn{3}{|l|}{ Atmospheric inversions } \\
\hline CAMS & $\begin{array}{l}\text { Chevallier et } \\
\text { al. }(2005)^{\mathrm{k}}\end{array}$ & Updated version of atmospheric transport model LMDz. \\
\hline CarbonTracker Europe (CTE) & $\begin{array}{l}\text { van der Laan-Luijkx et } \\
\text { al. (2017) }\end{array}$ & No change. \\
\hline Jena CarboScope & $\begin{array}{l}\text { Rödenbeck et al. (2003, } \\
\text { 2018) }\end{array}$ & Temperature-NEE relations additionally estimated. \\
\hline
\end{tabular}

cropland, pasture, and rangeland. The LUH2 data provide a distinction between rangelands and pasture, based on inputs from HYDE. To constrain the models' interpretation on whether rangeland implies the original natural vegetation to be transformed to grassland or not (e.g. browsing on shrubland), a forest mask was provided with LUH2; forest is assumed to be transformed, while all other natural vegetation remains. This is implemented in BLUE.

For $E_{\text {LUC }}$ from 1850 onwards we average the estimates from BLUE and H\&N2017. For the cumulative numbers starting at 1750 an average of four earlier publications is added (30 $\pm 20 \mathrm{GtC} 1750-1850$, rounded to the nearest $5 \mathrm{GtC}$; Le Quéré et al., 2016).

\subsubsection{Dynamic global vegetation models (DGVMs)}

Land use change $\mathrm{CO}_{2}$ emissions have also been estimated using an ensemble of 15 DGVM simulations. The DGVMs account for deforestation and regrowth, the most important components of $E_{\mathrm{LUC}}$, but they do not represent all processes resulting directly from human activities on land (Table A1). All DGVMs represent processes of vegetation growth and mortality, as well as decomposition of dead organic matter associated with natural cycles, and they include the vegetation and soil carbon response to increasing atmospheric $\mathrm{CO}_{2}$ concentration and to climate variability and change. Some models explicitly simulate the coupling of carbon and nitrogen cycles and account for atmospheric $\mathrm{N}$ deposition and $\mathrm{N}$ fertilisers (Table A1). The DGVMs are independent from the other budget terms except for their use of atmospheric $\mathrm{CO}_{2}$ concentration to calculate the fertilisation effect of $\mathrm{CO}_{2}$ on plant photosynthesis.

Many DGVMs used the HYDE land use change data set (Klein Goldewijk et al., 2017; Goldewijk et al., 2017), which provides annual (1700-2018), half-degree, fractional data on cropland and pasture. The data are based on the available annual FAO statistics of change in agricultural land area available until 2015. Last year's HYDE version used FAO statistics until 2012, which are now supplemented using the annual change anomalies from FAO data for the years 2013-2015 relative to the year 2012. HYDE forcing was also corrected for Brazil for the years 1951-2012. After the year 2015 HYDE extrapolates cropland, pasture, and urban land use data until the year 2018. Some models also use the LUH2 data set, an update of the more comprehensive harmonised land use data set (Hurtt et al., 2011), that further includes fractional data on primary and secondary forest vegetation, as well as all underlying transitions between land use states (1700-2019) (https://doi.org/10.22033/ESGF/input4MIPs.1127; Hurtt et al., 2011, 2019; Table A1). This new data set is of quarterdegree fractional areas of land use states and all transitions between those states, including a new wood harvest reconstruction, new representation of shifting cultivation, crop rotations, and management information including irrigation and fertiliser application. The land use states include five different crop types in addition to the pasture-rangeland split discussed before. Wood harvest patterns are constrained with Landsat-based tree cover loss data (Hansen et al., 2013). Updates of LUH2 over last year's version use the most recent HYDE-FAO release (covering the time period up to and in- 
cluding 2015), which also corrects an error in the version used for the 2018 budget in Brazil.

DGVMs implement land use change differently (e.g. an increased cropland fraction in a grid cell can either be at the expense of either grassland or shrubs, or forest, the latter resulting in deforestation; land cover fractions of the non-agricultural land differ between models). Similarly, model-specific assumptions are applied to convert deforested biomass or deforested area and other forest product pools into carbon, and different choices are made regarding the allocation of rangelands as natural vegetation or pastures.

The DGVM model runs were forced by either the merged monthly CRU and 6-hourly JRA-55 data set or by the monthly CRU data set, both providing observation-based temperature, precipitation, and incoming surface radiation on a $0.5^{\circ} \times 0.5^{\circ}$ grid and updated to 2018 (Harris et al., 2014). The combination of CRU monthly data with 6-hourly forcing from JRA-55 (Kobayashi et al., 2015) is performed with methodology used in previous years (Viovy, 2016) adapted to the specifics of the JRA-55 data. The forcing data also include global atmospheric $\mathrm{CO}_{2}$, which changes over time (Dlugokencky and Tans, 2019), and gridded, time-dependent $\mathrm{N}$ deposition and $\mathrm{N}$ fertilisers (as used in some models; Table A1).

Two sets of simulations were performed with the DGVMs. Both applied historical changes in climate, atmospheric $\mathrm{CO}_{2}$ concentration, and $\mathrm{N}$ inputs. The two sets of simulations differ, however, with respect to land use: one set applies historical changes in land use, and the other a time-invariant pre-industrial land cover distribution and pre-industrial wood harvest rates. By difference of the two simulations, the dynamic evolution of vegetation biomass and soil carbon pools in response to land use change can be quantified in each model $\left(E_{\mathrm{LUC}}\right)$. Using the difference between these two DGVM simulations to diagnose $E_{\mathrm{LUC}}$ means the DGVMs account for the loss of additional sink capacity (around $0.4 \pm 0.3 \mathrm{GtC} \mathrm{yr}^{-1}$; see Sect. 2.7.4), while the bookkeeping models do not.

As a criterion for inclusion in this carbon budget, we only retain models that simulate a positive $E_{\mathrm{LUC}}$ during the 1990s, as assessed in the IPCC AR4 (Denman et al., 2007) and AR5 (Ciais et al., 2013). All DGVMs met this criteria, although one model was not included in the $E_{\mathrm{LUC}}$ estimate from DGVMs as it exhibited a spurious response to the transient land cover change forcing after its initial spin-up.

\subsubsection{Uncertainty assessment for $E_{\mathrm{LUC}}$}

Differences between the bookkeeping models and DGVM models originate from three main sources: the different methodologies, the underlying land use and land cover data set, and the different processes represented (Table A1). We examine the results from the DGVM models and from the bookkeeping method, and we use the resulting variations as a way to characterise the uncertainty in $E_{\mathrm{LUC}}$.
The $E_{\text {LUC }}$ estimate from the DGVMs multi-model mean is consistent with the average of the emissions from the bookkeeping models (Table 5). However there are large differences among individual DGVMs (standard deviation at around $0.5 \mathrm{GtC} \mathrm{yr}^{-1}$; Table 5), between the two bookkeeping models (average difference of $0.7 \mathrm{GtC} \mathrm{yr}^{-1}$ ), and between the current estimate of $\mathrm{H} \& \mathrm{~N} 2017$ and its previous model version (Houghton et al., 2012). The uncertainty in $E_{\text {LUC }}$ of $\pm 0.7 \mathrm{GtC} \mathrm{yr}^{-1}$ reflects our best value judgement that there is at least a $68 \%$ chance $( \pm 1 \sigma)$ that the true land use change emission lies within the given range, for the range of processes considered here. Prior to the year 1959, the uncertainty in $E_{\mathrm{LUC}}$ was taken from the standard deviation of the DGVMs. We assign low confidence to the annual estimates of $E_{\mathrm{LUC}}$ because of the inconsistencies among estimates and of the difficulties to quantify some of the processes in DGVMs.

\subsubsection{Emissions projections}

We project the 2019 land use emissions for both H\&N2017 and BLUE, starting from their estimates for 2018 and adding observed changes in emissions from peat drainage (update on Hooijer et al., 2010) as well as emissions from peat fires, tropical deforestation, and degradation as estimated using active fire data (MCD14ML; Giglio et al., 2016). Those from degradation scale almost linearly with GFED over large areas (van der Werf et al., 2017) and thus allow for tracking fire emissions in deforestation and tropical peat zones in nearreal time. During most years, emissions during JanuarySeptember cover most of the fire season in the Amazon and Southeast Asia, where a large part of the global deforestation takes place. While the degree to which the fires in 2019 in the Amazon are related to land use change requires more scrutiny, initial analyses based on fire radiative power (FRP) of the fires detected indicate that many fires were associated with deforestation (http://www.globalfiredata.org/ forecast.html, last access: 31 October 2019). Most fires burning in Indonesia were on peatlands, which also represent a net source of $\mathrm{CO}_{2}$.

\subsection{Growth rate in atmospheric $\mathrm{CO}_{2}$ concentration $\left(G_{\text {ATM }}\right)$}

\subsubsection{Global growth rate in atmospheric $\mathrm{CO}_{2}$ concentration}

The rate of growth of the atmospheric $\mathrm{CO}_{2}$ concentration is provided by the US National Oceanic and Atmospheric Administration Earth System Research Laboratory (NOAA ESRL; Dlugokencky and Tans, 2019), which is updated from Ballantyne et al. (2012). For the 1959-1979 period, the global growth rate is based on measurements of atmospheric $\mathrm{CO}_{2}$ concentration averaged from the Mauna Loa and South Pole stations, as observed by the $\mathrm{CO}_{2}$ programme at Scripps Institution of Oceanography (Keeling et al., 1976). For the 
Table 5. Comparison of results from the bookkeeping method and budget residuals with results from the DGVMs and inverse estimates for different periods, the last decade, and the last year available. All values are in gigatonnes of carbon per year. The DGVM uncertainties represent $\pm 1 \sigma$ of the decadal or annual (for 2018 only) estimates from the individual DGVMs: for the inverse models the range of available results is given. All values are rounded to the nearest $0.1 \mathrm{GtC}$ and therefore columns do not necessarily add to zero.

\begin{tabular}{|c|c|c|c|c|c|c|c|}
\hline \multicolumn{8}{|c|}{ Mean $\left(\mathrm{GtC} \mathrm{yr}^{-1}\right)$} \\
\hline & 1960-1969 & 1970-1979 & 1980-1989 & 1990-1999 & 2000-2009 & 2009-2018 & 2018 \\
\hline \multicolumn{8}{|l|}{ Land use change emissions ( $\left.E_{\mathrm{LUC}}\right)$} \\
\hline Bookkeeping methods (1a) & $1.4 \pm 0.7$ & $1.2 \pm 0.7$ & $1.2 \pm 0.7$ & $1.3 \pm 0.7$ & $1.4 \pm 0.7$ & $1.5 \pm 0.7$ & $1.5 \pm 0.7$ \\
\hline DGVMs (1b) & $1.3 \pm 0.5$ & $1.3 \pm 0.5$ & $1.4 \pm 0.5$ & $1.2 \pm 0.4$ & $1.5 \pm 0.4$ & $2.0 \pm 0.5$ & $2.3 \pm 0.6$ \\
\hline \multicolumn{8}{|l|}{ Terrestrial sink $\left(S_{\text {LAND }}\right)$} \\
\hline $\begin{array}{l}\text { Residual sink from global budget } \\
\left(E_{\mathrm{FF}}+E_{\mathrm{LUC}}-G_{\mathrm{ATM}}-S_{\text {OCEAN }}\right)(2 \mathrm{a})\end{array}$ & $1.7 \pm 0.9$ & $1.8 \pm 0.9$ & $1.6 \pm 0.9$ & $2.6 \pm 0.9$ & $3.0 \pm 0.9$ & $3.6 \pm 1.0$ & $3.7 \pm 1.0$ \\
\hline DGVMs $(2 b)$ & $1.3 \pm 0.4$ & $2.0 \pm 0.3$ & $1.8 \pm 0.5$ & $2.4 \pm 0.4$ & $2.7 \pm 0.6$ & $3.2 \pm 0.6$ & $3.5 \pm 0.7$ \\
\hline \multicolumn{8}{|l|}{ Total land fluxes ( $\left.S_{\mathrm{LAND}}-E_{\mathrm{LUC}}\right)$} \\
\hline GCB2019 Budget (2b - 1a) & $-0.2 \pm 0.8$ & $0.9 \pm 0.8$ & $0.6 \pm 0.9$ & $1.0 \pm 0.8$ & $1.3 \pm 0.9$ & $1.7 \pm 0.9$ & $2.0 \pm 1.0$ \\
\hline Budget constraint $(2 \mathrm{a}-1 \mathrm{a})$ & $0.3 \pm 0.5$ & $0.6 \pm 0.5$ & $0.4 \pm 0.6$ & $1.3 \pm 0.6$ & $1.6 \pm 0.6$ & $2.1 \pm 0.7$ & $2.2 \pm 0.7$ \\
\hline DGVMs $(2 b-1 b)$ & $-0.1 \pm 0.5$ & $0.7 \pm 0.6$ & $0.4 \pm 0.6$ & $1.2 \pm 0.6$ & $1.1 \pm 0.6$ & $1.0 \pm 0.8$ & $1.0 \pm 0.8$ \\
\hline Inversions* & - & - & $-0.1-0.1$ & $0.5-1.1$ & $0.7-1.5$ & $1.1-2.2$ & $0.9-2.7$ \\
\hline
\end{tabular}

* Estimates are adjusted for the pre-industrial influence of river fluxes and adjusted to common $E_{\mathrm{FF}}$ (Sect. 2.7.2). The ranges given include two inversions from 1980 to 1999 and three inversions from 2001 onwards (Table A3).

1980-2018 time period, the global growth rate is based on the average of multiple stations selected from the marine boundary layer sites with well-mixed background air (Ballantyne et al., 2012), after fitting each station with a smoothed curve as a function of time and averaging by latitude band (Masarie and Tans, 1995). The annual growth rate is estimated by Dlugokencky and Tans (2019) from atmospheric $\mathrm{CO}_{2}$ concentration by taking the average of the most recent DecemberJanuary months corrected for the average seasonal cycle and subtracting this same average 1 year earlier. The growth rate in units of parts per million per year is converted to units of gigatonnes of carbon per year by multiplying by a factor of $2.124 \mathrm{GtC} \mathrm{ppm}^{-1}$ (Ballantyne et al., 2012).

The uncertainty around the atmospheric growth rate is due to four main factors. The first is the long-term reproducibility of reference gas standards (around $0.03 \mathrm{ppm}$ for $1 \sigma$ from the 1980s; Dlugokencky and Tans, 2019). Second, small unexplained systematic analytical errors that may have a duration of several months to 2 years come and go. They have been simulated by randomising both the duration and the magnitude (determined from the existing evidence) in a Monte Carlo procedure. The third is the network composition of the marine boundary layer with some sites coming or going, gaps in the time series at each site, etc (Dlugokencky and Tans, 2019). The latter uncertainty was estimated by NOAA ESRL with a Monte Carlo method by constructing 100 "alternative" networks (Masarie and Tans, 1995; NOAA/ESRL, 2019). The second and third uncertainties, summed in quadrature, add up to $0.085 \mathrm{ppm}$ on average (Dlugokencky and Tans, 2019). The fourth is the uncer- tainty associated with using the average $\mathrm{CO}_{2}$ concentration from a surface network to approximate the true atmospheric average $\mathrm{CO}_{2}$ concentration (mass-weighted, in three dimensions) as needed to assess the total atmospheric $\mathrm{CO}_{2}$ burden. In reality, $\mathrm{CO}_{2}$ variations measured at the stations will not exactly track changes in total atmospheric burden, with offsets in magnitude and phasing due to vertical and horizontal mixing. This effect must be very small on decadal and longer timescales, when the atmosphere can be considered well mixed. Preliminary estimates suggest this effect would increase the annual uncertainty, but a full analysis is not yet available. We therefore maintain an uncertainty around the annual growth rate based on the multiple stations' data set ranges between 0.11 and $0.72 \mathrm{GtC} \mathrm{yr}^{-1}$, with a mean of $0.61 \mathrm{GtC} \mathrm{yr}^{-1}$ for $1959-1979$ and $0.17 \mathrm{GtC} \mathrm{yr}^{-1}$ for 1980 2018, when a larger set of stations was available as provided by Dlugokencky and Tans (2019), but we recognise further exploration of this uncertainty is required. At this time, we estimate the uncertainty of the decadal averaged growth rate after 1980 at $0.02 \mathrm{GtC} \mathrm{yr}^{-1}$ based on the calibration and the annual growth rate uncertainty, but stretched over a 10 -year interval. For years prior to 1980 , we estimate the decadal av-

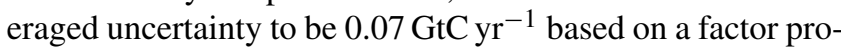
portional to the annual uncertainty prior to and after 1980 $\left(0.02 \times[0.61 / 0.17] \mathrm{GtC} \mathrm{yr}^{-1}\right)$.

We assign a high confidence to the annual estimates of $G_{\text {ATM }}$ because they are based on direct measurements from multiple and consistent instruments and stations distributed around the world (Ballantyne et al., 2012). 
In order to estimate the total carbon accumulated in the atmosphere since 1750 or 1850 , we use an atmospheric $\mathrm{CO}_{2}$ concentration of $277 \pm 3 \mathrm{ppm}$ or $286 \pm 3 \mathrm{ppm}$, respectively, based on a cubic spline fit to ice core data (Joos and Spahni, 2008). The uncertainty of $\pm 3 \mathrm{ppm}$ (converted to $\pm 1 \sigma$ ) is taken directly from the IPCC's assessment (Ciais et al., 2013). Typical uncertainties in the growth rate in atmospheric $\mathrm{CO}_{2}$ concentration from ice core data are equivalent to $\pm 0.1-0.15 \mathrm{GtC} \mathrm{yr}^{-1}$ as evaluated from the Law Dome data (Etheridge et al., 1996) for individual 20-year intervals over the period from 1850 to 1960 (Bruno and Joos, 1997).

\subsubsection{Atmospheric growth rate projection}

We provide an assessment of $G_{\text {ATM }}$ for 2019 based on the monthly calculated global atmospheric $\mathrm{CO}_{2}$ concentration (GLO) through August (Dlugokencky and Tans, 2019) and bias-adjusted Holt-Winters exponential smoothing with additive seasonality (Chatfield, 1978) to project to January 2020. The assessment method used this year differs from the forecast method used last year (Le Quéré et al., 2018b), which was based on the observed concentrations at Mauna Loa (MLO) only, using the historical relationship between the MLO and GLO series. Additional analysis suggests that the first half of the year shows more interannual variability than the second half of the year, so that the exact projection method applied to the second half of the year has a relatively smaller impact on the projection of the full year. Uncertainty is estimated from past variability using the standard deviation of the last 5 years' monthly growth rates.

\subsection{Ocean $\mathrm{CO}_{2}$ sink}

Estimates of the global ocean $\mathrm{CO}_{2}$ sink $S_{\text {OCEAN }}$ are from an ensemble of global ocean biogeochemistry models (GOBMs, Table A2) that meet observational constraints over the 1990s (see below). We use observation-based estimates of $S_{\text {OCEAN }}$ to provide a qualitative assessment of confidence in the reported results and two diagnostic ocean models to estimate $S_{\text {OCEAN }}$ over the industrial era (see below).

\subsubsection{Observation-based estimates}

We use the observational constraints assessed by IPCC of a mean ocean $\mathrm{CO}_{2}$ sink of $2.2 \pm 0.4 \mathrm{GtC} \mathrm{yr}^{-1}$ for the $1990 \mathrm{~s}$ (Denman et al., 2007) to verify that the GOBMs provide a realistic assessment of $S_{\text {OCEAN }}$. This is based on indirect observations with seven different methodologies and their uncertainties, using the methods that are deemed most reliable for the assessment of this quantity (Denman et al., 2007). The IPCC confirmed this assessment in 2013 (Ciais et al., 2013). The observational-based estimates use the oceanland $\mathrm{CO}_{2}$ sink partitioning from observed atmospheric $\mathrm{O}_{2}$ and $\mathrm{N}_{2}$ concentration trends (Manning and Keeling, 2006; updated in Keeling and Manning, 2014), an oceanic in- version method constrained by ocean biogeochemistry data (Mikaloff Fletcher et al., 2006), and a method based on a penetration timescale for chlorofluorocarbons (McNeil et al., 2003). The IPCC estimate of $2.2 \mathrm{GtC} \mathrm{yr}^{-1}$ for the $1990 \mathrm{~s}$ is consistent with a range of methods (Wanninkhof et al., 2013).

We also use three estimates of the ocean $\mathrm{CO}_{2}$ sink and its variability based on interpolations of measurements of surface ocean fugacity of $\mathrm{CO}_{2}\left(p \mathrm{CO}_{2}\right.$ corrected for the non-ideal behaviour of the gas; Pfeil et al., 2013). We refer to these as $p \mathrm{CO}_{2}$-based flux estimates. The measurements are from the Surface Ocean $\mathrm{CO}_{2}$ Atlas version 2019, which is an update of version 3 (Bakker et al., 2016) and contains quality-controlled data to 2018 (see data attribution Table A4). The SOCAT v2019 data were mapped using a data-driven diagnostic method (Rödenbeck et al., 2013; referred to here as Jena-MLS), a combined selforganising map and feed-forward neural network (Landschützer et al., 2014; MPI-SOMFFN), and an artificial neural network model (Denvil-Sommer et al., 2019; Copernicus Marine Environment Monitoring Service, CMEMS). The global $p \mathrm{CO}_{2}$-based flux estimates were adjusted to remove the pre-industrial ocean source of $\mathrm{CO}_{2}$ to the atmosphere of $0.78 \mathrm{GtC} \mathrm{yr}^{-1}$ from river input to the ocean (Resplandy et al., 2018), per our definition of $S_{\text {OCEAN }}$. Several other ocean sink products based on observations are also available but they continue to show large unresolved discrepancies with observed variability. Here we used, as in our previous annual budgets, the two $p \mathrm{CO}_{2}$-based flux products that had the best fit to observations for their representation of tropical and global variability (Rödenbeck et al., 2015), plus CMEMS, which has a similarly good fit with observations. The $\mathrm{CO}_{2}$ flux from each $p \mathrm{CO}_{2}$-based product is scaled by the ratio of the total ocean area covered by the respective product to the total ocean area $\left(361.9 \times 10^{6} \mathrm{~km}^{2}\right)$ from ETOPO1 (Amante and Eakins, 2009; Eakins and Sharman, 2010). In products where the covered area varies with time (MPI-SOMFFN, CMEMS) we use the maximum area coverage. The data products cover $88 \%$ (MPI-SOMFFN, CMEMS) to $101 \%$ of the observed total ocean area, so two products are effectively corrected upwards by a factor of 1.126 .

We further use results from two diagnostic ocean models of Khatiwala et al. (2013) and DeVries (2014) to estimate the anthropogenic carbon accumulated in the ocean prior to 1959. The two approaches assume constant ocean circulation and biological fluxes, with $S_{\text {OCEAN }}$ estimated as a response in the change in atmospheric $\mathrm{CO}_{2}$ concentration calibrated to observations. The uncertainty in cumulative uptake of $\pm 20 \mathrm{GtC}$ (converted to $\pm 1 \sigma$ ) is taken directly from the IPCC's review of the literature (Rhein et al., 2013) or as about $\pm 30 \%$ for the annual values (Khatiwala et al., 2009).

\subsubsection{Global ocean biogeochemistry models (GOBMs)}

The ocean $\mathrm{CO}_{2}$ sink for 1959-2018 is estimated using nine GOBMs (Table A2). The GOBMs represent the physical, 
chemical, and biological processes that influence the surface ocean concentration of $\mathrm{CO}_{2}$ and thus the air-sea $\mathrm{CO}_{2}$ flux. The GOBMs are forced by meteorological reanalysis and atmospheric $\mathrm{CO}_{2}$ concentration data available for the entire time period. They mostly differ in the source of the atmospheric forcing data (meteorological reanalysis), spin-up strategies, and their horizontal and vertical resolutions (Table A2). GOBMs do not include the effects of anthropogenic changes in nutrient supply, which could lead to an increase in the ocean sink of up to about $0.3 \mathrm{GtC} \mathrm{yr}^{-1}$ over the industrial period (Duce et al., 2008). They also do not include the perturbation associated with changes in riverine organic carbon (see Sect. 2.7.3).

The annual mean air-sea $\mathrm{CO}_{2}$ flux from the GOBMs is corrected for any model bias or drift by subtracting the timedependent model bias. The time-dependent model bias is calculated as a linear fit to the annual $\mathrm{CO}_{2}$ flux from a control simulation with no climate variability and change and constant pre-industrial $\mathrm{CO}_{2}$ concentration. The absolute biases per model in the 1990 s vary between 0.005 and $0.362 \mathrm{GtC} \mathrm{yr}^{-1}$, with some models having positive and some having negative biases. The bias correction reduces the model mean ocean carbon sink by $0.06 \mathrm{GtC} \mathrm{yr}^{-1}$ in the 1990s. The $\mathrm{CO}_{2}$ flux from each model is scaled by the ratio of the total ocean area covered by the respective GOBM to the total ocean area $\left(361.9 \times 10^{6} \mathrm{~km}^{2}\right)$ from ETOPO1 (Amante and Eakins, 2009; Eakins and Sharman, 2010). The ocean models cover $97 \%$ to $101 \%$ of the total ocean area, so the effect of this correction is small. All models fell within the observational constraint for the 1990s before and after applying the corrections.

\subsubsection{GOBM evaluation and uncertainty assessment for SOCEAN}

The mean ocean $\mathrm{CO}_{2}$ sink for all GOBMs falls within $90 \%$ confidence of the observed range, or 1.6 to $2.8 \mathrm{GtC} \mathrm{yr}^{-1}$ for the 1990s. Here we have adjusted the confidence interval to the IPCC confidence interval of $90 \%$ to avoid rejecting models that may be outliers but are still plausible.

The GOBMs and flux products have been further evaluated using air-sea $\mathrm{CO}_{2}$ flux $\left(f \mathrm{CO}_{2}\right)$ from the SOCAT v2019 database (Bakker et al., 2016, updated). We focused this evaluation on the root-mean-square error (RMSE) between observed $f \mathrm{CO}_{2}$ and modelled $p \mathrm{CO}_{2}$ and on a measure of the amplitude of the interannual variability of the flux (Rödenbeck et al., 2015). The amplitude of the $S_{\text {OCEAN interannual }}$ variability (A-IAV) is calculated as the temporal standard deviation of a 12-month running mean over the $\mathrm{CO}_{2}$ flux time series (Rödenbeck et al., 2015).
The RMSE is only calculated for open-ocean (water depth $>400 \mathrm{~m}$ ) grid points on a $1^{\circ} \times 1^{\circ}$ monthly grid where actual observations exist. These metrics are chosen because RMSE is the most direct measure of data-model mismatch and the A-IAV is a direct measure of the variability of $S_{\text {OCEAN }}$ on interannual timescales. We apply these metrics globally and by latitude bands (Fig. B1). Results are shown in Fig. B1 and discussed in Sect. 3.1.3.

The uncertainty around the mean ocean sink of anthropogenic $\mathrm{CO}_{2}$ was quantified by Denman et al. (2007) for the 1990s (see Sect. 2.4.1). To quantify the uncertainty around annual values, we examine the standard deviation of the GOBM ensemble, which averages $0.3 \mathrm{GtC} \mathrm{yr}^{-1}$ during 1959-2018. We estimate that the uncertainty in the annual ocean $\mathrm{CO}_{2}$ sink is about $\pm 0.5 \mathrm{GtC} \mathrm{yr}^{-1}$ from the combined uncertainty of the mean flux based on observations of $\pm 0.4 \mathrm{GtC} \mathrm{yr}^{-1}$ (Denman et al., 2007) and the standard deviation across GOBMs of up to $\pm 0.4 \mathrm{GtC} \mathrm{yr}^{-1}$, reflecting the uncertainty in both the mean sink from observations during the 1990s (Denman et al., 2007; Sect. 2.4.1) and in the interannual variability as assessed by GOBMs.

We examine the consistency between the variability of the model-based and the $p \mathrm{CO}_{2}$-based flux products to assess confidence in $S_{\text {OCEAN. The interannual variability of }}$ the ocean fluxes (quantified as the standard deviation) of the three $p \mathrm{CO}_{2}$-based flux products for 1985-2018 (where they overlap) is $\pm 0.37 \mathrm{GtC} \mathrm{yr}^{-1}$ (Jena-MLS), $\pm 0.46 \mathrm{GtC} \mathrm{yr}^{-1}$ (MPI-SOMFFN), and $\pm 0.51 \mathrm{GtC} \mathrm{yr}^{-1}$ (CMEMS). The interannual variability in the mean of the $p \mathrm{CO}_{2}$-based flux estimates is $\pm 0.41 \mathrm{GtC} \mathrm{yr}^{-1}$ for the $1985-2018$ period, compared to $\pm 0.31 \mathrm{GtC} \mathrm{yr}^{-1}$ for the GOBM ensemble. The standard deviation includes a component of trend and decadal variability in addition to interannual variability, and their relative influence differs across estimates. Individual estimates (both GOBM and flux products) generally produce a higher ocean $\mathrm{CO}_{2}$ sink during strong El Niño events. The annual $p \mathrm{CO}_{2}$-based flux products correlate with the ocean $\mathrm{CO}_{2}$ sink estimated here with a correlation of $r=0.75(0.55$ to 0.79 for individual GOBMs), $r=0.86$ (0.70 to 0.87 ), and 0.93 (0.83 to 0.93 ) for the $p \mathrm{CO}_{2}$-based flux products of Jena-MLS, MPI-SOMFFN, and CMEMS, respectively (simple linear regression). The averages of the GOBM estimates and of the data-based estimates have a mutual correlation of 0.91 . The agreement between the models and the flux products reflects some consistency in their representation of underlying variability since there is little overlap in their methodology or use of observations. We assess a medium confidence level for the annual ocean $\mathrm{CO}_{2}$ sink and its uncertainty because it is based on multiple lines of evidence, and the results are consistent in that the interannual variability in the GOBMs and data-based estimates is generally small compared to the variability in the growth rate of atmospheric $\mathrm{CO}_{2}$ concentration. 


\subsection{Terrestrial $\mathrm{CO}_{2}$ sink}

\subsubsection{DGVM simulations}

The terrestrial land sink ( $\left.S_{\text {LAND }}\right)$ is thought to be due to the combined effects of fertilisation by rising atmospheric $\mathrm{CO}_{2}$ and $\mathrm{N}$ inputs on plant growth, as well as the effects of climate change such as the lengthening of the growing season in northern temperate and boreal areas. $S_{\text {LAND }}$ does not include land sinks directly resulting from land use and land use change (e.g. regrowth of vegetation) as these are part of the land use flux $\left(E_{\mathrm{LUC}}\right)$, although system boundaries make it difficult to exactly attribute $\mathrm{CO}_{2}$ fluxes on land between $S_{\text {LAND }}$ and $E_{\text {LUC }}$ (Erb et al., 2013).

$S_{\text {LAND }}$ is estimated from the multi-model mean of 16 DGVMs (Table 4). As described in Sect. 2.2.2, DGVM simulations include all climate variability and $\mathrm{CO}_{2}$ effects over land, with some DGVMs also including the effect of $\mathrm{N}$ inputs. The DGVMs do not include the export of carbon to aquatic systems or its historical perturbation, which is discussed in Sect. 2.7.3.

\subsubsection{DGVM evaluation and uncertainty assessment for SLAND}

We apply three criteria for minimum DGVM realism by including only those DGVMs with (1) steady state after spin up; (2) net land fluxes ( $\left.S_{\text {LAND }}-E_{\mathrm{LUC}}\right)$, that is an atmosphere-to-land carbon flux over the 1990s ranging between -0.3 and $2.3 \mathrm{GtC} \mathrm{yr}^{-1}$, within $90 \%$ confidence of constraints by global atmospheric and oceanic observations (Keeling and Manning, 2014; Wanninkhof et al., 2013); and (3) global $E_{\mathrm{LUC}}$ that is a carbon source to the atmosphere over the 1990s, as mentioned in Sect. 2.2.2. All 16 DGVMs meet these three criteria.

In addition, the DGVM results are also evaluated using the International Land Model Benchmarking system (ILAMB; Collier et al., 2018). This evaluation is provided here to document, encourage, and support model improvements through time. ILAMB variables cover key processes that are relevant for the quantification of $S_{\text {LAND }}$ and resulting aggregated outcomes. The selected variables are vegetation biomass, gross primary productivity, leaf area index, net ecosystem exchange, ecosystem respiration, evapotranspiration, soil carbon, and runoff (see Fig. B2 for the results and for the list of observed databases). Results are shown in Fig. B2 and discussed in Sect. 3.1.3.

For the uncertainty for $S_{\text {LAND }}$, we use the standard deviation of the annual $\mathrm{CO}_{2}$ sink across the DGVMs, averaging to about $\pm 0.6 \mathrm{GtC} \mathrm{yr}^{-1}$ for the period from 1959 to 2018 . We attach a medium confidence level to the annual land $\mathrm{CO}_{2}$ sink and its uncertainty because the estimates from the residual budget and averaged DGVMs match well within their respective uncertainties (Table 5).

\subsection{The atmospheric perspective}

The worldwide network of atmospheric measurements can be used with atmospheric inversion methods to constrain the location of the combined total surface $\mathrm{CO}_{2}$ fluxes from all sources, including fossil and land use change emissions and land and ocean $\mathrm{CO}_{2}$ fluxes. The inversions assume $E_{\mathrm{FF}}$ to be well known, and they solve for the spatial and temporal distribution of land and ocean fluxes from the residual gradients of $\mathrm{CO}_{2}$ between stations that are not explained by fossil fuel emissions.

Three atmospheric inversions (Table A3) used atmospheric $\mathrm{CO}_{2}$ data to the end of 2018 (including preliminary values in some cases) to infer the spatio-temporal distribution of the $\mathrm{CO}_{2}$ flux exchanged between the atmosphere and the land or oceans. We focus here on the largest and most consistent sources of information, namely the total land and ocean $\mathrm{CO}_{2}$ flux and their partitioning among the midlatitude to high-latitude region of the Northern Hemisphere $\left(30-90^{\circ} \mathrm{N}\right)$, the tropics $\left(30^{\circ} \mathrm{S}-30^{\circ} \mathrm{N}\right)$, and the mid-latitude to high-latitude region of the Southern Hemisphere (30$\left.90^{\circ} \mathrm{S}\right)$. We also break down those estimates for the land and ocean regions separately, to further scrutinise the constraints from atmospheric observations. We use these estimates to comment on the consistency across various data streams and process-based estimates.

\subsubsection{Atmospheric inversions}

The three inversion systems used in this release are the CarbonTracker Europe (CTE; Van Der Laan-Luijkx et al., 2017), the Jena CarboScope (Rödenbeck, 2005, with updates from Rödenbeck et al., 2018), and the Copernicus Atmosphere Monitoring Service (CAMS; Chevallier et al., 2005). See Table A3 for version numbers. The inversions are based on Bayesian inversion principles with prior information on fluxes and their uncertainty that interpret the same, for the most part, observed time series (or subsets thereof), but use different methodologies (Table A3). These differences mainly concern the selection of atmospheric $\mathrm{CO}_{2}$ data, the used prior fluxes, spatial breakdown (i.e. grid size), assumed correlation structures, and mathematical approach. The details of these approaches are documented extensively in the references provided above. Each system uses a different transport model, which was demonstrated to be a driving factor behind differences in atmospheric-based flux estimates and specifically their distribution across latitudinal bands (e.g. Gaubert et al., 2019).

The inversions use atmospheric $\mathrm{CO}_{2}$ observations from various flask and in situ networks, as detailed in Table A3. They prescribe global fossil fuel emissions, which is already scaled to the present estimate of $E_{\mathrm{FF}}$ for CAMS, while CTE and CarboScope used slightly different $E_{\mathrm{FF}}$ values (< $0.39 \mathrm{GtC} \mathrm{yr}^{-1}$ ) based on alternative emissions compilations. Since this is known to result in different total $\mathrm{CO}_{2}$ uptake 
in atmospheric inversions (Peylin et al., 2013; Gaubert et al., 2019), we adjusted the land sink of each inversion estimate (where most of the fossil fuel emissions occur) by its fossil fuel difference to the CAMS model. These differences amount to up to $0.5 \mathrm{GtC}$ for certain years in the Northern Hemisphere and are thus an important consideration in an inverse flux comparison.

The land-ocean $\mathrm{CO}_{2}$ fluxes from atmospheric inversions contain anthropogenic perturbation and natural pre-industrial $\mathrm{CO}_{2}$ fluxes. Natural pre-industrial fluxes are primarily land $\mathrm{CO}_{2}$ sinks and ocean $\mathrm{CO}_{2}$ sources corresponding to carbon taken up on land, transported by rivers from land to ocean, and outgassed by the ocean. These pre-industrial land $\mathrm{CO}_{2}$ sinks are thus compensated for over the globe by ocean $\mathrm{CO}_{2}$ sources corresponding to the outgassing of riverine carbon inputs to the ocean. We apply the distribution of landto-ocean $\mathrm{C}$ fluxes from rivers in three latitude bands using estimates from Resplandy et al. (2018), which are constrained by ocean heat transport to a total land-to-ocean carbon transfer of $0.78 \mathrm{GtC} \mathrm{yr}^{-1}$. The latitude distribution of river-induced ocean $\mathrm{CO}_{2}$ sources (north: $0.20 \mathrm{GtC} \mathrm{yr}^{-1}$; tropics: $0.19 \mathrm{GtC} \mathrm{yr}^{-1}$; south: $\left.0.38 \mathrm{GtC} \mathrm{yr}^{-1}\right)$ is derived from a simulation of the IPSL GOBM using as an input the river flux constrained by heat transport of Resplandy et al. (2018). To facilitate the comparison, we adjusted the inversion estimates of the land and ocean fluxes per latitude band with these numbers based on these results to produce historical perturbation $\mathrm{CO}_{2}$ fluxes from inversions.

The atmospheric inversions are also evaluated using vertical profiles of atmospheric $\mathrm{CO}_{2}$ concentrations (Fig. B3). More than 30 aircraft programmes over the globe, either regular programmes or repeated surveys over at least 9 months, have been used in order to draw a robust picture of the model performance (with space-time data coverage irregular and denser in the $0-45^{\circ} \mathrm{N}$ latitude band). The three models are compared to the independent aircraft $\mathrm{CO}_{2}$ measurements between 2 and $7 \mathrm{~km}$ above sea level between 2001 and 2017 . Results are shown in Fig. B3 and discussed in Sect. 3.1.3.

\subsection{Processes not included in the global carbon budget}

The contribution of anthropogenic $\mathrm{CO}$ and $\mathrm{CH}_{4}$ to the global carbon budget is not fully accounted for in Eq. (1) and is described in Sect. 2.7.1. The contributions of other carbonates to $\mathrm{CO}_{2}$ emissions is described in Sect. 2.7.2. The contribution of anthropogenic changes in river fluxes is conceptually included in Eq. (1) in $S_{\text {OCEAN }}$ and in $S_{\text {LAND }}$, but it is not represented in the process models used to quantify these fluxes. This effect is discussed in Sect. 2.7.3. Similarly, the loss of additional sink capacity from reduced forest cover is missing in the combination of approaches used here to estimate both land fluxes ( $E_{\mathrm{LUC}}$ and $\left.S_{\mathrm{LAND}}\right)$, and their potential effect is discussed and quantified in Sect 2.7.4.

\subsubsection{Contribution of anthropogenic $\mathrm{CO}$ and $\mathrm{CH}_{4}$ to the global carbon budget}

Equation (1) only partly includes the net input of $\mathrm{CO}_{2}$ to the atmosphere from the chemical oxidation of reactive carboncontaining gases from sources other than the combustion of fossil fuels, such as (1) cement process emissions since these do not come from combustion of fossil fuels, (2) the oxidation of fossil fuels, and (3) the assumption of immediate oxidation of vented methane in oil production. It omits however any other anthropogenic carbon-containing gases that are eventually oxidised in the atmosphere, such as anthropogenic emissions of $\mathrm{CO}$ and $\mathrm{CH}_{4}$. An attempt is made in this section to estimate their magnitude and identify the sources of uncertainty. Anthropogenic CO emissions are from incomplete fossil fuel and biofuel burning and deforestation fires. The main anthropogenic emissions of fossil $\mathrm{CH}_{4}$ that matter for the global carbon budget are the fugitive emissions of coal, oil, and gas upstream sectors (see below). These emissions of $\mathrm{CO}$ and $\mathrm{CH}_{4}$ contribute a net addition of fossil carbon to the atmosphere.

In our estimate of $E_{\mathrm{FF}}$ we assumed (Sect. 2.1.1) that all the fuel burned is emitted as $\mathrm{CO}_{2}$; thus $\mathrm{CO}$ anthropogenic emissions associated with incomplete combustion and their atmospheric oxidation into $\mathrm{CO}_{2}$ within a few months are already counted implicitly in $E_{\mathrm{FF}}$ and should not be counted twice (same for $E_{\mathrm{LUC}}$ and anthropogenic $\mathrm{CO}$ emissions by deforestation fires). Anthropogenic emissions of fossil $\mathrm{CH}_{4}$ are not included in $E_{\mathrm{FF}}$ because these fugitive emissions are not included in the fuel inventories. Yet they contribute to the annual $\mathrm{CO}_{2}$ growth rate after $\mathrm{CH}_{4}$ gets oxidised into $\mathrm{CO}_{2}$. Anthropogenic emissions of fossil $\mathrm{CH}_{4}$ represent $15 \%$ of total $\mathrm{CH}_{4}$ emissions (Kirschke et al., 2013), that is $0.072 \mathrm{GtC} \mathrm{yr}^{-1}$ for the past decade. Assuming steady state, these emissions are all converted to $\mathrm{CO}_{2}$ by $\mathrm{OH}$ oxidation, and thus they explain $0.06 \mathrm{GtC} \mathrm{yr}^{-1}$ of the global $\mathrm{CO}_{2}$ growth rate in the past decade, or $0.07-0.1 \mathrm{GtC} \mathrm{yr}^{-1}$ using the higher $\mathrm{CH}_{4}$ emissions reported recently (Schwietzke et al., 2016).

Other anthropogenic changes in the sources of $\mathrm{CO}$ and $\mathrm{CH}_{4}$ from wildfires, vegetation biomass, wetlands, ruminants, or permafrost are similarly assumed to have a small effect on the $\mathrm{CO}_{2}$ growth rate. The $\mathrm{CH}_{4}$ and $\mathrm{CO}$ emissions and sinks are published and analysed separately in the global methane budget and global carbon monoxide budget publications, which follow a similar approach to that presented here (Saunois et al., 2016; Zheng et al., 2019).

\subsubsection{Contribution of other carbonates to $\mathrm{CO}_{2}$ emissions}

The contribution of fossil carbonates other than cement production is not systematically included in estimates of $E_{\mathrm{FF}}$, except at the national level where they are accounted for in the UNFCCC national inventories. The missing processes include $\mathrm{CO}_{2}$ emissions associated with the calcination of lime 
and limestone outside cement production and the reabsorption of $\mathrm{CO}_{2}$ by the rocks and concrete from carbonation through their lifetime (Xi et al., 2016). Carbonates are used in various industries, including in iron and steel manufacture and in agriculture. They are found naturally in some coals. Carbonation from the cement life cycle, including demolition and crushing, was estimated by one study to be around $0.25 \mathrm{GtC} \mathrm{yr}^{-1}$ for the year 2013 (Xi et al., 2016). Carbonation emissions from the cement life cycle would offset calcination emissions from lime and limestone production. The balance of these two processes is not clear.

\subsubsection{Anthropogenic carbon fluxes in the land-to-ocean aquatic continuum}

The approach used to determine the global carbon budget refers to the mean, variations, and trends in the perturbation of $\mathrm{CO}_{2}$ in the atmosphere, referenced to the pre-industrial era. Carbon is continuously displaced from the land to the ocean through the land-ocean aquatic continuum (LOAC) comprising freshwaters, estuaries, and coastal areas (Bauer et al., 2013; Regnier et al., 2013). A significant fraction of this lateral carbon flux is entirely "natural" and is thus a steady-state component of the pre-industrial carbon cycle. We account for this pre-industrial flux where appropriate in our study. However, changes in environmental conditions and land use change have caused an increase in the lateral transport of carbon into the LOAC - a perturbation that is relevant for the global carbon budget presented here.

The results of the analysis of Regnier et al. (2013) can be summarised in two points of relevance for the anthropogenic $\mathrm{CO}_{2}$ budget. First, the anthropogenic perturbation has increased the organic carbon export from terrestrial ecosystems to the hydrosphere by as much as $1.0 \pm 0.5 \mathrm{GtC} \mathrm{yr}^{-1}$ since pre-industrial times, mainly owing to enhanced carbon export from soils. Second, this exported anthropogenic carbon is partly respired through the LOAC, partly sequestered in sediments along the LOAC, and to a lesser extent transferred to the open ocean where it may accumulate. The increase in storage of land-derived organic carbon in the LOAC and open ocean combined is estimated by Regnier et al. (2013) at $0.65 \pm 0.35 \mathrm{GtC} \mathrm{yr}^{-1}$. We do not attempt to incorporate the changes in LOAC in our study.

The inclusion of freshwater fluxes of anthropogenic $\mathrm{CO}_{2}$ affects the estimates of, and partitioning between, $S_{\text {LAND }}$ and $S_{\text {OCEAN }}$ in Eq. (1) but does not affect the other terms. This effect is not included in the GOBMs and DGVMs used in our global carbon budget analysis presented here.

\subsubsection{Loss of additional sink capacity}

Historical land cover change was dominated by transitions from vegetation types that can provide a large carbon sink per area unit (typically forests) to others less efficient in removing $\mathrm{CO}_{2}$ from the atmosphere (typically croplands). The resultant decrease in land sink, called the "loss of sink capacity", is calculated as the difference between the actual land sink under changing land cover and the counterfactual land sink under pre-industrial land cover. An efficient protocol has yet to be designed to estimate the magnitude of the loss of additional sink capacity in DGVMs. Here, we provide a quantitative estimate of this term to be used in the discussion. Our estimate uses the compact Earth system model OSCAR whose land carbon cycle component is designed to emulate the behaviour of DGVMs (Gasser et al., 2017). We use OSCAR v2.2.1 (an update of v2.2 with minor changes) in a probabilistic setup identical to the one of Arneth et al. (2017) but with a Monte Carlo ensemble of 2000 simulations. For each, we calculate $S_{\text {LAND }}$ and the loss of additional sink capacity separately. We then constrain the ensemble by weighting each member to obtain a distribution of cumulative $S_{\text {LAND }}$ over 1850-2005 close to the DGVMs used here. From this ensemble, we estimate a loss of additional sink capacity of $0.4 \pm 0.3 \mathrm{GtC} \mathrm{yr}^{-1}$ on average over 2005-2014 and of about $20 \pm 15 \mathrm{GtC}$ when accumulated between 1850 and 2018 (using a linear extrapolation of the trend to estimate the last few years).

\section{Results}

\subsection{Global carbon budget mean and variability for 1959-2018}

The global carbon budget averaged over the last half-century is shown in Fig. 3. For this time period, $82 \%$ of the total emissions $\left(E_{\mathrm{FF}}+E_{\mathrm{LUC}}\right)$ were caused by fossil $\mathrm{CO}_{2}$ emissions and $18 \%$ by land use change. The total emissions were partitioned among the atmosphere (45\%), ocean (24\%), and land $(29 \%)$, with an unattributed budget imbalance $(2 \%)$. All components except land use change emissions have significantly grown since 1959 , with important interannual variability in the growth rate in atmospheric $\mathrm{CO}_{2}$ concentration and in the land $\mathrm{CO}_{2}$ sink (Fig. 4) and some decadal variability in all terms (Table 6). Differences with previous budget releases are documented in Fig. B4.

\subsection{1 $\mathrm{CO}_{2}$ emissions}

Global fossil $\mathrm{CO}_{2}$ emissions have increased every decade from an average of $3.0 \pm 0.2 \mathrm{GtC} \mathrm{yr}^{-1}$ in the $1960 \mathrm{~s}$ to an average of $9.5 \pm 0.5 \mathrm{GtC} \mathrm{yr}^{-1}$ during 2009-2018 (Table 6, Figs. 2 and 5). The growth rate in these emissions decreased between the $1960 \mathrm{~s}$ and the $1990 \mathrm{~s}$, from $4.4 \% \mathrm{yr}^{-1}$ in the $1960 \mathrm{~s}(1960-1969)$ to $2.8 \% \mathrm{yr}^{-1}$ in the $1970 \mathrm{~s}(1970-1979)$, $1.9 \% \mathrm{yr}^{-1}$ in the $1980 \mathrm{~s}(1980-1989)$, and $0.9 \% \mathrm{yr}^{-1}$ in the1990s (1990-1999). After this period, the growth rate began increasing again in the 2000s at an average growth rate of $3.0 \% \mathrm{yr}^{-1}$, decreasing to $0.9 \% \mathrm{yr}^{-1}$ for $2010-2018$, with $1.3 \% \mathrm{yr}^{-1}$ for the last decade (2009-2018). 
Table 6. Decadal mean in the five components of the anthropogenic $\mathrm{CO}_{2}$ budget for different periods and the last year available. All values are in gigatonnes of carbon per year, and uncertainties are reported as $\pm 1 \sigma$. The table also shows the budget imbalance $\left(B_{\mathrm{IM}}\right)$, which provides

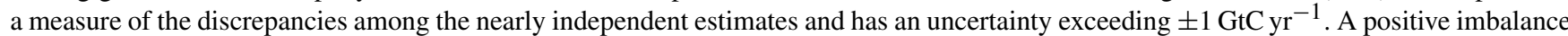
means the emissions are overestimated and/or the sinks are too small. All values are rounded to the nearest $0.1 \mathrm{GtC}$ and therefore columns do not necessarily add to zero.

\begin{tabular}{|c|c|c|c|c|c|c|c|}
\hline & \multicolumn{7}{|c|}{ Mean $\left(\mathrm{GtC} \mathrm{yr}^{-1}\right)$} \\
\hline & $1960-1969$ & 1970-1979 & 1980-1989 & 1990-1999 & $2000-2009$ & 2009-2018 & 2018 \\
\hline \multicolumn{8}{|l|}{ Total emissions $\left(E_{\mathrm{FF}}+E_{\mathrm{LUC}}\right)$} \\
\hline Fossil $\mathrm{CO}_{2}$ emissions $\left(E_{\mathrm{FF}}\right)$ & $3.0 \pm 0.2$ & $4.7 \pm 0.2$ & $5.5 \pm 0.3$ & $6.4 \pm 0.3$ & $7.8 \pm 0.4$ & $9.5 \pm 0.5$ & $10.0 \pm 0.5$ \\
\hline Land use change emissions ( $\left.E_{\mathrm{LUC}}\right)$ & $1.4 \pm 0.7$ & $1.2 \pm 0.7$ & $1.2 \pm 0.7$ & $1.3 \pm 0.7$ & $1.4 \pm 0.7$ & $1.5 \pm 0.7$ & $1.5 \pm 0.7$ \\
\hline Total emissions & $4.5 \pm 0.7$ & $5.8 \pm 0.7$ & $6.7 \pm 0.8$ & $7.7 \pm 0.8$ & $9.2 \pm 0.8$ & $11.0 \pm 0.8$ & $11.5 \pm 0.9$ \\
\hline \multicolumn{8}{|l|}{ Partitioning } \\
\hline $\begin{array}{l}\text { Growth rate in atmospheric } \mathrm{CO}_{2} \\
\text { concentration }\left(G_{\mathrm{ATM}}\right)\end{array}$ & $1.8 \pm 0.07$ & $2.8 \pm 0.07$ & $3.4 \pm 0.02$ & $3.1 \pm 0.02$ & $4.0 \pm 0.02$ & $4.9 \pm 0.02$ & $5.1 \pm 0.2$ \\
\hline Ocean sink $\left(S_{\text {OCEAN }}\right)$ & $1.0 \pm 0.6$ & $1.3 \pm 0.6$ & $1.7 \pm 0.6$ & $2.0 \pm 0.6$ & $2.2 \pm 0.6$ & $2.5 \pm 0.6$ & $2.6 \pm 0.6$ \\
\hline Terrestrial sink $\left(S_{\text {LAND }}\right)$ & $1.3 \pm 0.4$ & $2.0 \pm 0.3$ & $1.8 \pm 0.5$ & $2.4 \pm 0.4$ & $2.7 \pm 0.6$ & $3.2 \pm 0.6$ & $3.5 \pm 0.7$ \\
\hline \multicolumn{8}{|l|}{ Budget imbalance } \\
\hline $\begin{array}{l}B_{\mathrm{IM}}=E_{\mathrm{FF}}+E_{\mathrm{LUC}}-\left(G_{\mathrm{ATM}}+\right. \\
\left.S_{\text {OCEAN }}+S_{\mathrm{LAND}}\right)\end{array}$ & 0.5 & -0.2 & -0.2 & 0.3 & 0.3 & 0.4 & 0.3 \\
\hline
\end{tabular}

In contrast, $\mathrm{CO}_{2}$ emissions from land use, land use change, and forestry have remained relatively constant, at around $1.3 \pm 0.7 \mathrm{GtC} \mathrm{yr}^{-1}$ over the past half-century (Table 6) but with large spread across estimates (Table 5, Fig. 6). These emissions are also relatively constant in the DGVM ensemble of models, except during the last decade when they increase to $2.0 \pm 0.5 \mathrm{GtC} \mathrm{yr}^{-1}$. However, there is no agreement on this recent increase between the two bookkeeping models, each suggesting an opposite trend (Fig. 6).

\subsubsection{Partitioning among the atmosphere, ocean, and land}

The growth rate in atmospheric $\mathrm{CO}_{2}$ level increased from $1.8 \pm 0.07 \mathrm{GtC} \mathrm{yr}^{-1}$ in the 1960 s to $4.9 \pm 0.02 \mathrm{GtC} \mathrm{yr}^{-1}$ during 2009-2018 with important decadal variations (Table 6 and Fig. 2). Both ocean and land $\mathrm{CO}_{2}$ sinks have increased roughly in line with the atmospheric increase, but with significant decadal variability on land (Table 6 and Fig. 6) and possibly in the ocean (Fig. 7). The ocean $\mathrm{CO}_{2}$ sink increased from $1.0 \pm 0.6 \mathrm{GtC} \mathrm{yr}^{-1}$ in the 1960 s to $2.5 \pm 0.6 \mathrm{GtC} \mathrm{yr}^{-1}$ during 2009-2018, with interannual variations of the order of a few tenths of gigatonnes of carbon per year generally showing an increased ocean sink during large El Niño events (i.e. 1997-1998) (Fig. 7; Rödenbeck et al., 2014). There is coherence among the GOBMs and $p \mathrm{CO}_{2}$-based flux products regarding the mean and the patterns of temporal variability; however, the ocean models underestimate the magnitude of decadal variability (Sect. 2.4.3 and Fig. 7; DeVries et al., 2019).
The terrestrial $\mathrm{CO}_{2}$ sink increased from $1.3 \pm 0.4 \mathrm{GtC} \mathrm{yr}^{-1}$ in the 1960 s to $3.2 \pm 0.7 \mathrm{GtC} \mathrm{yr}^{-1}$ during 2009-2018, with

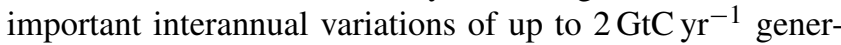
ally showing a decreased land sink during El Niño events (Fig. 6), responsible for the corresponding enhanced growth rate in atmospheric $\mathrm{CO}_{2}$ concentration. The larger land $\mathrm{CO}_{2}$ sink during 2009-2018 compared to the 1960s is reproduced by all the DGVMs in response to the combined atmospheric $\mathrm{CO}_{2}$ increase and the changes in climate and consistent with constraints from the other budget terms (Table 5).

The total atmosphere-to-land fluxes $\left(S_{\mathrm{LAND}}-E_{\mathrm{LUC}}\right)$, calculated here as the difference between $S_{\text {LAND }}$ from the DGVMs and $E_{\text {LUC }}$ from the bookkeeping models, increased

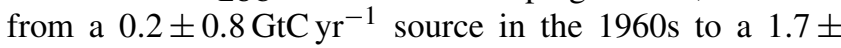
$0.9 \mathrm{GtC} \mathrm{yr}^{-1}$ sink during 2009-2018 (Table 5). Estimates of total atmosphere-to-land fluxes $\left(S_{\mathrm{LAND}}-E_{\mathrm{LUC}}\right)$ from the DGVMs alone are consistent with our estimate and also with the global carbon budget constraint $\left(E_{\mathrm{FF}}-G_{\mathrm{ATM}}-\right.$ SOCEAN, Table 5), except during 2009-2018, where the DGVM ensemble estimates a total atmosphere-to-land flux of $1.0 \pm 0.8 \mathrm{GtC} \mathrm{yr}^{-1}$, likely below both our estimate of

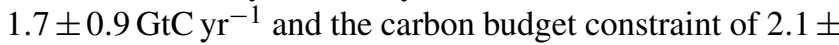
$0.7 \mathrm{GtC} \mathrm{yr}^{-1}$ but still within the range of the inversions (1.12.2 $\mathrm{GtC} \mathrm{yr}^{-1}$ ) (Table 5). Over the last decade, the land use emission estimate from the DGVMs is significantly larger than the bookkeeping estimate, mainly explaining why the DGVMs' total atmosphere-to-land flux estimate is lower than the other estimates. 


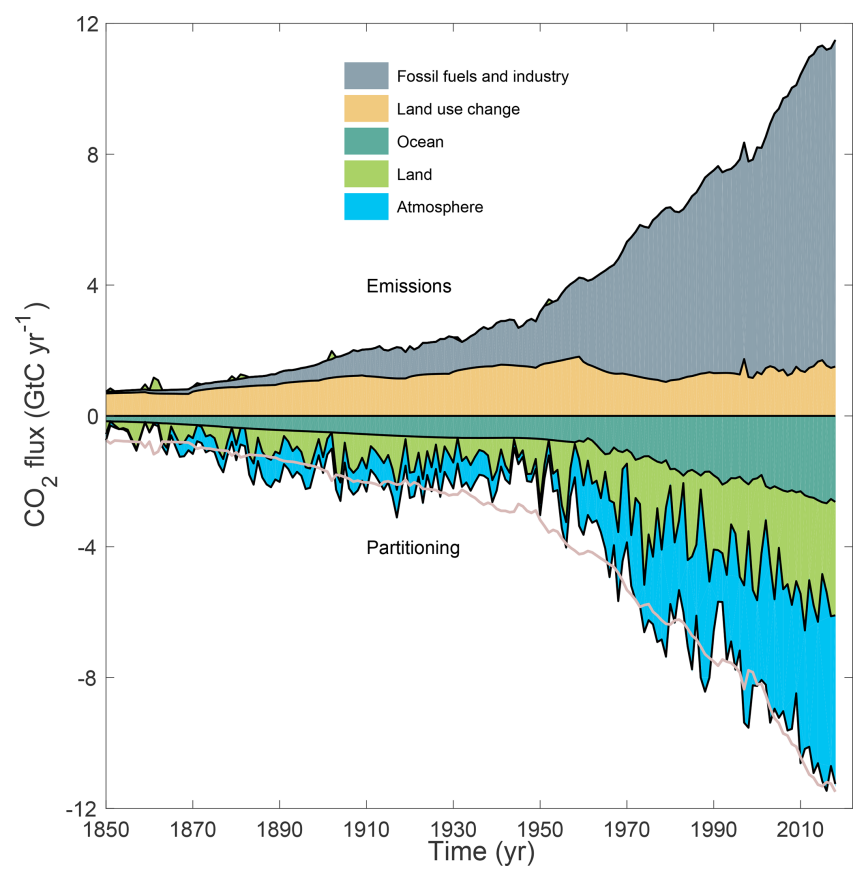

Figure 3. Combined components of the global carbon budget illustrated in Fig. 2 as a function of time, for fossil $\mathrm{CO}_{2}$ emissions ( $E_{\mathrm{FF}}$, grey) and emissions from land use change ( $E_{\mathrm{LUC}}$, brown), as well as their partitioning among the atmosphere $\left(G_{\mathrm{ATM}}\right.$, blue), ocean ( $S_{\text {OCEAN }}$, turquoise), and land $\left(S_{\text {LAND }}\right.$, green). The partitioning is based on nearly independent estimates from observations (for $G_{\mathrm{ATM}}$ ) and from process model ensembles constrained by data (for $S_{\text {OCEAN }}$ and $S_{\text {LAND }}$ ), and it does not exactly add up to the sum of the emissions, resulting in a budget imbalance, which is represented by the difference between the bottom pink line (reflecting total emissions) and the sum of the ocean, land, and atmosphere. All time series are in gigatonnes of carbon per year.

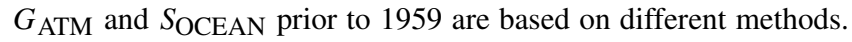
$E_{\mathrm{FF}}$ is primarily from Gilfillan et al. (2019), with uncertainty of about $\pm 5 \%( \pm 1 \sigma) ; E_{\mathrm{LUC}}$ is from two bookkeeping models (Table 2) with uncertainties of about $\pm 50 \%$; $G_{\text {ATM }}$ prior to 1959 is from Joos and Spahni (2008) with uncertainties equivalent to about $\pm 0.1-0.15 \mathrm{GtC} \mathrm{yr}^{-1}$ and from Dlugokencky and Tans (2019) from 1959 with uncertainties of about $\pm 0.2 \mathrm{GtC} \mathrm{yr}^{-1} ; S_{\text {OCEAN }}$ prior to 1959 is averaged from Khatiwala et al. (2013) and DeVries (2014) with uncertainty of about $\pm 30 \%$ and from a multi-model mean (Table 4) from 1959 with uncertainties of about $\pm 0.5 \mathrm{GtC} \mathrm{yr}^{-1}$; $S_{\text {LAND }}$ is a multi-model mean (Table 4 ) with uncertainties of about

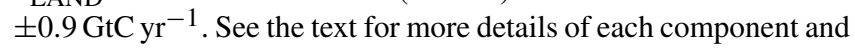
their uncertainties.

\subsubsection{Model evaluation}

The evaluation of the ocean estimates (Fig. B1) shows a RMSE of 15 to $17 \mu \mathrm{atm}$ for the three $p \mathrm{CO}_{2}$-based flux products over the globe, relative to the $p \mathrm{CO}_{2}$ observations from the SOCAT v2019 database for the period 1985-2018. The GOBM RMSEs are a factor of 2 to 3 larger and range between 29 and $49 \mu \mathrm{atm}$. The RMSEs are generally larger at high latitudes compared to the tropics, for both the flux prod- ucts and the GOBMs. The three flux products have similar RMSEs of around 12 to $14 \mu \mathrm{atm}$ in the tropics, around 17 to $18 \mu$ atm in the north, and 17 to $24 \mu$ atm in the south. Note that the flux products are based on the SOCAT v2019 database; hence these are no independent data sets for the evaluation of the flux products. The GOBM RMSEs are more spread across regions, ranging from 21 to $34 \mu \mathrm{atm}$ in the tropics, 32 to $48 \mu \mathrm{atm}$ in the north, and 31 to $77 \mu \mathrm{atm}$ in the south. The higher RMSEs occur in regions with stronger climate variability, such as the northern and southern high latitudes (poleward of the subtropical gyres).

The evaluation of the DGVMs (Fig. B2) shows generally high skill scores across models for runoff, and to a lesser extent for vegetation biomass, gross primary productivity (GPP), and ecosystem respiration (Fig. B2, left panel). Skill score was lowest for leaf area index and net ecosystem exchange, with the widest disparity among models for soil carbon. Further analysis of the results will be provided separately, focusing on the strengths and weaknesses in the DGVM ensemble and its validity for use in the global carbon budget.

The evaluation of the atmospheric inversions (Fig. B3) shows long-term mean biases in the free troposphere better than $0.4 \mathrm{ppm}$ in absolute values for each product. These biases show some dependency on latitude and are different for each inverse model, which may reveal biases in the surface fluxes (e.g. Houweling et al., 2015). Such model- and campaign-specific performance will be analysed separately.

\subsubsection{Budget imbalance}

The carbon budget imbalance ( $B_{\mathrm{IM}}$, Eq. 1 ) quantifies the mismatch between the estimated total emissions and the estimated changes in the atmosphere, land, and ocean reservoirs. The mean budget imbalance from 1959 to 2018 is small (average of $0.17 \mathrm{GtC} \mathrm{yr}^{-1}$ ) and shows no trend over the full time series. The process models (GOBMs and DGVMs) have been selected to match observational constraints in the 1990s but no further constraints have been applied to their representation of trend and variability. Therefore, the near-zero mean and trend in the budget imbalance is indirect evidence of a coherent community understanding of the emissions and their partitioning on those timescales (Fig. 4). However, the budget imbalance shows substantial variability of the order of $\pm 1 \mathrm{GtC} \mathrm{yr}^{-1}$, particularly over semi-decadal timescales, although most of the variability is within the uncertainty of the estimates. The positive carbon imbalance during the 1960s, early 1990s, and in the last decade suggests that either the emissions were overestimated or the sinks were underestimated during these periods. The reverse is true for the 1970s and around 1995-2000 (Fig. 4).

We cannot attribute the cause of the variability in the budget imbalance with our analysis. We only note that the budget imbalance is unlikely to be explained by errors or biases in the emissions alone because of its large semi-decadal vari- 

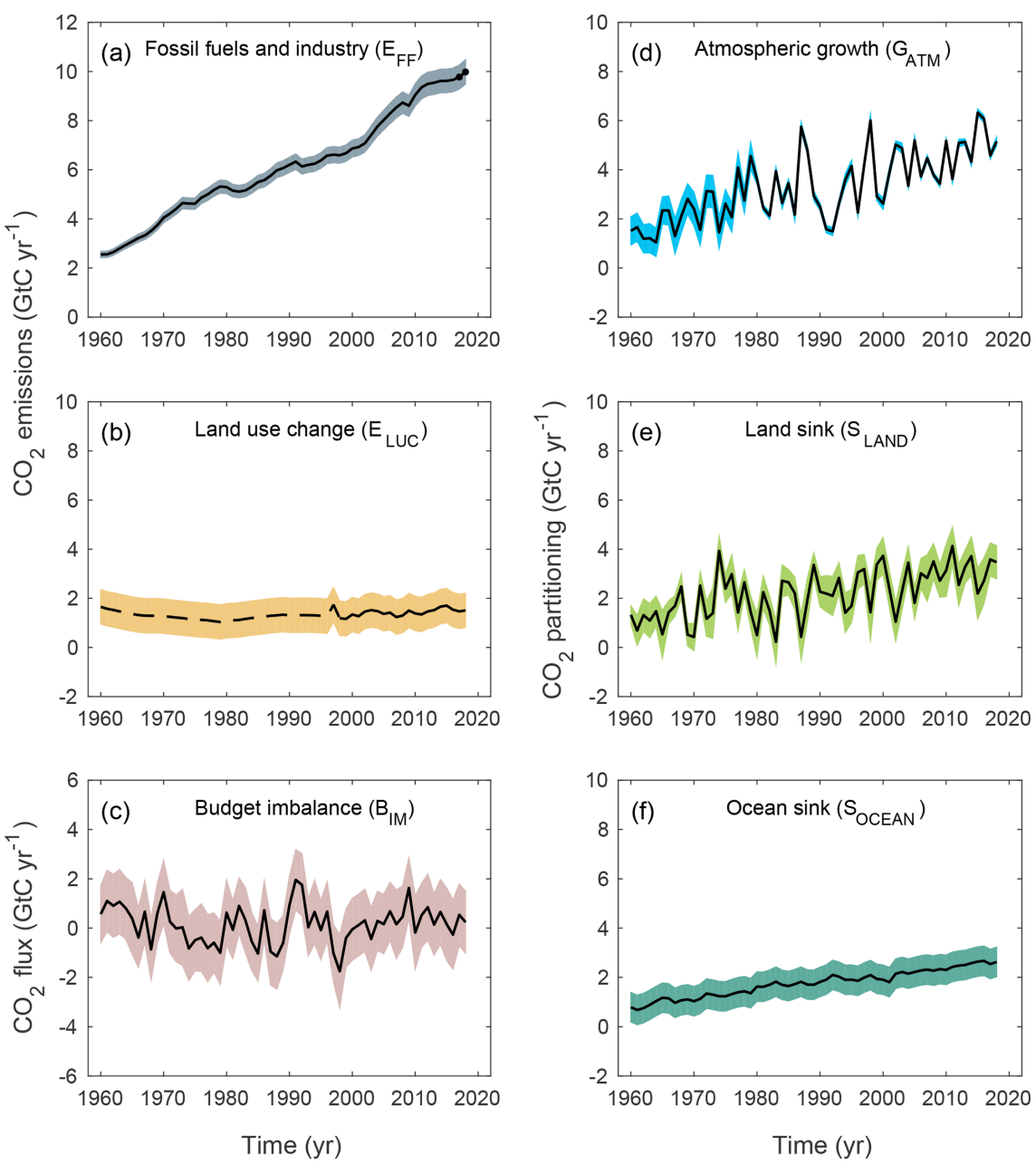

Figure 4. Components of the global carbon budget and their uncertainties as a function of time, presented individually for (a) fossil $\mathrm{CO}_{2}$ emissions $\left(E_{\mathrm{FF}}\right),(\mathbf{b})$ emissions from land use change $\left(E_{\mathrm{LUC}}\right),(\mathbf{c})$ the budget imbalance that is not accounted for by the other terms, $(\mathbf{d})$ growth rate in atmospheric $\mathrm{CO}_{2}$ concentration $\left(G_{\mathrm{ATM}}\right)$, and (e) the land $\mathrm{CO}_{2} \operatorname{sink}\left(S_{\mathrm{LAND}}\right.$, positive indicates a flux from the atmosphere to the land), and (f) the ocean $\mathrm{CO}_{2} \operatorname{sink}\left(S_{\mathrm{OCEAN}}\right.$, positive indicates a flux from the atmosphere to the ocean). All time series are in gigatonnes of carbon per year with the uncertainty bounds representing $\pm 1 \sigma$ in shaded colour. Data sources are as in Fig. 3. The black dots in (a) show values for 2017-2018 that originate from a different data set to the remainder of the data (see text). The dashed line in (b) identifies the pre-satellite period before the inclusion of emissions from peatland burning.

ability component, a variability that is untypical of emissions and has not changed in the past 50 years in spite of a near tripling in emissions (Fig. 4). Errors in $S_{\text {LAND }}$ and $S_{\text {OCEAN }}$ are more likely to be the main cause for the budget imbalance. For example, underestimation of the $S_{\text {LAND }}$ by DGVMs has been reported following the eruption of Mount Pinatubo in 1991 possibly due to missing responses to changes in diffuse radiation (Mercado et al., 2009) or other yet unknown factors, and DGVMs are suspected to overestimate the land sink in response to the wet decade of the 1970s (Sitch et al., 2008). Decadal and semi-decadal variability in the ocean sink has also been reported recently (DeVries et al., 2019, 2017; Landschützer et al., 2015), with the $p \mathrm{CO}_{2}$-based ocean flux products and a decadal ocean inverse model suggesting a smaller-than-expected ocean $\mathrm{CO}_{2}$ sink in the 1990 s and a larger than expected sink in the 2000s (Fig. 7; DeVries et al., 2019). The decadal variability is possibly caused by changes in ocean circulation (DeVries et al., 2017) not captured in coarse resolution GOBMs used here (Dufour et al., 2013), or by internal variability, which is not captured by single realisations of coarse resolution model simulations ( $\mathrm{Li}$ and Ilyina, 2018) The decadal variability is thought to be largest in regions with strong seasonal and interannual climate variability, i.e. the high latitude ocean regions (poleward of the subtropical gyres) and the equatorial Pacific ( $\mathrm{Li}$ and Ilyina, 2018; McKinley et al., 2016). Some of these errors could be driven by errors in the climatic forcing data, particularly precipitation (for $S_{\text {LAND }}$ ) and wind (for $S_{\text {OCEAN }}$ ) rather than in the models. 

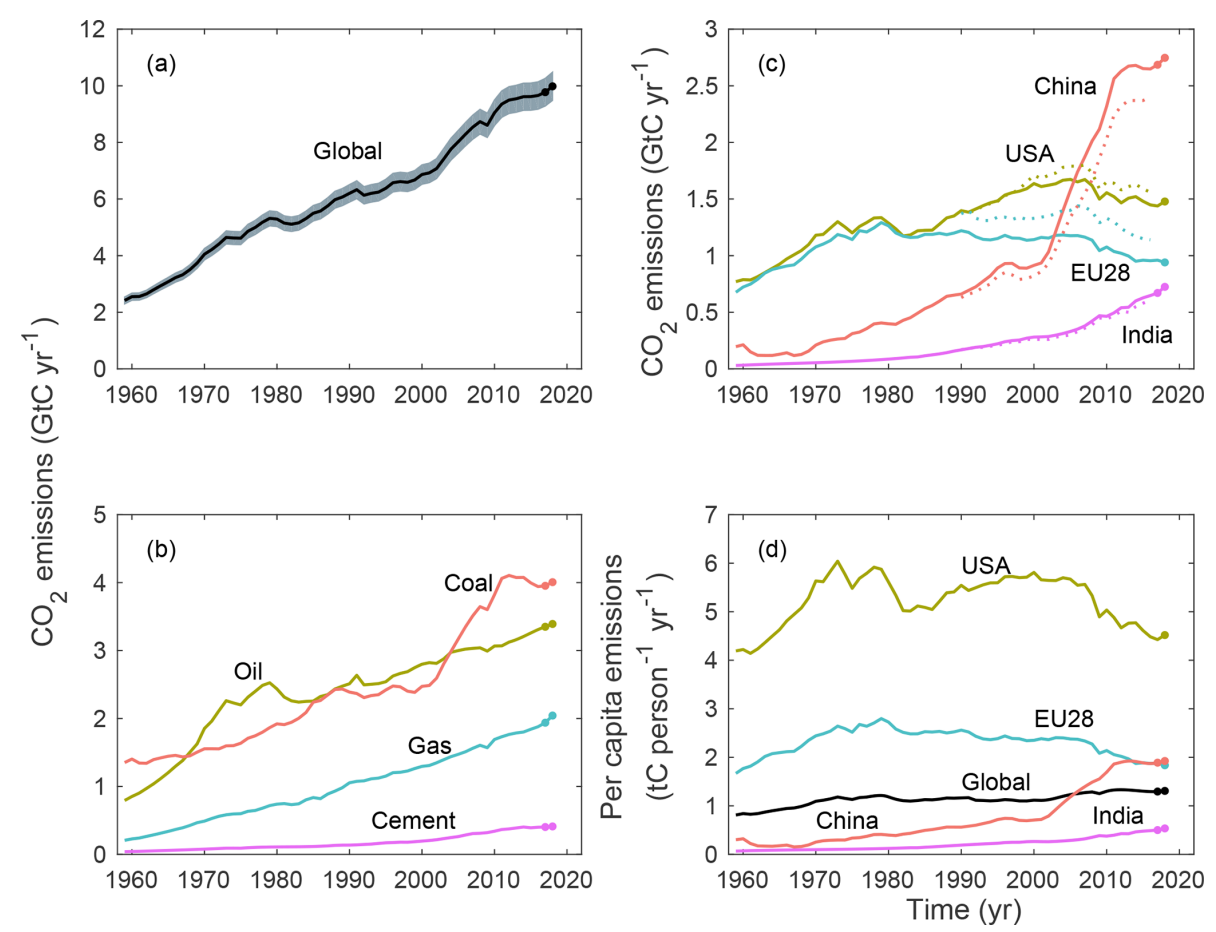

Figure 5. Fossil $\mathrm{CO}_{2}$ emissions for (a) the globe, including an uncertainty of $\pm 5 \%$ (grey shading), and the emissions extrapolated using BP energy statistics (black dots), (b) global emissions by fuel type, including coal (salmon), oil (olive), gas (turquoise), and cement (purple), and excluding gas flaring, which is small (0.6\% in 2013). (c) Territorial (solid lines) and consumption (dashed lines) emissions for the top three country emitters (USA - olive; China - salmon; India - purple) and for the European Union (EU; turquoise for the 28 member states of the EU as of 2012) and (d) per capita emissions for the top three country emitters and the EU (all colours as in panel c) and the world (black). In (b)-(c), the dots show the data that were extrapolated from BP energy statistics for 2017-2018. All time series are in gigatonnes of carbon per year except the per capita emissions (d), which are in tonnes of carbon per person per year (tC per person per year). Territorial emissions are primarily from Gilfillan et al. (2019) except national data for the USA and EU28 (the 28 member states of the EU) for 1990-2017, which are reported by the countries to the UNFCCC as detailed in the text; consumption-based emissions are updated from Peters et al. (2011a). See Sect. 2.1.1 for details of the calculations and data sources.

\subsection{Global carbon budget for the last decade (2009-2018)}

The global carbon budget averaged over the last decade (2009-2018) is shown in Figs. 2 and 9. For this time period, $86 \%$ of the total emissions $\left(E_{\mathrm{FF}}+E_{\mathrm{LUC}}\right)$ were from fossil $\mathrm{CO}_{2}$ emissions $\left(E_{\mathrm{FF}}\right)$ and $14 \%$ from land use change $\left(E_{\mathrm{LUC}}\right)$. The total emissions were partitioned among the atmosphere (44\%), ocean (23\%), and land (29\%), with an unattributed budget imbalance $(4 \%)$.

\subsection{1 $\mathrm{CO}_{2}$ emissions}

Global fossil $\mathrm{CO}_{2}$ emissions have grown at a rate of $1.3 \% \mathrm{yr}^{-1}$ for the last decade (2009-2018). China's emissions increased by $+2.2 \% \mathrm{yr}^{-1}$ on average (increasing by $+0.063 \mathrm{GtC} \mathrm{yr}^{-1}$ during the 10 -year period) dominating the global trend, followed by India's emissions increase by $+5.1 \% \mathrm{yr}^{-1}$ (increasing by $+0.025 \mathrm{GtC} \mathrm{yr}^{-1}$ ), while emissions decreased in EU28 by $-1.4 \% \mathrm{yr}^{-1}$ (decreasing by $-0.010 \mathrm{GtC} \mathrm{yr}^{-1}$ ) and in the USA by $-0.5 \% \mathrm{yr}^{-1}$ (de-

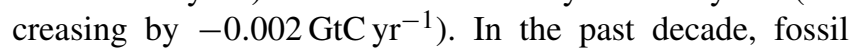

$\mathrm{CO}_{2}$ emissions decreased significantly (at the $95 \%$ level) in 19 growing economies: Belgium, Croatia, Czech Republic, Denmark, Finland, France, Italy, Latvia, Luxembourg, Republic of Macedonia, Malta, the Netherlands, Romania, Slovenia, Sweden, Switzerland, the United Kingdom, the USA, and Uzbekistan. The drivers of recent decarbonisation are examined in Le Quéré et al. (2019).

In contrast, there is no clear trend in $\mathrm{CO}_{2}$ emissions from land use change over the last decade (Fig. 6), though the data are very uncertain, with only one of the two bookkeeping estimates showing a positive trend over the last decade. Larger emissions are increasingly expected over time for DGVMbased estimates as they include the loss of additional sink capacity, while the bookkeeping estimates do not. The LUH2 data set also features large dynamics in land use in particular in the tropics in recent years, causing higher emissions in DGVMs and BLUE than in H\&N. 

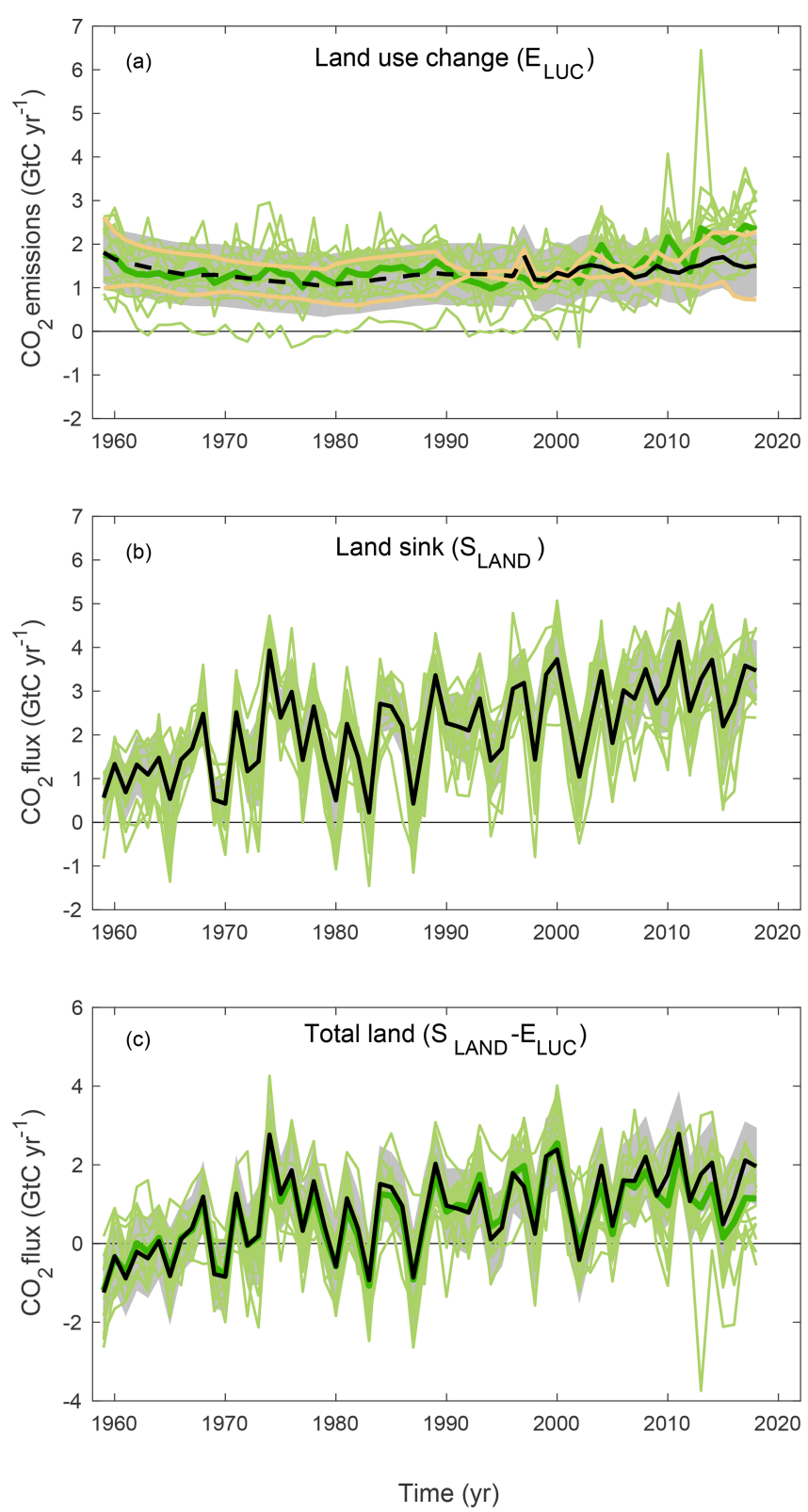

Figure 6. $\mathrm{CO}_{2}$ exchanges between the atmosphere and the terrestrial biosphere as used in the global carbon budget (black with $\pm 1 \sigma$ uncertainty in grey shading), for (a) $\mathrm{CO}_{2}$ emissions from land use change $\left(E_{\mathrm{LUC}}\right)$, also showing the two bookkeeping models (two brown lines) and the DGVM model results (green) and their multi-model mean (dark green) individually. The dashed line identifies the pre-satellite period before the inclusion of peatland burning. (b) Land $\mathrm{CO}_{2}$ sink $\left(S_{\mathrm{LAND}}\right)$ with individual DGVMs (green). (c) Total land $\mathrm{CO}_{2}$ fluxes (b-a) with individual DGVMs (green) and their multi-model mean (dark green).

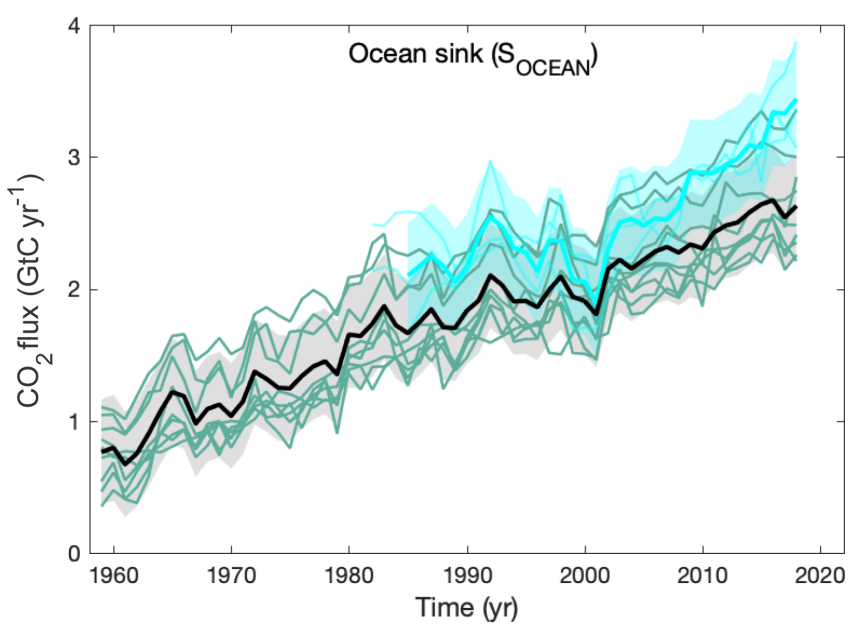

Figure 7. Comparison of the anthropogenic atmosphere-ocean $\mathrm{CO}_{2}$ flux showing the budget values of $S_{\text {OCEAN }}$ (black; with $\pm 1 \sigma$ uncertainty in grey shading), individual ocean models (teal), and the three ocean $p \mathrm{CO}_{2}$-based flux products (light blue; with $\pm 1 \sigma$ uncertainty in light blue shading; see Table 4). The $p \mathrm{CO}_{2}$-based flux products were adjusted for the pre-industrial ocean source of $\mathrm{CO}_{2}$ from river input to the ocean, which is not present in the ocean models, by adding a sink of $0.78 \mathrm{GtC} \mathrm{yr}^{-1}$ (Resplandy et al., 2018), to make them comparable to $S_{\text {OCEAN. This adjustment does not }}$ take into account the anthropogenic contribution to river fluxes (see Sect. 2.7.3)

\subsubsection{Partitioning among the atmosphere, ocean, and land}

The growth rate in atmospheric $\mathrm{CO}_{2}$ concentration increased during 2009-2018, in contrast to more constant levels in the previous decade and reflecting a similar decrease in the land sink compared to an increase in the previous decade, albeit with large interannual variability (Fig. 4). During the same period, the ocean $\mathrm{CO}_{2}$ sink appears to have intensified, an effect which is particularly apparent in the $p \mathrm{CO}_{2}$-based flux products (Fig. 7) and a decadal ocean inverse model (DeVries et al., 2019). The GOBMs show the same patterns of decadal variability as the mean of the $p \mathrm{CO}_{2}$-based flux products, but of weaker magnitude (Fig. 7). The $p \mathrm{CO}_{2}$-based flux products and the ocean inverse model highlight different regions as the main origin of this decadal variability, with the $p \mathrm{CO}_{2}-$ based flux products placing more of the weakening trend in the Southern Ocean and the ocean inverse model suggesting that more of the weakening trend occurred in the North Atlantic and North Pacific (DeVries et al., 2019). Both approaches also show decadal trends in the low-latitude oceans (DeVries et al., 2019).

The budget imbalance (Table 6) and the residual sink from global budget (Table 5) include an error term due to the inconsistency that arises from using $E_{\mathrm{LUC}}$ from bookkeeping models and $S_{\text {LAND }}$ from DGVMs. This error term includes the fundamental differences between bookkeeping models 
and DGVMs, most notably the loss of additional sink capacity. Other differences include an incomplete account of LUC practices and processes in DGVMs, while they are all accounted for in bookkeeping models by using observed carbon densities, and bookkeeping error of keeping present-day carbon densities fixed in the past. That the budget imbalance shows no clear trend towards larger values over time is an indication that the loss of additional sink capacity plays a minor role compared to other errors in $S_{\text {LAND }}$ or $S_{\text {OCEAN }}$ (discussed in Sect. 3.1.4).

\subsubsection{Regional distribution}

Figure 8 shows the partitioning of the total atmosphereto-surface fluxes excluding fossil $\mathrm{CO}_{2}$ emissions ( $S_{\mathrm{LAND}}+$ $\left.S_{\text {OCEAN }}-E_{\text {LUC }}\right)$ according to the multi-model average of the process models in the ocean and on land (GOBMs and DGVMs) and to the atmospheric inversions. Figure 8 provides information on the regional distribution of those fluxes by latitude bands. The global mean total atmosphere-tosurface $\mathrm{CO}_{2}$ flux from process models for 2009-2018 is

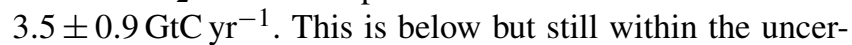
tainty range of a global mean atmosphere-to-surface flux of $4.6 \pm 0.5 \mathrm{GtC} \mathrm{yr}^{-1}$ inferred from the carbon budget $\left(E_{\mathrm{FF}}-\right.$ $G_{\text {ATM }}$ in Eq. 1; Table 6). The total atmosphere-to-surface $\mathrm{CO}_{2}$ fluxes from the three inversions are very similar, ranging from 4.6 to $4.9 \mathrm{GtC} \mathrm{yr}^{-1}$, consistent with the carbon budget as expected from the constraints on the inversions and the adjustments to the same $E_{\mathrm{FF}}$ distribution (See Sect. 2.6).

In the south (south of $30^{\circ} \mathrm{S}$ ), the atmospheric inversions suggest an atmosphere-to-surface flux for 2009-2018 around $1.7-2.0 \mathrm{GtC} \mathrm{yr}^{-1}$, slightly above the process models' estimate of $1.4 \pm 0.3 \mathrm{GtC} \mathrm{yr}^{-1}$ (Fig. 8). The higher flux in the $p \mathrm{CO}_{2}$-based flux products than in the ocean models might be explained by a known lack of surface ocean $p \mathrm{CO}_{2}$ observations in winter, when $\mathrm{CO}_{2}$ outgassing occurs south of the Polar Front (Gray et al., 2018).

The interannual variability in the south is low because of the dominance of ocean area with low variability compared to land areas. The split between land $\left(S_{\mathrm{LAND}}-E_{\mathrm{LUC}}\right)$ and ocean ( $\left.S_{\text {OCEAN }}\right)$ shows a small contribution to variability in the south coming from the land, with no consistency between the DGVMs and the inversions or among inversions. This is expected due to the difficulty of separating exactly the land and oceanic fluxes when viewed from atmospheric observations alone. The oceanic variability in the south is estimated to be significant in the three $p \mathrm{CO}_{2}$-based flux products, with decadal variability of 0.18 to $0.22 \mathrm{GtC} \mathrm{yr}^{-1}$ (Fig. B1). The GOBMs show slightly lower interannual variability ( 0.11 to $0.18 \mathrm{GtC} \mathrm{yr}^{-1}$, Fig. B1).

In the tropics $\left(30^{\circ} \mathrm{S}-30^{\circ} \mathrm{N}\right)$, both the atmospheric inversions and process models suggest the total carbon balance in this region has been close to neutral on average over the past decade. The three inversion models suggest an atmosphereto-surface flux between -0.5 and $+0.3 \mathrm{GtC} \mathrm{yr}^{-1}$ for the
2009-2018 period, which is within the range of the process models' estimates of $0.1 \pm 0.4 \mathrm{GtC} \mathrm{yr}^{-1}$. The agreement between inversions and models is significantly better for the last decade than for any previous decade, although the reasons for this better agreement are still unclear. Both the process models and the inversions consistently allocate more year-to-year variability of $\mathrm{CO}_{2}$ fluxes to the tropics compared to the north (north of $30^{\circ} \mathrm{N}$; Fig. 8). The split between the land and ocean indicates the land is the origin of most of the tropical variability, consistently among models (both for the land and for the ocean) and inversions. The oceanic variability in the tropics is similar among the three ocean flux products (A-IAV 0.12 to $0.14 \mathrm{GtC} \mathrm{yr}^{-1}$ ) and the models, although the model spread is larger (A-IAV 0.08 to $0.19 \mathrm{GtC} \mathrm{yr}^{-1}$, Sect. 3.1.3, Fig. B1). While the inversions indicate that atmosphere-toland $\mathrm{CO}_{2}$ fluxes are more variable than atmosphere-to-ocean $\mathrm{CO}_{2}$ fluxes in the tropics, the correspondence between the inversions and the ocean flux products or GOBMs is much poorer, partly caused by a substantial tropical ocean carbon sink produced by one of the three inversions.

In the north (north of $30^{\circ} \mathrm{N}$ ), models, inversions, and $p \mathrm{CO}_{2}$-based flux products consistently suggest that most of the variability stems from the land (Fig. 8). Inversions, GOBMs, and $p \mathrm{CO}_{2}$-based flux products agree on the mean of $S_{\text {OCEAN }}$, but with a higher variability in the $p \mathrm{CO}_{2}$-based flux products (A-IAV: 0.12 to $0.13 \mathrm{GtC} \mathrm{yr}^{-1}$ ) than in the models (A-IAV: 0.03 to $0.08 \mathrm{GtC} \mathrm{yr}^{-1}$, Fig. B1). Atmospheric inversions and process models show less agreement on the magnitude of the atmosphere-to-land flux, with the ensemble mean of the process models suggesting a total Northern Hemisphere sink for 2009-2018 of $2.1 \pm 0.5 \mathrm{GtC} \mathrm{yr}^{-1}$, below the estimates from the inversions ranging from 2.5 to $3.4 \mathrm{GtC} \mathrm{yr}^{-1}$ (Fig. 8). The discrepancy in the northern tropics distribution of $\mathrm{CO}_{2}$ fluxes between the inversions and models arises from the differences in mean fluxes over the northern land. This discrepancy is also evidenced over the previous decade and highlights not only persistent issues with the quantification of the drivers of the net land $\mathrm{CO}_{2}$ flux (Arneth et al., 2017; Huntzinger et al., 2017) but also the distribution of atmosphere-to-land fluxes between the tropics and higher latitudes that is particularly marked in previous decades, as highlighted previously (Baccini et al., 2017; Schimel et al., 2015; Stephens et al., 2007).

Differences between inversions may be related for example to differences in their interhemispheric transport and other inversion settings (Table A3). Separate analysis has shown that the influence of the chosen prior land and ocean fluxes is minor compared to other aspects of each inversion, while fossil fuel inputs were adjusted to match those of $E_{\mathrm{FF}}$ used in this analysis (see Sect. 2.6), therefore removing differences due to fossil emissions prior. Differences between inversions and the ensemble of process models in the north cannot be simply explained. They could either reflect a bias in the inversions or missing processes or biases in the process models, such as the lack of adequate parameterisations 

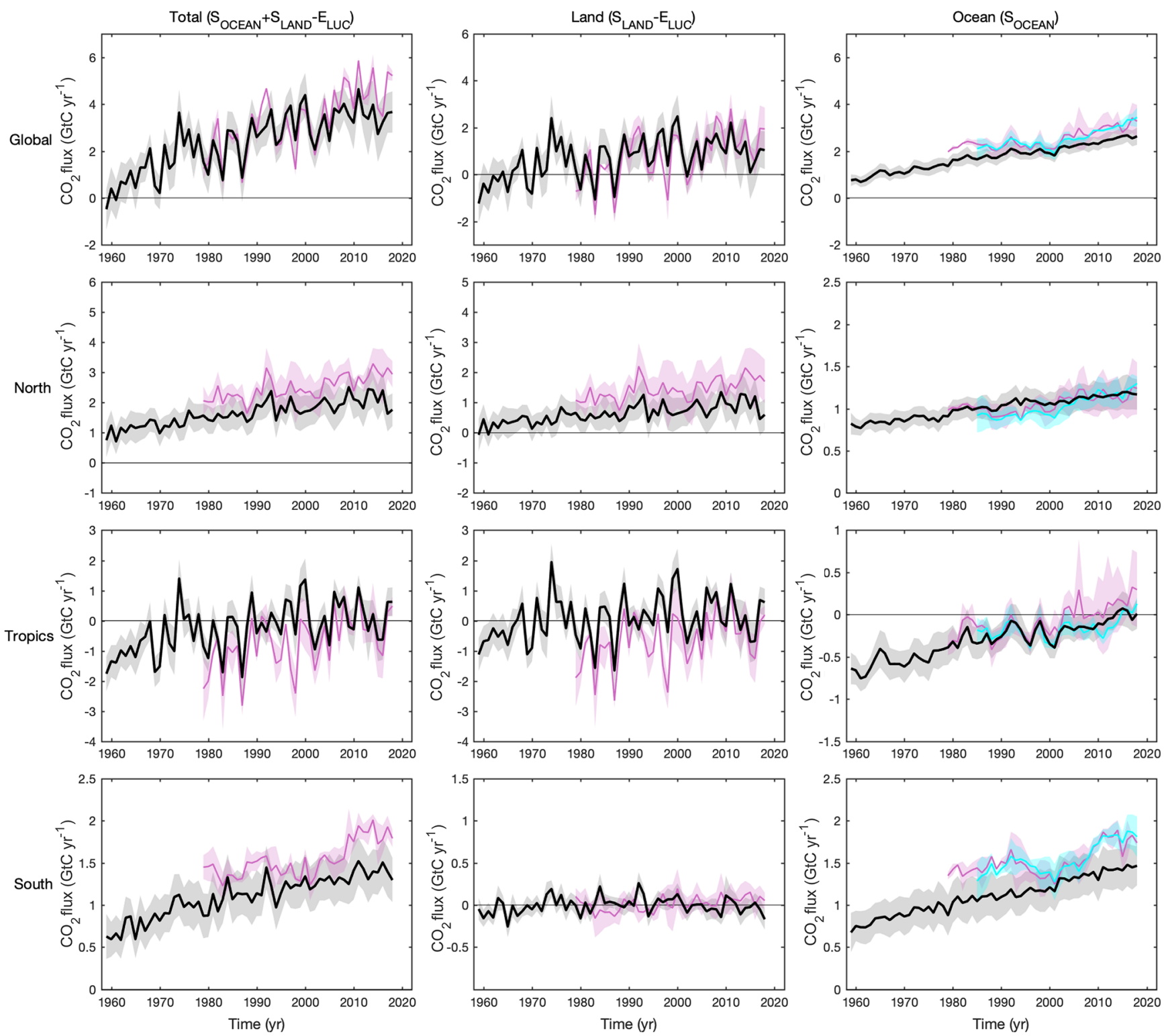

Figure 8. $\mathrm{CO}_{2}$ fluxes between the atmosphere and the surface, $S_{\mathrm{OCEAN}}$ and ( $S_{\mathrm{LAND}}-E_{\mathrm{LUC}}$ ), by latitude bands for the (top) globe, (second row) north (north of $30^{\circ} \mathrm{N}$ ), (third row) tropics $\left(30^{\circ} \mathrm{S}-30^{\circ} \mathrm{N}\right)$, and (bottom) south (south of $\left.30^{\circ} \mathrm{S}\right)$ and over (left) total ( $S_{\mathrm{OCEAN}}+S_{\mathrm{LAND}}-$ $\left.E_{\mathrm{LUC}}\right)$, (middle) land only $\left(S_{\mathrm{LAND}}-E_{\mathrm{LUC}}\right)$, and (right) ocean only ( $\left.S_{\mathrm{OCEAN}}\right)$. Positive values indicate a flux from the atmosphere to the land and/or ocean. Mean estimates from the combination of the process models for the land and oceans are shown (black line) with $\pm 1 \sigma$ of the model ensemble (grey shading). For total uncertainty, the land and ocean uncertainties are summed in quadrature. Mean estimates from the atmospheric inversions are shown (pink lines) with their $\pm 1 \sigma$ spread (pink shading). Mean estimates from the $p \mathrm{CO}_{2}$-based flux products are shown for the ocean domain (cyan lines) with their $\pm 1 \sigma$ spread (cyan shading). The global $S_{\text {OCEAN }}$ (upper right) and the sum of $S_{\text {OCEAN }}$ in all three regions represents the anthropogenic atmosphere-to-ocean flux based on the assumption that the pre-industrial ocean sink was $0 \mathrm{GtC} \mathrm{yr}^{-1}$ when riverine fluxes are not considered. This assumption does not hold on the regional level, where pre-industrial fluxes can be significantly different from zero. Hence, the regional panels for $S_{\text {OCEAN }}$ represent a combination of natural and anthropogenic fluxes. Bias correction and area weighting were only applied to global $S_{\text {OCEAN }}$; hence the sum of the regions is slightly different from the global estimate $\left(<0.05 \mathrm{GtC} \mathrm{yr}^{-1}\right)$. 
for land management for the DGVMs. The estimated contribution of the north and its uncertainty from process models is sensitive both to the ensemble of process models used and to the specifics of each inversion.

Resolving the differences in the Northern Hemisphere land sink will require the consideration and inclusion of larger volumes of semi-continuous observations of concentrations, fluxes, and auxiliary variables collected from (tall) towers close to the surface $\mathrm{CO}_{2}$ exchange. Moreover, effective use of such information would demand a more processbased approach to land-surface exchange of $\mathrm{CO}_{2}$ than currently employed in inverse models. Such a process-based approach would represent constraints on carbon exchange derived from local observations and biogeochemical relations on multiple timescales, which in turn would be constrained by the regional- to continental-scale mass balance of atmospheric $\mathrm{CO}_{2}$. Some of these near-surface data are now becoming available but are not used in the current inverse models sometimes due to the short records and sometimes because the coarse transport models cannot adequately represent these time series. Improvements in model resolution and atmospheric transport realism together with expansion of the observational record (also in the data-sparse boreal Eurasian area) will help anchor the mid-latitude fluxes per continent. In addition, new metrics could potentially differentiate between the more and less realistic realisations of the Northern Hemisphere land sink shown in Fig. 8.

\subsubsection{Budget imbalance}

The budget imbalance was $+0.4 \mathrm{GtC} \mathrm{yr}^{-1}$ on average over 2009-2018. Although the uncertainties are large in each term, the sustained imbalance over this last decade suggests an overestimation of the emissions and/or an underestimation of the sinks. An origin in the land and/or ocean sink may be more likely, given the large variability of the land sink and the suspected underestimation of decadal variability in the ocean sink. An underestimate of $S_{\text {LAND }}$ would also reconcile model results with inversion estimates for fluxes in the total land during the past decade (Fig. 8, Table 5). An underestimation of $S_{\text {OCEAN }}$ is also possible given slightly higher estimates for $S_{\text {OCEAN }}$ from ocean interior carbon observations over the period 1994 to 2007 (2.6 $\pm 0.3 \mathrm{GtC} \mathrm{yr}^{-1}$; Gruber et al., 2019) compared to the estimate from GOBMs of $2.1 \pm 0.5 \mathrm{GtC} \mathrm{yr}^{-1}$ over the same period, although uncertainties overlap. However, we cannot exclude that the budget imbalance over the last decade could partly be due to an overestimation of $\mathrm{CO}_{2}$ emissions, in particular from land use change, given their large uncertainty, as has been suggested elsewhere (Piao et al., 2018). More integrated use of observations in the global carbon budget, either on their own or for further constraining model results, should help resolve some of the budget imbalance (Peters et al., 2017; Sect. 4).

\subsection{Global carbon budget for the year 2018}

\subsection{1 $\mathrm{CO}_{2}$ emissions}

Preliminary estimates of global fossil $\mathrm{CO}_{2}$ emissions are for growth of $2.1 \%$ between 2017 and 2018 to reach $10.0 \pm$ $0.5 \mathrm{GtC}$ in 2018 (Fig. 5), distributed among coal (40\%), oil $(34 \%)$, natural gas $(20 \%)$, cement $(4 \%)$, and others $(1.3 \%)$. Compared to the previous year, emissions from coal increased by $1.4 \%$, while emissions from oil, natural gas, and cement increased by $1.2 \%, 5.4 \%$, and $2.1 \%$, respectively. All growth rates presented are adjusted for the leap year, unless stated otherwise.

In 2018, the largest absolute contributions to global $\mathrm{CO}_{2}$ emissions were from China ( $28 \%$ ), the USA (15\%), the EU (28 member states; 9\%), and India (7\%). These four regions account for $59 \%$ of global $\mathrm{CO}_{2}$ emissions, while the rest of the world contributed $41 \%$, which includes aviation and marine bunker fuels ( $3.4 \%$ of the total). Growth rates for these countries from 2017 to 2018 were $2.3 \%$ (China), $2.8 \%$ (USA), $-2.1 \%$ (EU28), and $8.0 \%$ (India), with $1.8 \%$ for the rest of the world. The per capita $\mathrm{CO}_{2}$ emissions in 2018 were $1.3 \mathrm{tC}$ per person per year for the globe and were 4.5 (USA), 1.9 (China), 1.8 (EU28) and 0.5 (India) $\mathrm{tC}$ per person per year for the four highest emitting countries (Fig. 5).

The growth in emissions of $2.1 \%$ in 2018 is within the range of the projected growth of $2.7 \%$ (range of $1.8 \%$ to $3.7 \%$ ) published in Le Quéré et al. (2018b) based on national emissions projections for China, the USA, and India and projections of gross domestic product corrected for $I_{\mathrm{FF}}$ trends for the rest of the world. The growth in emissions in 2018 for China, the USA, EU28, India, and the rest of the world were all within their previously projected range (Table 7).

In 2016 (the last year available), the largest absolute contributions to global $\mathrm{CO}_{2}$ emissions from a consumption perspective were China (25\%), the USA (16\%), the EU (12\%), and India $(6 \%)$. The difference between territorial and consumption emissions (the net emission transfer via international trade) has generally increased from 1990 to around 2005 and remained relatively stable afterwards until the last year available (2016; Fig. 5).

The global $\mathrm{CO}_{2}$ emissions from land use change are estimated as $1.5 \pm 0.7 \mathrm{GtC}$ in 2018 , close to the previous decade but with low confidence in the annual change. This brings the total $\mathrm{CO}_{2}$ emissions from fossil fuel plus land use change $\left(E_{\mathrm{FF}}+E_{\mathrm{LUC}}\right)$ to $11.5 \pm 0.9 \mathrm{GtC}\left(42.5 \pm 3.3 \mathrm{GtCO}_{2}\right)$.

\subsubsection{Partitioning among the atmosphere, ocean, and land}

The growth rate in atmospheric $\mathrm{CO}_{2}$ concentration was $5.1 \pm$ $0.2 \mathrm{GtC}$ in 2018 (2.42 \pm 0.08 ppm; Fig. 4; Dlugokencky and Tans, 2019). This is near the 2009-2018 average of $4.9 \pm$ $0.02 \mathrm{GtC} \mathrm{yr}^{-1}$. 


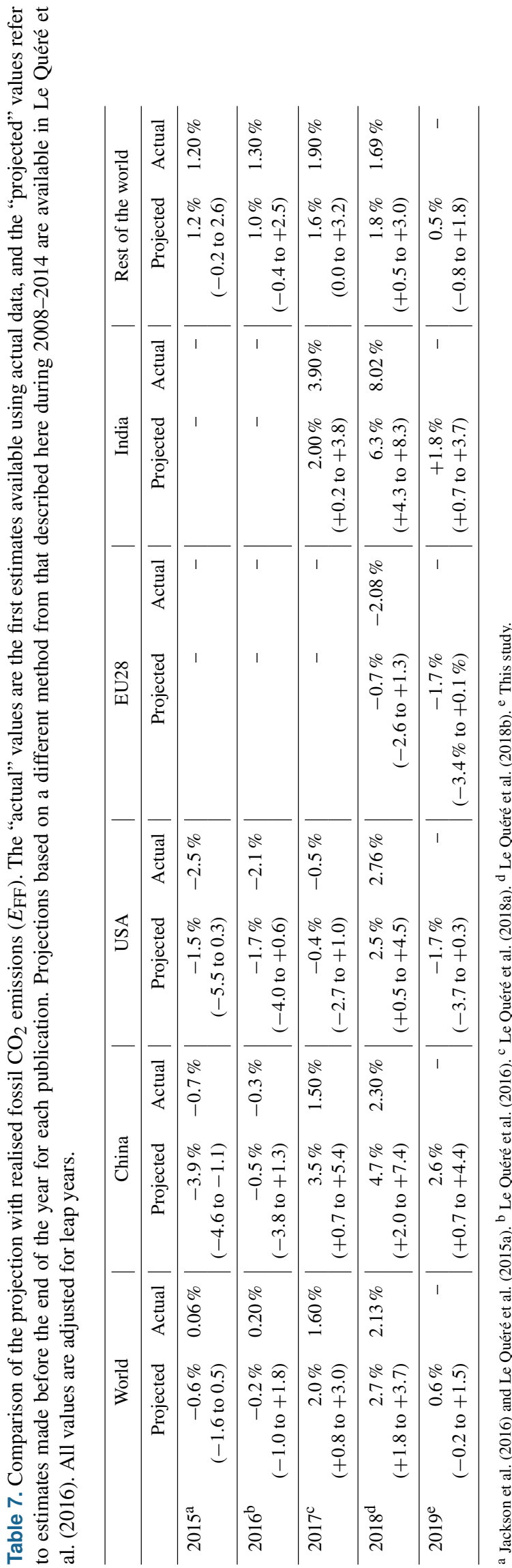

The estimated ocean $\mathrm{CO}_{2}$ sink was $2.6 \pm 0.6 \mathrm{GtC}$ in 2018 . The multi-model mean agrees with the mean of the $p \mathrm{CO}_{2}$ based flux products on an average increase of $0.1 \mathrm{GtC}$ in 2018. Six models and two flux products show an increase

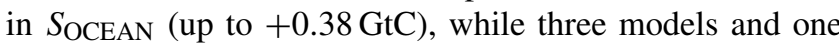
flux product show no change or a decrease in $S_{\text {OCEAN }}$ (down to $-0.15 \mathrm{GtC}$ ) (Fig. 7).

The terrestrial $\mathrm{CO}_{2}$ sink from the DGVM model ensemble was $3.5 \pm 0.7 \mathrm{GtC}$ in 2018 , slightly above the decadal average (Fig. 4) and consistent with constraints from the rest of the budget (Table 5). The budget imbalance was $+0.3 \mathrm{GtC}$ in 2018, consistent with its average over the last decade (Table 6). This imbalance is indicative only, given the large uncertainties in the estimation of the $B_{\mathrm{IM}}$.

\subsection{Global carbon budget projection for the year 2019}

\subsection{1 $\mathrm{CO}_{2}$ emissions}

Based on the available data as of 14 November 2019 (see Sect. 2.1.5), fossil $\mathrm{CO}_{2}$ emissions $\left(E_{\mathrm{FF}}\right)$ for 2019 are projected to increase by $+0.6 \%$ (range of $-0.2 \%$ to $+1.5 \%$; Table 7). Our method contains several assumptions that could influence the estimate beyond the given range, and as such it has an indicative value only. Within the given assumptions, global emissions would be $10.0 \pm 0.5 \mathrm{GtC}\left(36.8 \pm 1.8 \mathrm{GtCO}_{2}\right)$ in 2019.

For China, the expected change is for an increase in emissions of $+2.6 \%$ (range of $+0.7 \%$ to $+4.4 \%$ ) in 2019 compared to 2018. This is based on estimated growth in coal $(+0.8 \%$, the main fuel source in China), oil $(+6.9 \%)$, and natural gas $(+9.1 \%)$ consumption and cement production $(+6.3 \%)$. The uncertainty range considers the variations in the difference between preliminary January-September data and final full-year data, lack of monthly data on stock changes, variances in the discrepancies between supply-side and demand data, the uncertainty in the preliminary data used for the 2018 base, and uncertainty in the evolution of the average energy density of each of the fossil fuels.

For the USA, the EIA emissions projection for 2019 combined with cement data from USGS gives a decrease of $-1.7 \%$ (range of $-3.7 \%$ to $+0.3 \%$ ) compared to 2018 . This is based on separate projections for coal $-10.5 \%$, oil $-0.5 \%$, natural gas $+3.5 \%$, and cement $+0.7 \%$.

For the European Union, our projection for 2019 is for a decrease of $-1.7 \%$ (range of $-3.4 \%$ to $+0.1 \%$ ) over 2018 . This is based on separate projections for coal of $-10.0 \%$, oil of $+0.5 \%$, natural gas of $+3.0 \%$, and stable cement emissions. Uncertainty is largest in coal, where two alternative methods give divergent estimates.

For India, our projection for 2019 is for an increase of $+1.8 \%$ (range of $+0.7 \%$ to $+3.7 \%$ ) over 2018 . This is based on separate projections for coal $(+2.0 \%)$, oil $(+1.5 \%)$, natural gas $(+2.5 \%)$, and cement $(+0.0 \%)$. The wide uncertainty range reflects an anomalous year: the 
2019 monsoon year produced above-average rainfall, particularly in September, with $52 \%$ higher rainfall than the long-term average (IMD, 2019). This heavier rainfall led to both flooded coal mines (Varadhan, 2019) and high hydropower generation (CEA, 2019b). In addition, the Indian economy has slowed rapidly during the year (IMF, 2019b). Furthermore, our forecast for India covers its financial year, April 2019 to March 2020, reflecting the underlying emissions data, adding to uncertainty.

For the rest of the world, the expected growth for 2019 is $+0.5 \%$ (range of $-0.8 \%$ to $+1.8 \%$ ). This is computed using the GDP projection for the world excluding China, the USA, the EU, and India of $1.9 \%$ made by the IMF (IMF, 2019a) and a decrease in $I_{\mathrm{FF}}$ of $-1.4 \% \mathrm{yr}^{-1}$, which is the average from 2009 to 2018 . The uncertainty range is based on the standard deviation of the interannual variability in $I_{\mathrm{FF}}$ during 2009-2018 of $\pm 0.8 \% \mathrm{yr}^{-1}$ and our estimates of uncertainty in the IMF's GDP forecast of $\pm 0.5 \%$. The methodology allows independent projections for coal, oil, natural gas, cement, and other components, which add to the total emissions in the rest of the world. The 2019 growth rates for coal were $+0.1 \%$ (range $-2.9 \%$ to $+3.2 \%$ ), oil $+0.1 \%$ (range $-0.9 \%$ to $+1.2 \%$ ), natural gas $+1.3 \%$ (range $-0.7 \%$ to $+3.4 \%$ ), and cement $+1.3 \%$ (range $-1.2 \%$ to $+3.9 \%$ ).

Each of our regional projections contains separate projections for coal, oil, natural gas, cement, and other smaller components. This allows us, for the first time, to supplement our global fossil $\mathrm{CO}_{2}$ emission projection of $+0.6 \%$ (range of $-0.2 \%$ to $+1.5 \%$ ) with separate global projections of the $\mathrm{CO}_{2}$ emissions from coal $-0.9 \%$ (range $-2.0 \%$ to $+0.2 \%$ ), oil $+0.9 \%$ (range $0.3 \%$ to $+1.6 \%$ ), natural gas $+2.6 \%$ (range $+1.3 \%$ to $+3.9 \%$ ), and cement $+3.7 \%$ (range $+0.4 \%$ to $+7.3 \%$ ).

Preliminary estimate of fire emissions in deforestation zones indicate that emissions from land use change $\left(E_{\mathrm{LUC}}\right)$ for 2019 were above the 2009-2018 average, amounting to $427 \mathrm{TgC}$ by 31 October and are expected to remain at this level for the remainder of the year. We therefore expect $E_{\mathrm{LUC}}$ emissions of around $1.7 \mathrm{GtC}$ in 2019 , for total anthropogenic $\mathrm{CO}_{2}$ emissions of $11.8 \pm 0.9 \mathrm{GtC}\left(43.1 \pm 3.2 \mathrm{GtCO}_{2}\right)$ in 2019.

\subsubsection{Partitioning among the atmosphere, ocean, and land}

The 2019 growth in atmospheric $\mathrm{CO}_{2}$ concentration $\left(G_{\text {ATM }}\right)$ is projected to be $5.2 \pm 0.9 \mathrm{GtC}(2.5 \pm 0.4 \mathrm{ppm})$ based on GLO observations until the end of August 2019, bringing the atmospheric $\mathrm{CO}_{2}$ concentration to an expected level of $410 \mathrm{ppm}$ averaged over the year. Combining projected $E_{\mathrm{FF}}$, $E_{\mathrm{LUC}}$, and $G_{\mathrm{ATM}}$ suggest a combined land and ocean sink $\left(S_{\text {LAND }}+S_{\text {OCEAN }}\right)$ of about $6.5 \mathrm{GtC}$ for 2019. Although each term has large uncertainty, the oceanic sink $S_{\text {OCEAN }}$ has generally low interannual variability and is likely to remain close to its 2018 value of around $2.6 \mathrm{GtC}$, leaving a rough esti- mated land sink $S_{\text {LAND }}$ (including any budget imbalance) of around $3.9 \mathrm{GtC}$, slightly above the 2018 estimate.

\subsection{Cumulative sources and sinks}

Cumulative historical sources and sinks are estimated as in Eq. (1) with semi-independent estimates for each term and a global carbon budget imbalance. Cumulative fossil $\mathrm{CO}_{2}$ emissions for $1850-2018$ were $440 \pm 20 \mathrm{GtC}$ for $E_{\mathrm{FF}}$ and $205 \pm 60 \mathrm{GtC}$ for $E_{\mathrm{LUC}}$ (Table 8; Fig. 9), for a total of $645 \pm$ $65 \mathrm{GtC}$. The cumulative emissions from $E_{\mathrm{LUC}}$ are particularly uncertain, with large spread among individual estimates of $150 \mathrm{GtC}(\mathrm{H} \& \mathrm{~N})$ and $260 \mathrm{GtC}$ (BLUE) for the two bookkeeping models and a similar wide estimate of $185 \pm 60 \mathrm{GtC}$ for the DGVMs. These estimates are consistent with indirect constraints from vegetation biomass observations ( $\mathrm{Li}$ et al., 2017), but given the large spread a best estimate is difficult to ascertain.

Emissions during the period 1850-2018 were partitioned among the atmosphere $(255 \pm 5 \mathrm{GtC} ; 40 \%)$, ocean $(160 \pm$ $20 \mathrm{GtC} ; 25 \%)$, and land $(195 \pm 40 \mathrm{GtC} ; 31 \%)$. This cumulative land sink is broadly equal to the cumulative land use emissions, making the global land near neutral over the 1850-2018 period. The use of nearly independent estimates for the individual terms shows a cumulative budget imbalance of $30 \mathrm{GtC}$ (4\%) during 1850-2018 (Fig. 2), which, if correct, suggests emissions are too high by the same proportion or the land or ocean sinks are underestimated. The bulk of the imbalance could originate from the estimation of large $E_{\text {LUC }}$ between the mid-1920s and the mid-1960s, which is unmatched by a growth in atmospheric $\mathrm{CO}_{2}$ concentration as recorded in ice cores (Fig. 3). The known loss of additional sink capacity of about $20 \pm 15 \mathrm{GtC}$ due to reduced forest cover has not been accounted in our method and would further exacerbate the budget imbalance (Sect. 2.7.4).

Cumulative emissions through to the year 2019 increase to $655 \pm 65 \mathrm{GtC}\left(2340 \pm 240 \mathrm{GtCO}_{2}\right)$, with about $70 \%$ contribution from $E_{\mathrm{FF}}$ and about $30 \%$ contribution from $E_{\mathrm{LUC}}$. Cumulative emissions and their partitioning for different periods are provided in Table 8.

Given the large and persistent uncertainties in historical cumulative emissions, extreme caution is needed if using this estimate to determine the remaining cumulative $\mathrm{CO}_{2}$ emissions consistent with an ambition to stay below a given temperature limit (Millar et al., 2017; Rogelj et al., 2016, 2019).

\section{Discussion}

Each year when the global carbon budget is published, each flux component is updated for all previous years to consider corrections that are the result of further scrutiny and verification of the underlying data in the primary input data sets. Annual estimates may improve with improvements in data quality and timeliness (e.g. to eliminate the need for extrapolation of forcing data such as land use). Of the various terms in the 
Table 8. Cumulative $\mathrm{CO}_{2}$ for different time periods in gigatonnes of carbon (GtC). All uncertainties are reported as $\pm 1 \sigma$. The budget imbalance provides a measure of the discrepancies among the nearly independent estimates. Its uncertainty exceeds $\pm 60 \mathrm{GtC}$. The method used here does not capture the loss of additional sink capacity from reduced forest cover, which is about $20 \mathrm{GtC}$ for the years $1850-2018$ and would exacerbate the budget imbalance (see Sect. 2.7.4). All values are rounded to the nearest $5 \mathrm{GtC}$, and therefore columns do not necessarily add to zero.

\begin{tabular}{|c|c|c|c|c|c|}
\hline Units of GtC & $1750-2018$ & $1850-2014$ & 1959-2018 & $1850-2018$ & $1850-2019^{\mathrm{a}}$ \\
\hline \multicolumn{6}{|l|}{ Emissions } \\
\hline Fossil $\mathrm{CO}_{2}$ emissions $\left(E_{\mathrm{FF}}\right)$ & $440 \pm 20$ & $400 \pm 20$ & $365 \pm 20$ & $440 \pm 20$ & $450 \pm 20$ \\
\hline Land use change $\mathrm{CO}_{2}$ emissions ( $\left.E_{\mathrm{LUC}}\right)$ & $235 \pm 75^{b}$ & $195 \pm 60^{\mathrm{c}}$ & $80 \pm 40^{\mathrm{d}}$ & $205 \pm 60^{c}$ & $205 \pm 60$ \\
\hline Total emissions & $675 \pm 80$ & $600 \pm 65$ & $445 \pm 30$ & $645 \pm 65$ & $655 \pm 65$ \\
\hline \multicolumn{6}{|l|}{ Partitioning } \\
\hline Growth rate in atmospheric $\mathrm{CO}_{2}$ concentration $\left(G_{\mathrm{ATM}}\right)$ & $275 \pm 5$ & $235 \pm 5$ & $200 \pm 5$ & $255 \pm 5$ & $260 \pm 5$ \\
\hline Ocean sink $\left(S_{\text {OCEAN }}\right)^{\mathrm{e}}$ & $170 \pm 20$ & $150 \pm 20$ & $105 \pm 20$ & $160 \pm 20$ & $160 \pm 20$ \\
\hline Terrestrial sink $\left(S_{\text {LAND }}\right)$ & $220 \pm 50$ & $185 \pm 40$ & $130 \pm 25$ & $195 \pm 40$ & $200 \pm 40$ \\
\hline \multicolumn{6}{|l|}{ Budget imbalance } \\
\hline$B_{\mathrm{IM}}=E_{\mathrm{FF}}+E_{\mathrm{LUC}}-\left(G_{\mathrm{ATM}}+S_{\mathrm{OCEAN}}+S_{\mathrm{LAND}}\right)$ & 10 & 30 & 10 & 30 & 30 \\
\hline \multicolumn{6}{|c|}{$\begin{array}{l}\text { a Using projections for the year } 2019 \text { (Sect. 3.4). Uncertainties are the same as for the } 1850-2018 \text { period. }{ }^{\text {b }} \text { Cumulative } E_{\mathrm{LUC}} 1750-1849 \text { of } 30 \mathrm{GtC} \text { based on multi-model } \\
\text { mean of Pongratz et al. (2009), Shevliakova et al. (2009), Zaehle et al. (2011), and Van Minnen et al. (2009). The } 1850-2018 \text { period from mean of H\&N (Houghton and } \\
\text { Nassikas, 2017) and BLUE (Hansis et al., 2015). The 1750-2018 uncertainty is estimated from standard deviation of DGVMs over } 1850-2018 \text { scaled by } 1750-2018 \\
\text { emissions. }{ }^{c} \text { Cumulative } E_{\text {LUC }} \text { based on H\&N and BLUE. Uncertainty is estimated from the standard deviation of DGVM estimates. }{ }^{d} \text { Cumulative } E_{\text {LUC }} \text { based on } \mathrm{H} \& \mathrm{~N} \\
\text { and BLUE. Uncertainty is formed from the uncertainty in annual } E_{\mathrm{LUC}} \text { over } 1959-2018 \text {, which is } 0.7 \mathrm{GtC} \text { yr }{ }^{-1} \text { multiplied by the length of the time series. }{ }^{\text {e }} \text { Ocean sink } \\
\text { uncertainty from IPCC (Denman et al., 2007). }\end{array}$} \\
\hline
\end{tabular}

global budget, only the fossil $\mathrm{CO}_{2}$ emissions and the growth rate in atmospheric $\mathrm{CO}_{2}$ concentration are based primarily on empirical inputs supporting annual estimates in this carbon budget. Although it is an imperfect measure, the carbon budget imbalance provides a strong indication of the limitations in observations, in understanding or full representation of processes in models, and/or in the integration of the carbon budget components.

The persistent unexplained variability in the carbon budget imbalance limits our ability to verify reported emissions (Peters et al., 2017) and suggests we do not yet have a complete understanding of the underlying carbon cycle processes. Resolving most of this unexplained variability should be possible through different and complementary approaches. First, as intended with our annual updates, the imbalance as an error term is reduced by improvements of individual components of the global carbon budget that follow from improving the underlying data and statistics and by improving the models through the resolution of some of the key uncertainties detailed in Table 9. Second, additional clues to the origin and processes responsible for the current imbalance could be obtained through a closer scrutiny of carbon variability in light of other Earth system data (e.g. heat balance, water balance) and the use of a wider range of biogeochemical observations to better understand the land-ocean partitioning of the carbon imbalance (e.g. oxygen, carbon isotopes). Finally, additional information could also be obtained through higher resolution and process knowledge at the regional level, and through the introduction of inferred fluxes such as those based on satellite $\mathrm{CO}_{2}$ retrievals. The limit of the resolution of the carbon budget imbalance is yet unclear but most certainly not yet reached given the possibilities for improvements that lie ahead.

The assessment of the GOBMs used for $S_{\text {OCEAN with flux }}$ products based on observations highlights substantial discrepancy at mid-latitudes and high latitudes. Given the good data coverage of $p \mathrm{CO}_{2}$ observations in the Northern Hemisphere (Bakker et al., 2016), this discrepancy points at an underestimation of variability in the GOBMs globally, and consequently the variability in $S_{\text {OCEAN }}$ appears to be underestimated. The size of the underestimation of the amplitude of interannual variability (order of $0.1 \mathrm{GtC} \mathrm{yr}^{-1}$, A-IAV; see Fig. B1) could account for some of the budget imbalance, but not all. Increasing model resolution or using model ensembles (Li and Ilyina, 2018) has been suggested as a way to increase model variability (Sect. 3.1.4).

The assessment of the net land-atmosphere exchange derived from land sink and net land use change flux with atmospheric inversions also shows substantial discrepancy, particularly for the estimate of the total land flux over the northern extra-tropics in the past decade. This discrepancy highlights the difficulty to quantify complex processes $\left(\mathrm{CO}_{2}\right.$ fertilisation, nitrogen deposition, $\mathrm{N}$ fertilisers, climate change and variability, land management, etc.) that collectively determine the net land $\mathrm{CO}_{2}$ flux. Resolving the differences in the 


\section{Anthropogenic carbon flows}

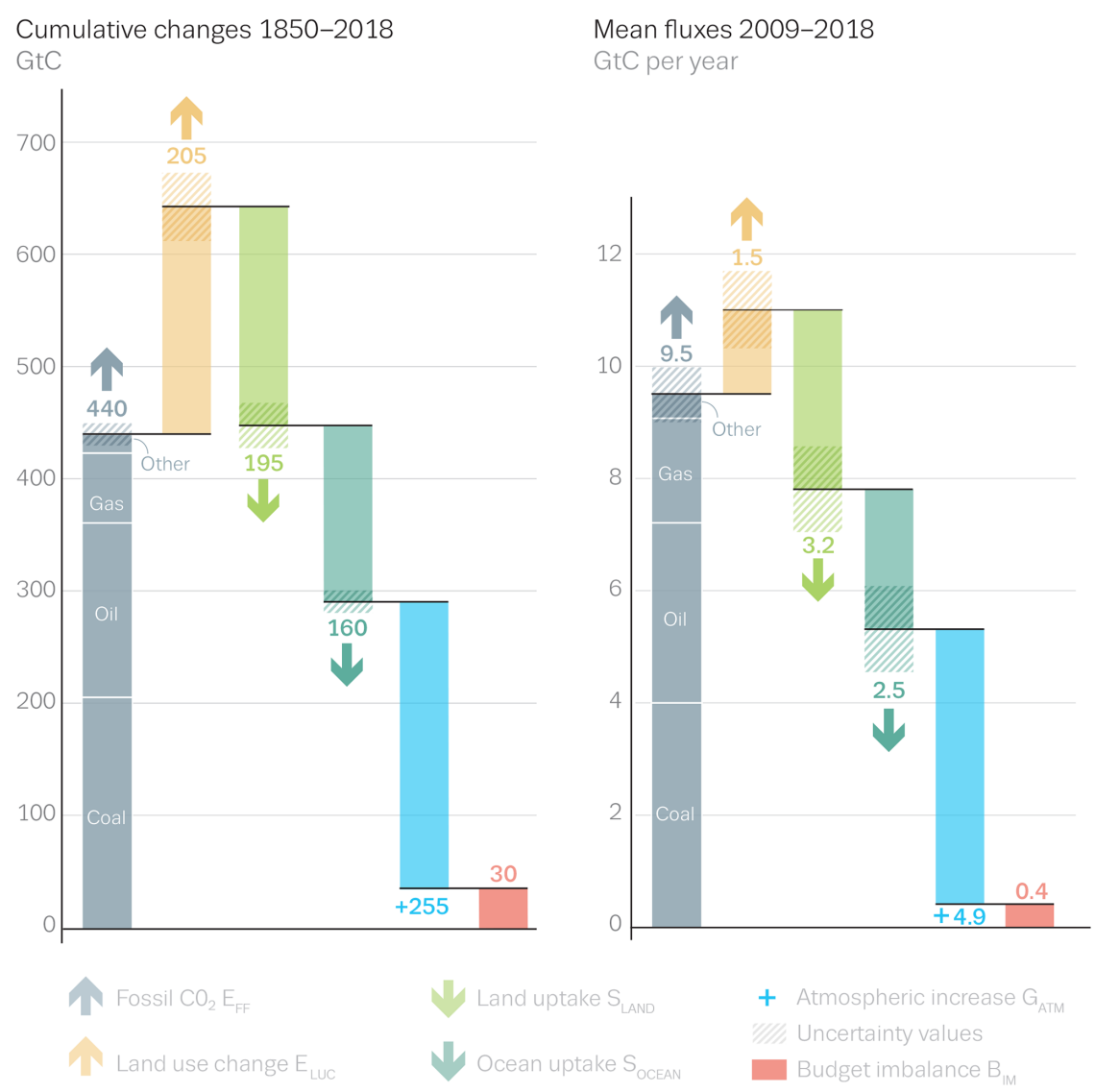

Figure 9. Cumulative changes during 1850-2018 and mean fluxes during 2009-2018 for the anthropogenic perturbation as defined in the legend.

Northern Hemisphere land sink will require the consideration and inclusion of larger volumes of observations (Sect. 3.2.3).

Estimates of $E_{\mathrm{LUC}}$ suffer from a range of intertwined issues, including the poor quality of historical land cover and land use change maps, the rudimentary representation of management processes in most models, and the confusion in methodologies and boundary conditions used across methods (e.g. Arneth et al., 2017; Pongratz et al., 2014) and Sect. 2.7.4 on the loss of sink capacity). Uncertainties in current and historical carbon stocks in soils and vegetation also add uncertainty in the LUC flux estimates. Unless a major effort to resolve these issues is made, little progress is expected in the resolution of $E_{\mathrm{LUC}}$. This is particularly concerning given the growing importance of $E_{\mathrm{LUC}}$ for climate mitigation strategies and the large issues in the quantification of the cumulative emissions over the historical period that arise from large uncertainties in $E_{\mathrm{LUC}}$.

As introduced last year, we provide metrics for the evaluation of the ocean and land models and atmospheric inversions. These metrics expand the use of observations in the global carbon budget, helping (1) to support improvements in the ocean and land carbon models that produce the sink estimates and (2) to constrain the representation of key underlying processes in the models and to allocate the regional partitioning of the $\mathrm{CO}_{2}$ fluxes. This is an initial step towards the introduction of a broader range of observations that we hope will support continued improvements in the annual estimates of the global carbon budget.

We assessed before (Peters et al., 2017) that a sustained decrease of $-1 \%$ in global emissions could be detected at the $66 \%$ likelihood level after a decade only. Similarly, a change in behaviour of the land and/or ocean carbon sink would take as long to detect, and much longer if it emerges more slowly. Reducing the carbon imbalance, regionalising the carbon budget, and integrating multiple variables are powerful ways to shorten the detection limit and ensure the research community can rapidly identify growing issues of concern in the evolution of the global carbon cycle under the current rapid and unprecedented changing environmental conditions. 
Table 9. Major known sources of uncertainties in each component of the global carbon budget, defined as input data or processes that have a demonstrated effect of at least $\pm 0.3 \mathrm{GtC} \mathrm{yr}^{-1}$.

\begin{tabular}{|c|c|c|c|c|}
\hline Source of uncertainty & Timescale (years) & Location & Status & Evidence \\
\hline \multicolumn{5}{|c|}{ Fossil $\mathrm{CO}_{2}$ emissions ( $E_{\mathrm{FF}} ;$ Sect. 2.1) } \\
\hline Energy statistics & annual to decadal & $\begin{array}{l}\text { global, but mainly China \& } \\
\text { major developing countries }\end{array}$ & see Sect. 2.1 & Korsbakken et al. (2016) \\
\hline Carbon content of coal & annual to decadal & $\begin{array}{l}\text { global, but mainly China \& } \\
\text { major developing countries }\end{array}$ & see Sect. 2.1 & Liu et al. (2015) \\
\hline System boundary & annual to decadal & all countries & see Sect. 2.1 & \\
\hline \multicolumn{5}{|c|}{ Emissions from land use change ( $E_{\mathrm{LUC}} ;$ Sect. 2.2) } \\
\hline $\begin{array}{l}\text { Land cover and land use change } \\
\text { statistics }\end{array}$ & continuous & global; in particular tropics & see Sect. 2.2 & Houghton et al. (2012) \\
\hline Sub-grid-scale transitions & annual to decadal & global & see Table A1 & Wilkenskjeld et al. (2014) \\
\hline Vegetation biomass & annual to decadal & global; in particular tropics & see Table A1 & Houghton et al. (2012) \\
\hline Wood and crop harvest & annual to decadal & global; SE Asia & see Table A1 & Arneth et al. (2017) \\
\hline Peat burning ${ }^{\mathrm{a}}$ & multi-decadal trend & global & see Table A1 & van der Werf et al. (2010) \\
\hline Loss of additional sink capacity & multi-decadal trend & global & not included; Sect. 2.7 .4 & Gitz and Ciais (2003) \\
\hline \multicolumn{5}{|c|}{ Atmospheric growth rate $\left(G_{\mathrm{ATM}}\right)$, no demonstrated uncertainties larger than $\pm 0.3 \mathrm{GtC}_{\mathrm{yr}}{ }^{-1^{\mathrm{b}}}$} \\
\hline \multicolumn{5}{|c|}{ Ocean sink $\left(S_{\text {OCEAN }}\right)$} \\
\hline Variability in oceanic circulation ${ }^{\mathrm{c}}$ & semi-decadal to decadal & global & see Sect. 2.4 & DeVries et al. $(2017,2019)$ \\
\hline Internal variability & annual to decadal & $\begin{array}{l}\text { high latitudes; equatorial } \\
\text { Pacific }\end{array}$ & no ensembles/coarse resolution & McKinley et al. (2016) \\
\hline Anthropogenic & multi-decadal trend & global & not included & Duce et al. (2008) \\
\hline Changes in nutrient supply & & & & \\
\hline \multicolumn{5}{|l|}{ Land sink $\left(S_{\text {LAND }}\right)$} \\
\hline Strength of $\mathrm{CO}_{2}$ fertilisation & multi-decadal trend & global & see Sect. 2.5 & Wenzel et al. (2016) \\
\hline $\begin{array}{l}\text { Response to variability in } \\
\text { temperature and rainfall }\end{array}$ & annual to decadal & global; in particular tropics & see Sect. 2.5 & Cox et al. (2013) \\
\hline Nutrient limitation and supply & multi-decadal trend & global & see Sect. 2.5 & Zaehle et al. (2011) \\
\hline Response to diffuse radiation & annual & global & see Sect. 2.5 & Mercado et al. (2009) \\
\hline
\end{tabular}

${ }^{\mathrm{a}}$ As a result of interactions between land use and climate. ${ }^{\mathrm{b}}$ The uncertainties in $G_{\mathrm{ATM}}$ have been estimated as $\pm 0.2 \mathrm{GtC}^{-1}$, although the conversion of the growth rate into a global annual flux assuming instantaneous mixing throughout the atmosphere introduces additional errors that have not yet been quantified. ${ }^{c}$ Could in part be due to uncertainties in atmospheric forcing (Swart et al., 2014).

\section{Conclusions}

The estimation of global $\mathrm{CO}_{2}$ emissions and sinks is a major effort by the carbon cycle research community that requires a careful compilation and synthesis of measurements, statistical estimates, and model results. The delivery of an annual carbon budget serves two purposes. First, there is a large demand for up-to-date information on the state of the anthropogenic perturbation of the climate system and its underpinning causes. A broad stakeholder community relies on the data sets associated with the annual carbon budget including scientists, policymakers, businesses, journalists, and nongovernmental organisations engaged in adapting to and mitigating human-driven climate change. Second, over the last decade we have seen unprecedented changes in the human and biophysical environments (e.g. changes in the growth of fossil fuel emissions, Earth's temperatures, and strength of the carbon sinks), which call for frequent assessments of the state of the planet, a better quantification of the causes of changes in the contemporary global carbon cycle, and an improved capacity to anticipate its evolution in the future.
Building this scientific understanding to meet the extraordinary climate mitigation challenge requires frequent, robust, transparent, and traceable data sets and methods that can be scrutinised and replicated. This paper via "living data" helps to keep track of new budget updates.

\section{Data availability}

The data presented here are made available in the belief that their wide dissemination will lead to greater understanding and new scientific insights into how the carbon cycle works, how humans are altering it, and how we can mitigate the resulting human-driven climate change. The free availability of these data does not constitute permission for publication of the data. For research projects, if the data are essential to the work, or if an important result or conclusion depends on the data, co-authorship may need to be considered for the relevant data providers. Full contact details and information on how to cite the data shown here are given at the top of each page in the accompanying database and summarised in Table 2 . 
The accompanying database includes two Excel files organised in the following spreadsheets.

File Global_Carbon_Budget_2019v1.0.xlsx includes the following:

1. summary,

2. the global carbon budget (1959-2018),

3. global $\mathrm{CO}_{2}$ emissions from fossil fuels and cement production by fuel type and the per capita emissions (19592018),

4. $\mathrm{CO}_{2}$ emissions from land use change from the individual methods and models (1959-2018),

5. ocean $\mathrm{CO}_{2}$ sink from the individual ocean models and $p \mathrm{CO}_{2}$-based products (1959-2018),

6. terrestrial $\mathrm{CO}_{2}$ sink from the DGVMs (1959-2018),

7. additional information on the historical global carbon budget prior to 1959 (1750-2018).

File National_Carbon_Emissions_2019v1.0.xlsx includes the following:

1. summary;

2. territorial country $\mathrm{CO}_{2}$ emissions from fossil $\mathrm{CO}_{2}$ emissions (1959-2018) from CDIAC with UNFCCC data overwritten where available, extended to 2018 using BP data;

3. consumption country $\mathrm{CO}_{2}$ emissions from fossil $\mathrm{CO}_{2}$ emissions and emissions transfer from the international trade of goods and services (1990-2016) using CDIAC/UNFCCC data (worksheet 3 above) as reference;

4. emissions transfers (consumption minus territorial emissions; 1990-2016);

5. country definitions;

6. details of disaggregated countries;

7. details of aggregated countries.

Both spreadsheets are published by the Integrated Carbon Observation System (ICOS) Carbon Portal and are available at https://doi.org/10.18160/gcp-2019 (Friedlingstein et al., 2019). National emissions data are also available from the Global Carbon Atlas (http://www.globalcarbonatlas.org/, last access: 4 December 2019). 
Appendix A

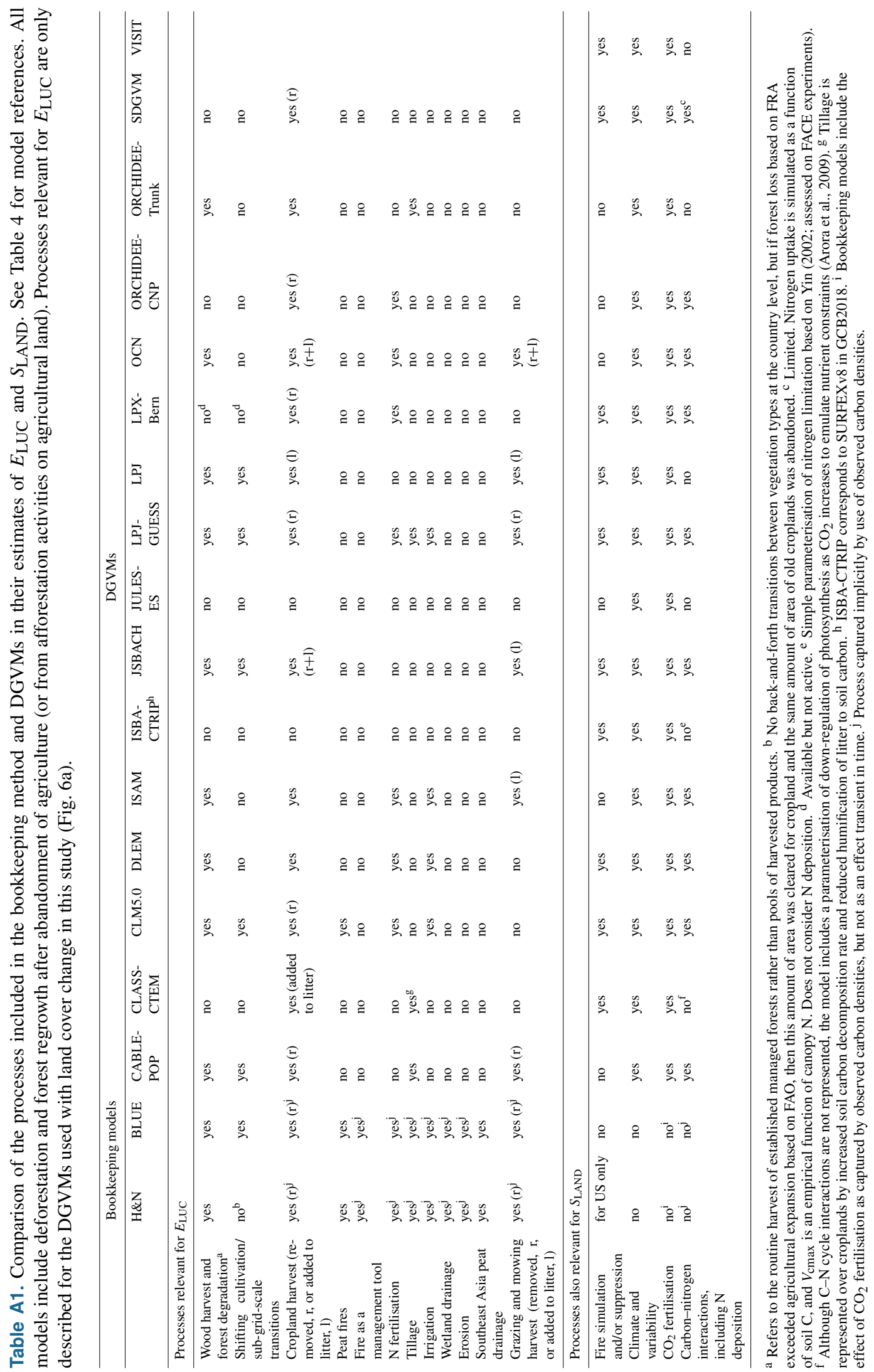




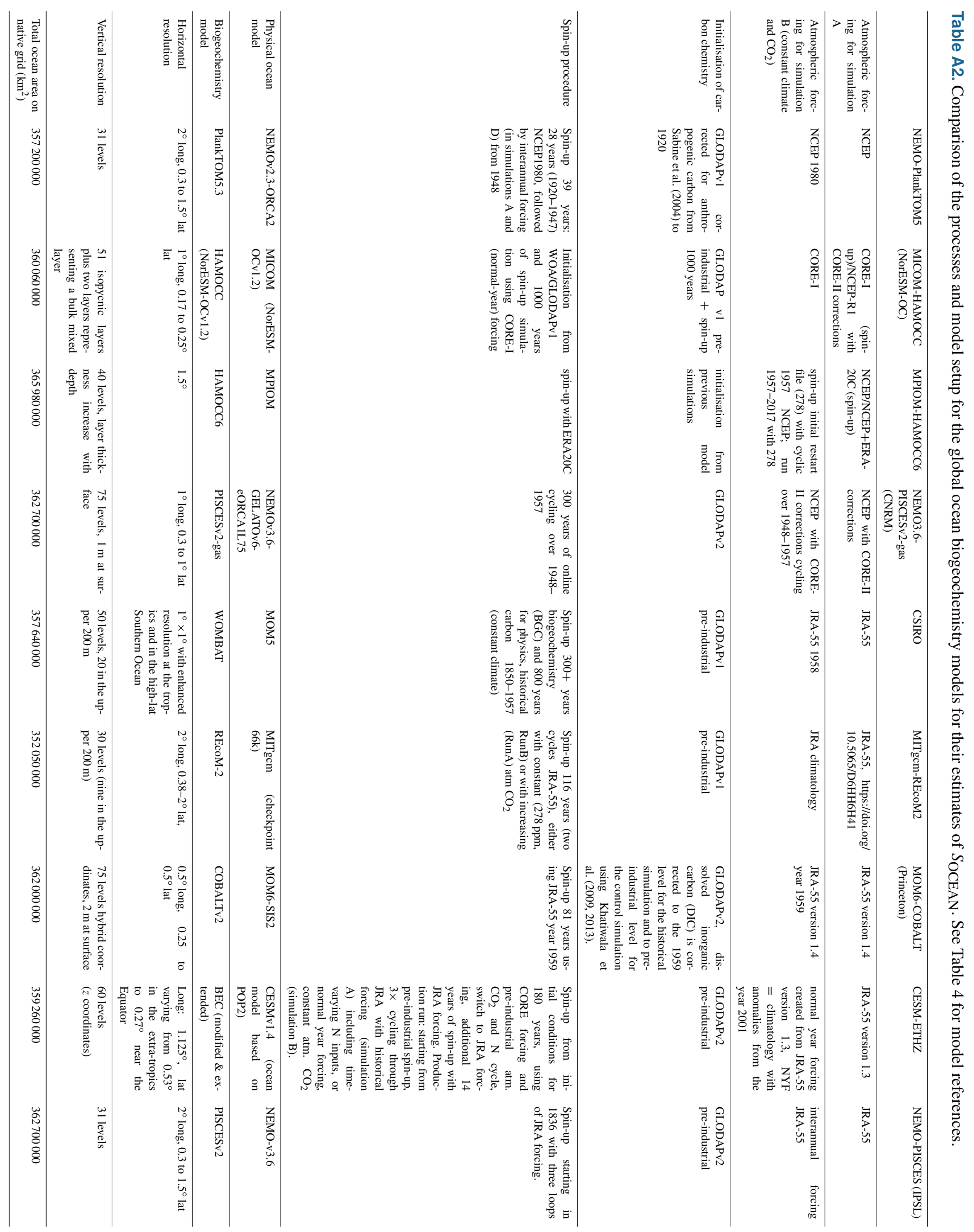


Table A3. Comparison of the inversion setup and input fields for the atmospheric inversions. Atmospheric inversions include the full $\mathrm{CO}_{2}$ fluxes, including the anthropogenic and pre-industrial fluxes. Hence they need to be adjusted for the pre-industrial flux of $\mathrm{CO}_{2}$ from the land to the ocean that is part of the natural carbon cycle before they can be compared with $S_{\text {OCEAN }}$ and $S_{\text {LAND }}$ from process models. See Table 4 for references.

\begin{tabular}{|c|c|c|c|}
\hline Version number & $\begin{array}{l}\text { CarbonTracker Europe (CTE) } \\
\text { CTE2019-FT }\end{array}$ & $\begin{array}{l}\text { Jena CarboScope } \\
\text { sEXTocNEET_v4.3 }\end{array}$ & $\begin{array}{l}\text { CAMS } \\
\text { v18r2 }\end{array}$ \\
\hline \multicolumn{4}{|l|}{ Observations } \\
\hline $\begin{array}{l}\text { Atmospheric } \\
\text { observations }\end{array}$ & $\begin{array}{l}\text { Hourly resolution } \\
\text { (well-mixed conditions) ObsPack } \\
\text { GLOBALVIEWplus v4.2 and } \\
\text { NRT_v4.4 }{ }^{\mathrm{a}} \text { ) }\end{array}$ & $\begin{array}{l}\text { Flasks and hourly (outliers } \\
\text { removed by } 2 \sigma \text { criterion) }\end{array}$ & $\begin{array}{l}\text { Daily averages of well-mixed } \\
\text { conditions - ObsPack GLOB- } \\
\text { ALVIEWplus v4.2a\& NRT v4.4, } \\
\text { WDCGG, RAMCES and ICOS } \\
\text { ATC }\end{array}$ \\
\hline \multicolumn{4}{|l|}{ Prior fluxes } \\
\hline Biosphere and fires & SiBCASA-GFED4s ${ }^{b}$ & No prior & $\begin{array}{l}\text { ORCHIDEE (climatological), } \\
\text { GFEDv4.1 \& GFAS }\end{array}$ \\
\hline Ocean & $\begin{array}{l}\text { Ocean inversion by Jacobson et } \\
\text { al. (2007) }\end{array}$ & $\begin{array}{l}\text { oc_v1.7 updates: from 1993, in- } \\
\text { terannual variability from Plank- } \\
\text { TOM5 (Buitenhuis et al., 2013) } \\
\text { GOBM; before } 1985 \text {, linear tran- } \\
\text { sition over the years in between } \\
\text { (update of Rödenbeck et al., } \\
\text { 2014) }\end{array}$ & Landschützer et al. (2018) \\
\hline Fossil fuels & $\begin{array}{l}\text { EDGAR+IER, scaled to } \\
\text { GCP2018 and GCP2019 }\end{array}$ & $\begin{array}{l}\text { Jones et al. (2019) - EDGAR } \\
\text { scaled nationally and by fuel type } \\
\text { to GCP } 2019\end{array}$ & EDGAR scaled to GCP2019 \\
\hline \multicolumn{4}{|c|}{ Transport and optimisation } \\
\hline Transport model & TM5 & TM3 & LMDz v6A \\
\hline Weather forcing & ECMWF & NCEP & ECMWF \\
\hline Resolution (degrees) & $\begin{array}{l}\text { Global: } 3^{\circ} \times 2^{\circ} \text {, Europe: } 1^{\circ} \times 1^{\circ} \text {, } \\
\text { North America: } 1^{\circ} \times 1^{\circ}\end{array}$ & Global: $4^{\circ} \times 5^{\circ}$ & Global: $3.75^{\circ} \times 1.875^{\circ}$ \\
\hline Optimisation & Ensemble Kalman filter & $\begin{array}{l}\text { Conjugate gradient (re-ortho- } \\
\text { normalisation) })^{\mathrm{c}}\end{array}$ & Variational \\
\hline
\end{tabular}

${ }^{a}$ CGADIP (2019), Carbontracker Team (2019). ${ }^{b}$ Van der Velde et al. (2014). ${ }^{c}$ Ocean prior not optimised. 
Table A4. Attribution of $f \mathrm{CO}_{2}$ measurements for the year 2018 included in SOCATv2019 (Bakker et al., 2016) to inform ocean $p$ CO 2 -based flux products.

\begin{tabular}{|c|c|c|c|c|c|}
\hline Platform & Regions & No. of samples & Principal investigators & No. of data sets & Platform type \\
\hline AkzoNobel & North Atlantic, Southern Ocean & 553 & Tanhua, T.; Gutekunst, S. & 1 & Ship \\
\hline Allure of the Seas & Tropical Atlantic & 118652 & Wanninkhof, R.; Pierrot, D. & 50 & Ship \\
\hline Aurora Australis & Southern Ocean & 59586 & Tilbrook, B. & 3 & Ship \\
\hline Bjarni Saemundsson & North Atlantic & 7938 & $\begin{array}{l}\text { Benoit-Cattin-Breton, A.; } \\
\text { Ólafsdóttir, S. R. }\end{array}$ & 1 & Ship \\
\hline Cap Blanche & Southern Ocean, tropical Pacific & 28554 & $\begin{array}{l}\text { Cosca, C.; Alin, S.; Feely, } \\
\text { R.; Herndon, J.; Collins A. }\end{array}$ & 5 & Ship \\
\hline Cap San Lorenzo & Tropical Atlantic & 16071 & Lefèvre, N. & 4 & Ship \\
\hline Colibri & North Atlantic, tropical Atlantic & 6541 & Lefèvre, N. & 1 & Ship \\
\hline Equinox & Tropical Atlantic & 119384 & Wanninkhof, R.; Pierrot, D. & 48 & Ship \\
\hline F.G. Walton Smith & North Atlantic & 2830 & Millero, F.; Wanninkhof, R. & 2 & Ship \\
\hline Finnmaid & North Atlantic & 135597 & Rehder, G.; Glockzin, M. & 9 & Ship \\
\hline G.O.Sars & North Atlantic & 105172 & Skjelvan, I. & 11 & Ship \\
\hline Gordon Gunter & North Atlantic & 73634 & Wanninkhof, R.; Pierrot, D. & 12 & Ship \\
\hline Henry B. Bigelow & North Atlantic & 64935 & Wanninkhof, R.; Pierrot, D. & 14 & Ship \\
\hline Heron Island & Tropical Pacific & 3631 & Tilbrook, B. & 2 & Mooring \\
\hline Investigator & Southern Ocean & 88217 & Tilbrook, B. & 6 & Ship \\
\hline Isabu & North Pacific & 2350 & Park, G.-H. & 1 & Ship \\
\hline Kangaroo Island & Southern Ocean & 4016 & Tilbrook, B. & 2 & Mooring \\
\hline Laurence M. Gould & Southern Ocean & 28666 & $\begin{array}{l}\text { Sweeney, C.; Takahashi, T.; } \\
\text { Newberger, T.; Sutherland, } \\
\text { S. C.; Munro, D. R. }\end{array}$ & 5 & Ship \\
\hline Maria Island & Southern Ocean & 4015 & Tilbrook, B. & 2 & Mooring \\
\hline Marion Dufresne & Southern Ocean, Indian & 6796 & Lo Monaco, C.; Metzl, N. & 1 & Ship \\
\hline New Century 2 & $\begin{array}{l}\text { North Pacific, tropical Pacific, } \\
\text { North Atlantic }\end{array}$ & 33316 & Nakaoka, S.-I. & 14 & Ship \\
\hline Nuka Arctica & North Atlantic & 143430 & Becker, M.; Olsen, A. & 23 & Ship \\
\hline Ronald H. Brown & North Atlantic, tropical Pacific & 28239 & Wanninkhof, R.; Pierrot, D. & 5 & Ship \\
\hline Simon Stevin & North Atlantic & 33760 & Gkritzalis, $\mathrm{T}$. & 8 & Ship \\
\hline Soyo Maru & North Pacific & 91491 & Ono, $\mathrm{T}$. & 5 & Ship \\
\hline Station M & North Atlantic & 1313 & Skjelvan, I.; Lauvset, S. K. & 1 & Mooring \\
\hline Tangaroa & Southern Ocean & 136893 & Currie, K. I. & 8 & Ship \\
\hline Trans Carrier & North Atlantic & 12966 & $\begin{array}{l}\text { Omar, A. M.; } \\
\text { Johannessen, T. }\end{array}$ & 1 & Ship \\
\hline Trans Future 5 & $\begin{array}{l}\text { North Pacific, tropical Pacific, } \\
\text { Southern Ocean }\end{array}$ & 27856 & Nakaoka, S.-I.; Nojiri, Y. & 19 & Ship \\
\hline Turn the Tide on Plastic & $\begin{array}{l}\text { North Atlantic, tropical Atlantic, } \\
\text { Southern Ocean, tropical Pacific }\end{array}$ & 13043 & Gutekunst, S. & 1 & Ship \\
\hline Wakmatha & Tropical Pacific & 25457 & Tilbrook, B. & 8 & Ship \\
\hline
\end{tabular}


Table A5. Funding supporting the production of the various components of the global carbon budget in addition to the authors' supporting institutions (see also acknowledgements).

\begin{tabular}{|c|c|}
\hline Funder and grant number (where relevant) & Author initials \\
\hline Australia, Integrated Marine Observing System (IMOS) & BT, CN \\
\hline Australian government as part of the Antarctic Science Collaboration Initiative programme & $\mathrm{AL}$ \\
\hline Australian Government National Environment Science Program (NESP) & JGC, VH \\
\hline Belgium Research Foundation - Flanders (FWO) (grant number UA C130206-18) & TG \\
\hline $\begin{array}{l}\text { BNP Paribas Foundation through Climate \& Biodiversity initiative, philanthropic grant for developments of the } \\
\text { Global Carbon Atlas }\end{array}$ & $\mathrm{PC}, \mathrm{AP}$ \\
\hline BONUS INTEGRAL & GR \\
\hline EC Copernicus Atmosphere Monitoring Service implemented by ECMWF & FC \\
\hline EC Copernicus Marine Environment Monitoring Service implemented by Mercator Ocean & MG \\
\hline EC H2020 (AtlantOS: grant no. 633211) & SV, MG \\
\hline EC H2020 (CCiCC; grant no. 821003) & PF, RMA, SS, GPP, MOS, JIK, SL, NG, PL \\
\hline EC H2020 (CHE; grant no. 776186) & MWJ \\
\hline EC H2020 (CRESCENDO: grant no. 641816) & RS, EJ \\
\hline $\begin{array}{l}\text { EC H2020 European Research Council (ERC) Synergy grant (IMBALANCE-P; grant no. ERC-2013-SyG- } \\
610028 \text { ) }\end{array}$ & DSG \\
\hline EC H2020 ERC (QUINCY; grant no. 647204) & SZ \\
\hline EC H2020 (RINGO: grant no. 730944) & $\mathrm{DB}$ \\
\hline EC H2020 project (VERIFY: grant no. 776810) & CLQ, GPP, JIK, RMA, MWJ, PC \\
\hline $\begin{array}{l}\text { European Space Agency Climate Change Initiative ESA-CCI RECCAP2 project } 655 \\
\text { (ESRIN/4000123002/18/I-NB) }\end{array}$ & $\mathrm{PF}, \mathrm{PC}, \mathrm{SS}, \mathrm{MOS}$ \\
\hline $\begin{array}{l}\text { French Institut National des Sciences de l'Univers (INSU) and Institut Pau- Emile Victor (IPEV), Sorbonne } \\
\text { Universités (OSU Ecce-Terra) }\end{array}$ & NM \\
\hline French Institut de Recherche pour le Développement (IRD) & NL \\
\hline French Integrated Carbon Observation System (ICOS) France Océan; & NL \\
\hline German Integrated Carbon Observation System (ICOS), Federal Ministry for Education and Research (BMBF); & GR \\
\hline German Future Ocean (grant number CP1756) & SG \\
\hline German Helmholtz Association in its ATMO programme & PA \\
\hline German Helmholtz Association Innovation and Network Fund (VH-NG-1301) & $\mathrm{JH}$ \\
\hline German Research Foundation's Emmy Noether Programme (grant no. PO1751/1-1) & $\mathrm{JP}$ \\
\hline Japan Ministry of the Environment (grant number E1432) & TO \\
\hline $\begin{array}{l}\text { Japan Global Environmental Research Coordination System, Ministry of the Environment (grant number } \\
\text { E1751) }\end{array}$ & SN \\
\hline Netherlands Organization for Scientific Research (NWO; Ruisdael Infrastructure) & NS \\
\hline Norwegian Research Council (grant no. 270061) & JS \\
\hline $\begin{array}{l}\text { Norwegian ICOS Norway and OTC Research Infrastructure Project, Research Council of Norway (grant num- } \\
\text { ber 245927) }\end{array}$ & $\mathrm{SV}, \mathrm{MB}, \mathrm{AO}$ \\
\hline New Zealand, NIWA SSIF funding & $\mathrm{KC}$ \\
\hline Swiss National Science Foundation (grant no. 200020_172476) & SL \\
\hline UK Natural Environment Research Council (SONATA: grant no. NE/P021417/1) & ЕTB \\
\hline UK Newton Fund, Met Office Climate Science for Service Partnership Brazil (CSSP Brazil) & $\mathrm{AW}, \mathrm{ER}$ \\
\hline UK Royal Society (grant no. RP $\backslash R 1 \backslash 191063$ ) & CLQ \\
\hline $\begin{array}{l}\text { US Department of Agriculture, National Institute of Food and Agriculture (grant nos. 2015-67003-23489 and } \\
\text { 2015-67003-23485) }\end{array}$ & DLL \\
\hline US Department of Commerce, NOAA/OAR's Global Observations and Monitoring of the Oceans Program & $\mathrm{RF}$ \\
\hline $\begin{array}{l}\text { US Department of Commerce, NOAA/OAR's Ocean Observations and Monitoring Division (grant number } \\
\text { 100007298); }\end{array}$ & LB, DP \\
\hline US Department of Commerce, NOAA/OAR's Ocean Acidification Program & DP, LB \\
\hline US Department of Energy, Office of Science and BER prg. (grant no. DE-SC000 0016323) & ATJ \\
\hline $\begin{array}{l}\text { US Department of Energy, SciDac award number is DESC0012972; IDS grant award number is } \\
\text { 80NSSC17K0348 }\end{array}$ & LC, GH \\
\hline $\begin{array}{l}\text { US CIMAS, a Cooperative Institute of the University of Miami and the National Oceanic and Atmospheric } \\
\text { Administration (cooperative agreement NA10OAR4320143) }\end{array}$ & DP, LB \\
\hline US NASA Interdisciplinary Research in Earth Science Program. & BP \\
\hline US National Science Foundation (grant number 1461590) & JOK \\
\hline US National Science Foundation (grant number 1903722) & HT \\
\hline US National Science Foundation (grant number PLR-1543457) & $\mathrm{DM}$ \\
\hline $\begin{array}{l}\text { US Princeton University Environmental Institute and the NASA OCO2 science team, grant number } \\
\text { 80NSSC18K0893. }\end{array}$ & LR \\
\hline
\end{tabular}


Table A5. Continued.

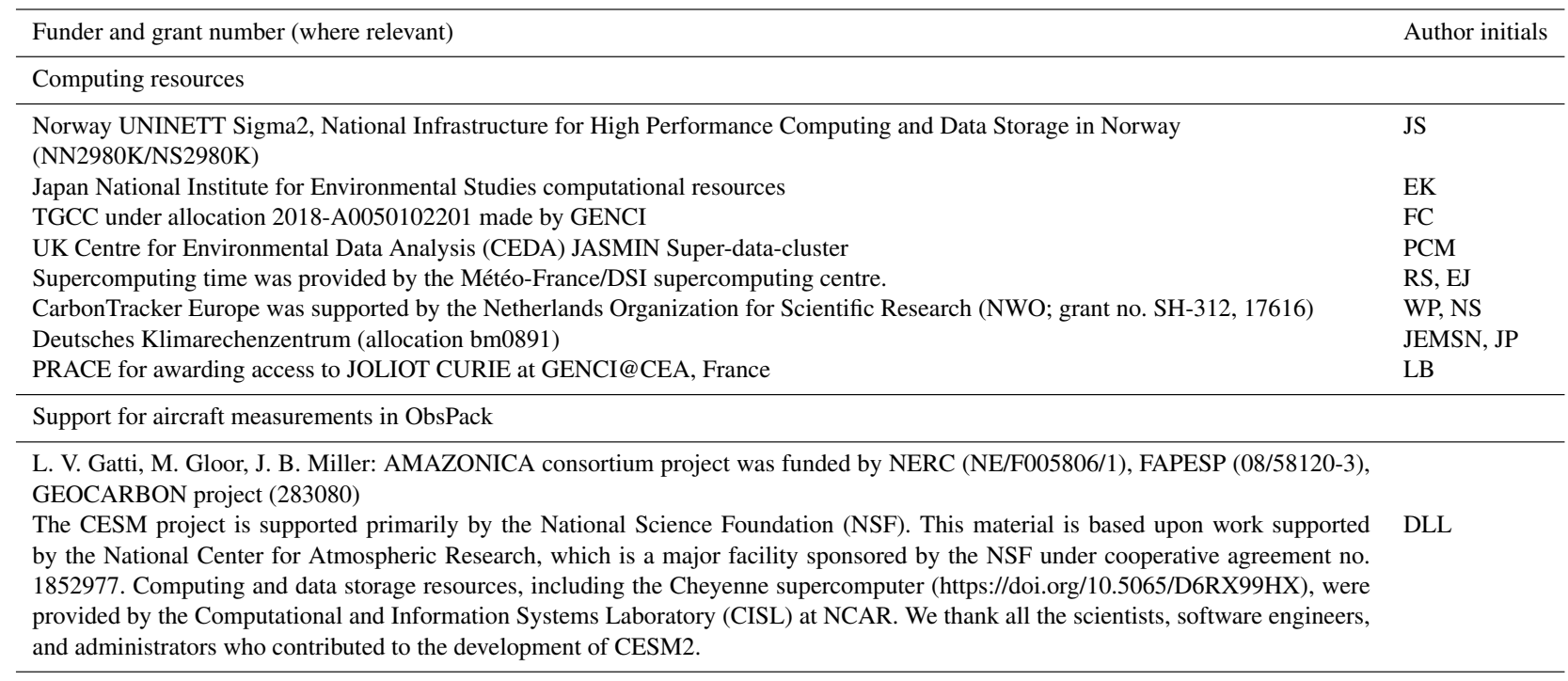

Table A6. Aircraft measurement programmes archived by Cooperative Global Atmospheric Data Integration Project (CGADIP, 2019) that contribute to the evaluation of the atmospheric inversions (Fig. B3).

\begin{tabular}{|c|c|c|}
\hline Measurement programme name in ObsPack & Specific DOI & Data providers \\
\hline Alta Floresta & & Gatti, L. V.; Gloor, E.; Miller, J. B.; \\
\hline Aircraft Observation of Atmospheric trace gases by JMA & & ghg_obs@met.kishou.go.jp \\
\hline Beaver Crossing, Nebraska & & Sweeney, C.; Dlugokencky, E. J. \\
\hline Bradgate, Iowa & & Sweeney, C.; Dlugokencky, E. J. \\
\hline Briggsdale, Colorado & & Sweeney, C.; Dlugokencky, E. J. \\
\hline Cape May, New Jersey & & Sweeney, C.; Dlugokencky, E. J. \\
\hline $\begin{array}{l}\text { CONTRAIL (Comprehensive Observation Network for TRace } \\
\text { gases by AIrLiner) }\end{array}$ & https://doi.org/10.17595/20180208.001 & Machida, T.; Matsueda, H.; Sawa, Y.; Niwa, Y. \\
\hline $\begin{array}{l}\text { Carbon in Arctic Reservoirs Vulnerability Experiment } \\
\text { (CARVE) }\end{array}$ & & $\begin{array}{l}\text { Sweeney, C.; Karion, A.; Miller, J. B.; Miller, } \\
\text { C. E.; Dlugokencky, E. J. }\end{array}$ \\
\hline Dahlen, North Dakota & & Sweeney, C.; Dlugokencky, E. J. \\
\hline Estevan Point, British Columbia & & Sweeney, C.; Dlugokencky, E. J. \\
\hline East Trout Lake, Saskatchewan & & Sweeney, C.; Dlugokencky, E. J. \\
\hline Fairchild, Wisconsin & & Sweeney, C.; Dlugokencky, E. J. \\
\hline Molokai Island, Hawaii & & Sweeney, C.; Dlugokencky, E. J. \\
\hline Homer, Illinois & & Sweeney, C.; Dlugokencky, E. J. \\
\hline HIPPO (HIAPER Pole-to-Pole Observations) & https://doi.org/10.3334/CDIAC/HIPPO_010 & $\begin{array}{l}\text { Wofsy, S. C.; Stephens, B. B.; Elkins, J. W.; } \\
\text { Hintsa, E. J.; Moore, F. }\end{array}$ \\
\hline INFLUX (Indianapolis Flux Experiment) & & $\begin{array}{l}\text { Sweeney, C.; Dlugokencky, E. J.; Shepson, } \\
\text { P. B.; Turnbull, J. }\end{array}$ \\
\hline NASA Goddard Space Flight Center Aircraft Campaign & & Kawa, S. R.; Abshire, J. B.; Riris, H. \\
\hline Park Falls, Wisconsin & & Sweeney, C.; Dlugokencky, E. J. \\
\hline Offshore Corpus Christi, Texas & & Sweeney, C.; Dlugokencky, E. J. \\
\hline Offshore Portsmouth, New Hampshire (Isles of Shoals) & & Sweeney, C.; Dlugokencky, E. J. \\
\hline Oglesby, Illinois & & Sweeney, C.; Dlugokencky, E. J. \\
\hline Poker Flat, Alaska & & Sweeney, C.; Dlugokencky, E. J. \\
\hline Rio Branco & & Gatti, L. V.; Gloor, E.; Miller, J. B. \\
\hline Rarotonga & & Sweeney, C.; Dlugokencky, E. J. \\
\hline Santarém & & Sweeney, C.; Dlugokencky, E. J. \\
\hline Charleston, South Carolina & & Sweeney, C.; Dlugokencky, E. J. \\
\hline Southern Great Plains, Oklahoma & & Sweeney, C.; Dlugokencky, E. J.; Biraud, S. \\
\hline Harvard University Aircraft Campaign & & Wofsy, S. C. \\
\hline Tabatinga & & Gatti, L. V.; Gloor, E.; Miller, J. B. \\
\hline Trinidad Head, California & & Sweeney, C.; Dlugokencky, E. J. \\
\hline West Branch, Iowa & & Sweeney, C.; Dlugokencky, E. J. \\
\hline
\end{tabular}




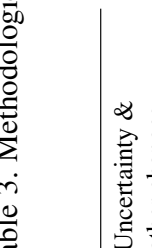$$
\text { . }
$$

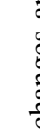
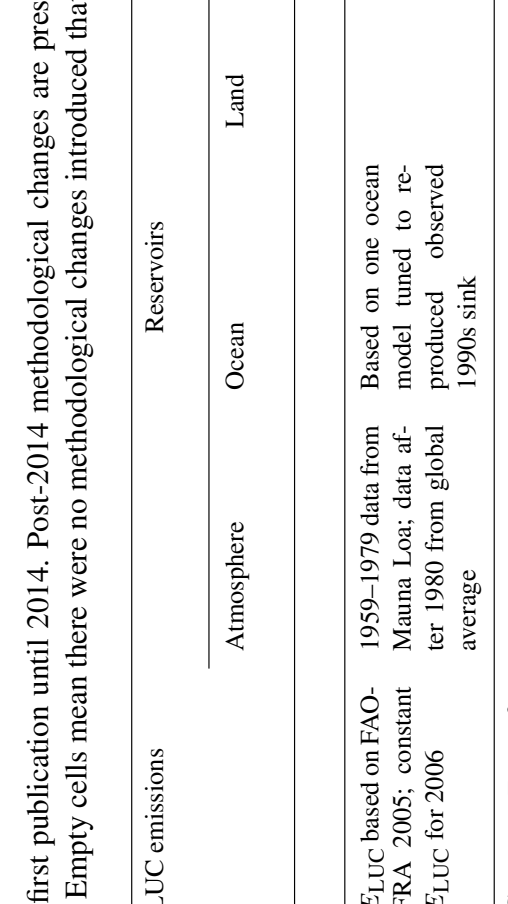

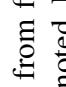

章

部

高

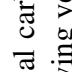

䇏

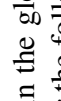

(1)

崖旁

$\frac{2}{2}$

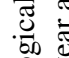

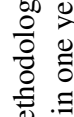

部

高旁

(1)

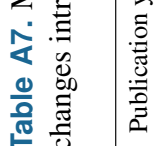

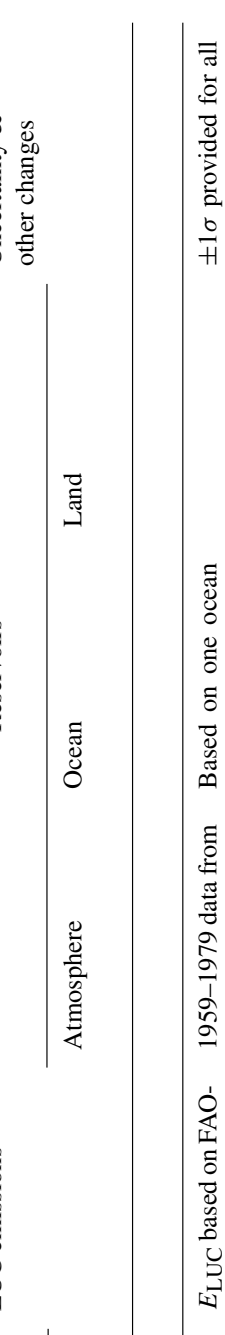

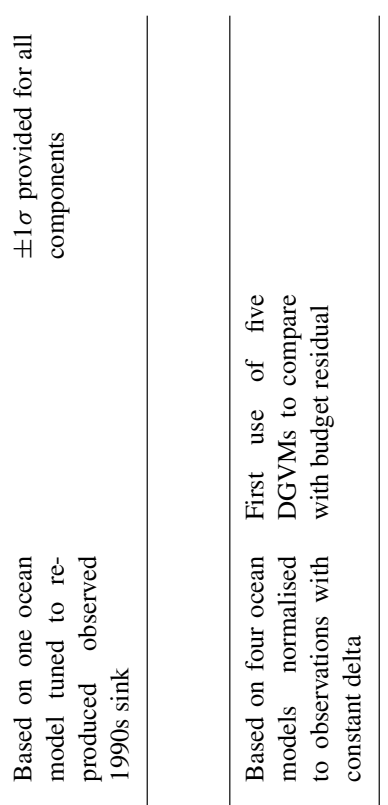

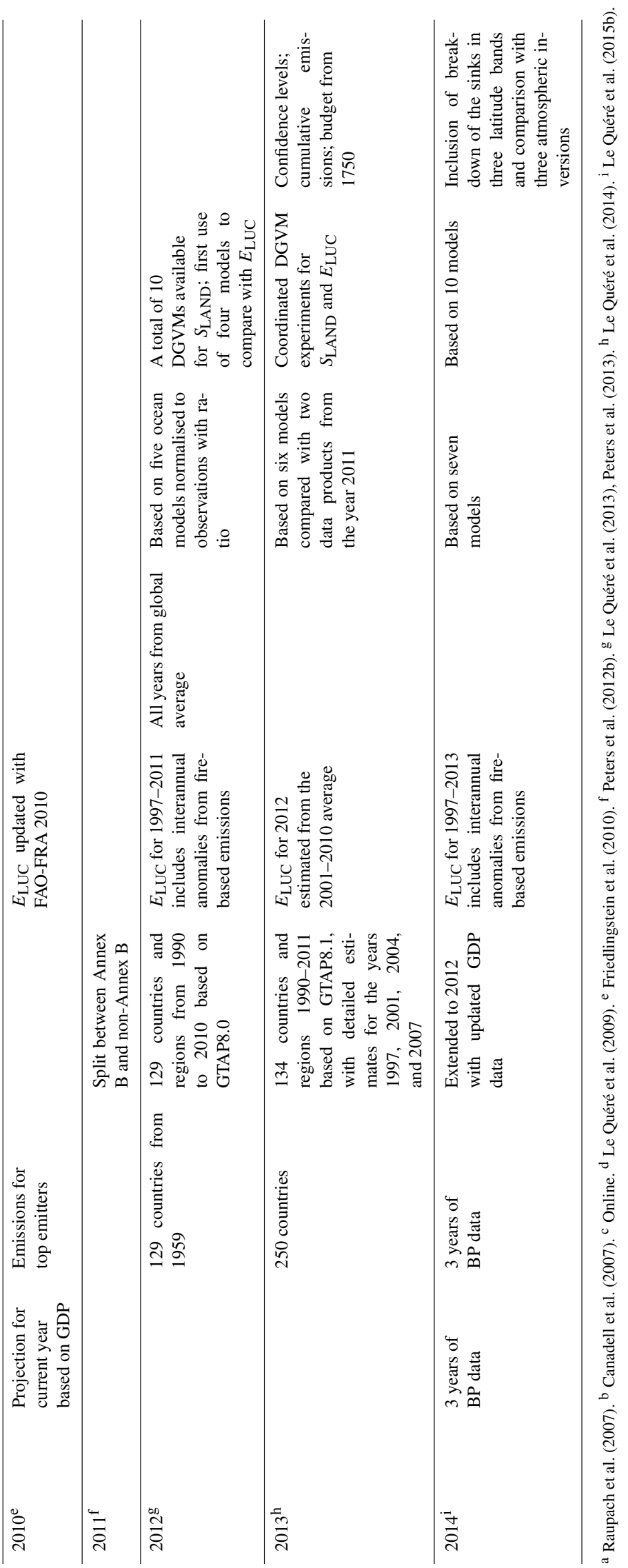




\section{Appendix B}
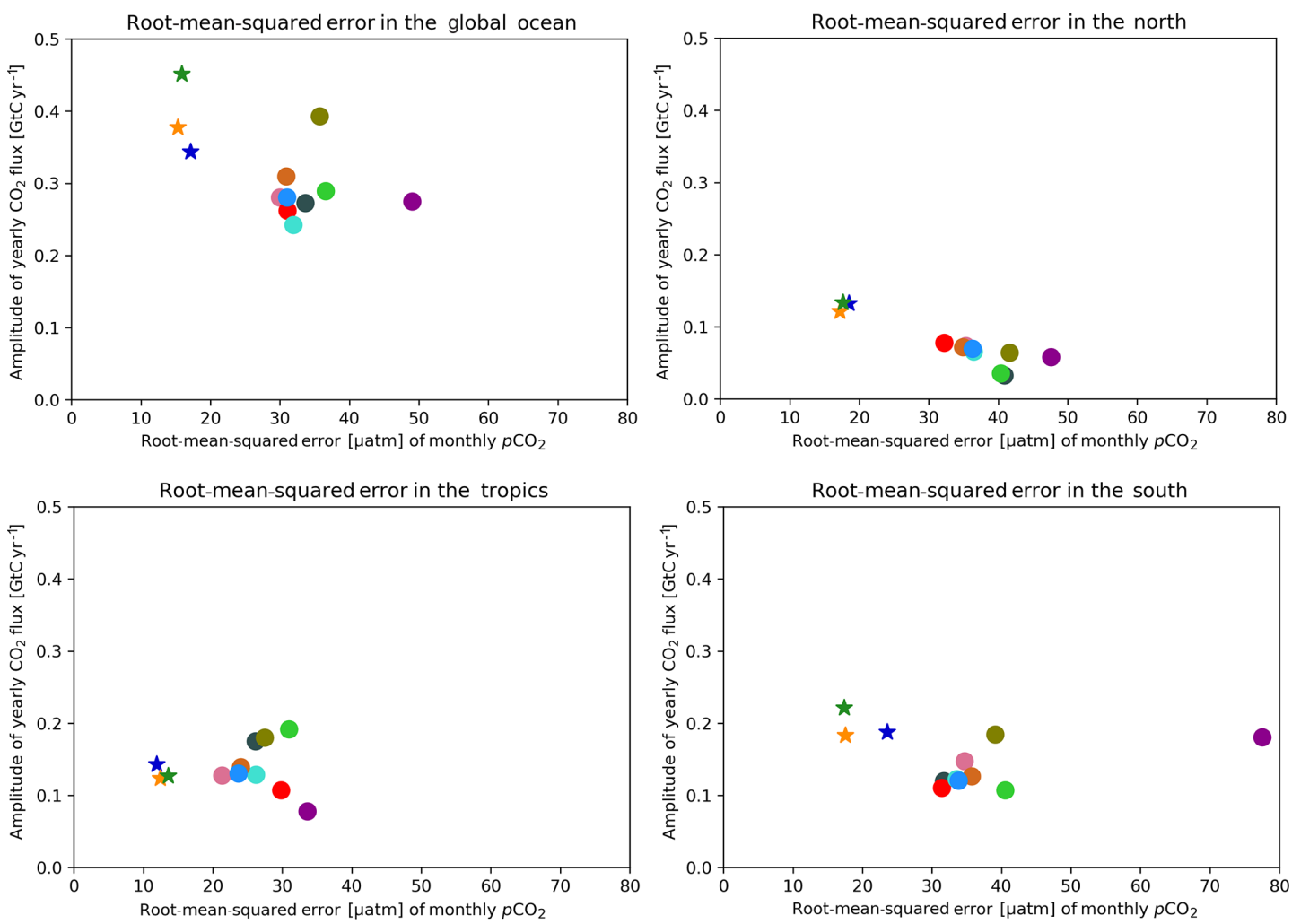

\begin{tabular}{|llll}
$\star$ Jena-MLS & MITgcm-REcoM & NEMO-planktom \\
$\star$ MPI-SOMFFN & MPI & CSIRO \\
$\star$ CMEMS & CNRM & MOM6-COBALT \\
CESM-ETH & NorESM & & IPSL-PISCES
\end{tabular}

Figure B1. Evaluation of the GOBMs and flux products using the root-mean-squared error (RMSE) for the period 1985 to 2018 , between the individual surface ocean $p \mathrm{CO}_{2}$ estimates and the SOCAT v2019 database. The $y$ axis shows the amplitude of the interannual variability (A-IAV, taken as the standard deviation of a 12-month running mean over the monthly flux time series; Rödenbeck et al., 2015). Results are presented for the globe, north $\left(>30^{\circ} \mathrm{N}\right)$, tropics $\left(30^{\circ} \mathrm{S}-30^{\circ} \mathrm{N}\right)$, and south $\left(<30^{\circ} \mathrm{S}\right)$ for the GOBMs (circles) and for the $p \mathrm{CO}_{2}-\mathrm{based}$ flux products (star symbols). The three $p \mathrm{CO}_{2}$-based flux products use the SOCAT database and therefore are not fully independent from the data (see Sect. 2.4.1). 


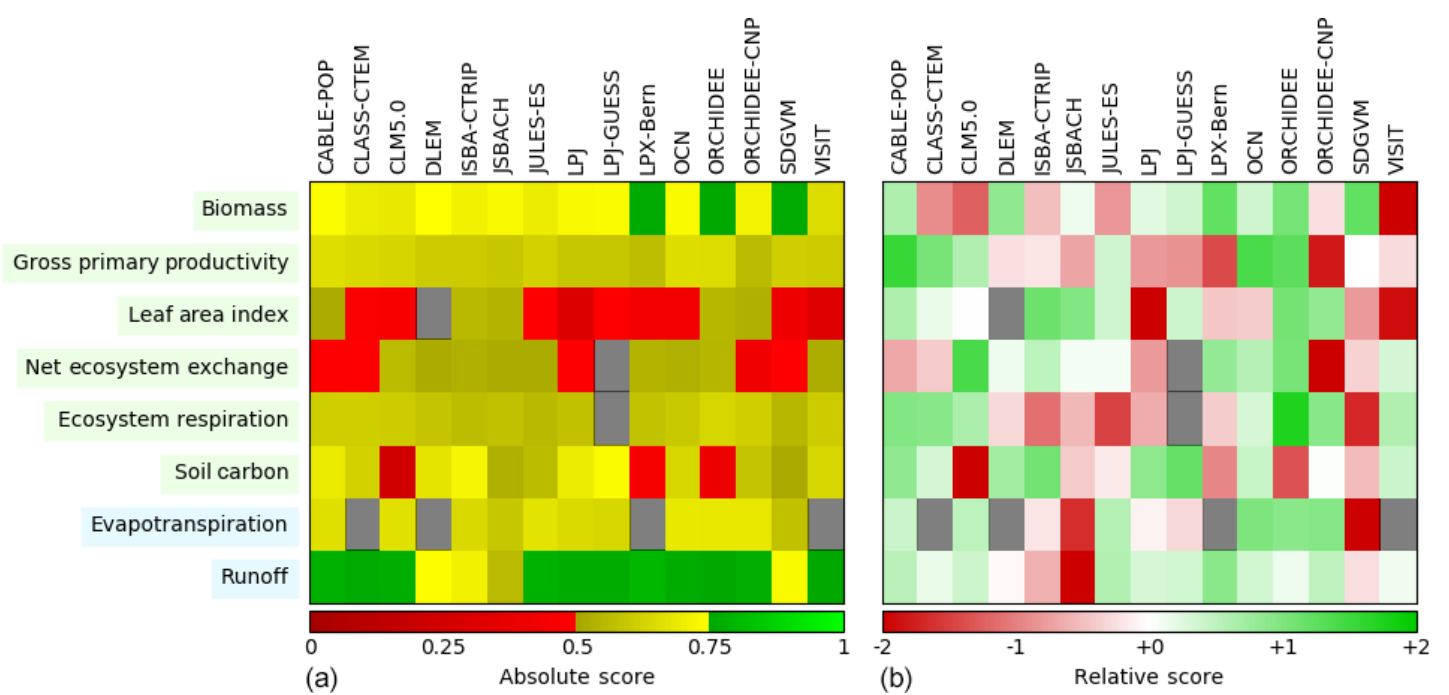

Figure B2. Evaluation of the DGVM using the International Land Model Benchmarking system (ILAMB; Collier et al., 2018) (a) absolute skill scores and (b) skill scores relative to other models. The benchmarking is done with observations for vegetation biomass (Saatchi et al., 2011; GlobalCarbon, unpublished data; Avitabile et al., 2016), GPP (Jung et al., 2010; Lasslop et al., 2010), leaf area index (De Kauwe et al., 2011; Myneni et al., 1997), net ecosystem exchange (Jung et al., 2010; Lasslop et al., 2010), ecosystem respiration (Jung et al., 2010; Lasslop et al., 2010), soil carbon (Hugelius et al., 2013; Todd-Brown et al., 2013), evapotranspiration (De Kauwe et al., 2011), and runoff (Dai and Trenberth, 2002). For each model-observation comparison a series of error metrics are calculated, scores are then calculated as an exponential function of each error metric, finally for each variable the multiple scores from different metrics and observational data sets are combined to give the overall variable scores shown in (a). Overall variable scores increase from 0 to 1 with improvements in model performance. The set of error metrics vary with data set and can include metrics based on the period mean, bias, root-mean-squared error, spatial distribution, interannual variability, and seasonal cycle. The relative skill score shown in (b) is a $Z$ score, which indicates in units of standard deviation the model scores relative to the multi-model mean score for a given variable. Grey boxes represent missing model data.

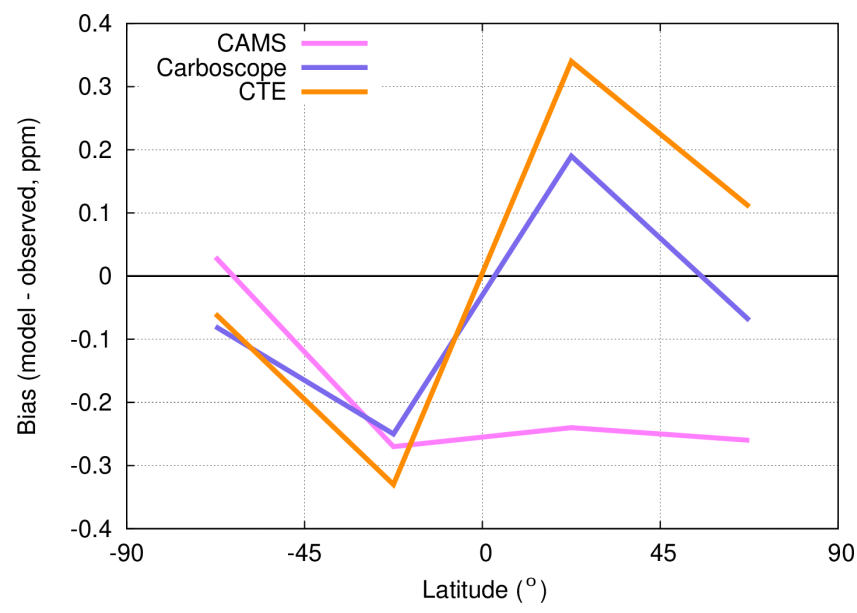

Figure B3. Evaluation of the atmospheric inversion products. The mean of the model minus observations is shown for four latitude bands. The four models are compared to independent $\mathrm{CO}_{2}$ measurements made on board aircraft over many places of the world between 2 and $7 \mathrm{~km}$ above sea level. Aircraft measurements archived in the Cooperative Global Atmospheric Data Integration Project (CGADIP, 2019) from sites, campaigns, or programmes that cover at least 9 months between 2001 and 2017 and that have not been assimilated have been used to compute the biases of the differences in four $45^{\circ}$ latitude bins. Land and ocean data are used without distinction. The number of data for each latitude band is $5000\left(90-45^{\circ} \mathrm{S}\right), 124000\left(45^{\circ} \mathrm{S}-0^{\circ}\right), 1042000\left(0-45^{\circ} \mathrm{N}\right)$, and $139000\left(45-90^{\circ} \mathrm{N}\right)$, rounded off to the nearest thousand. 

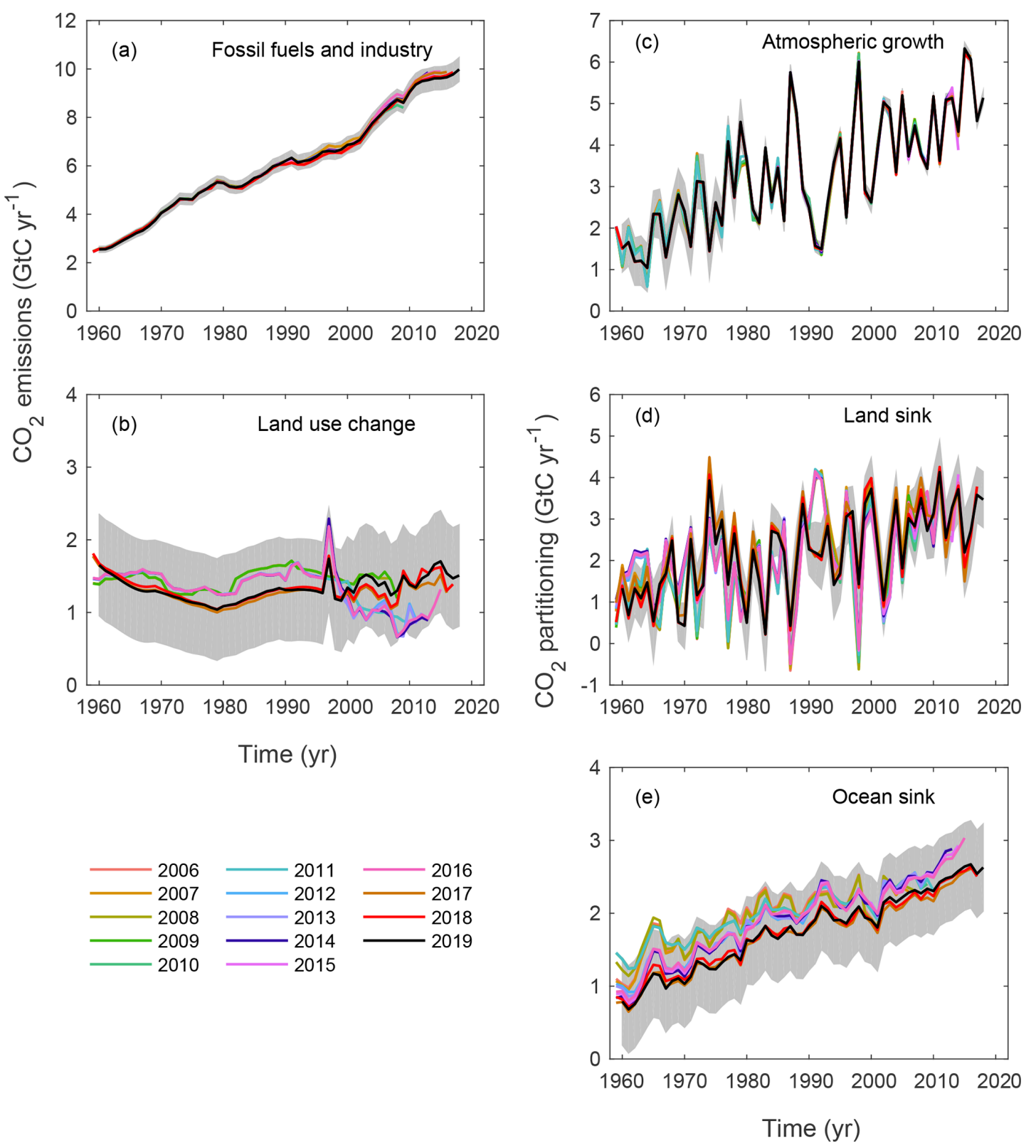

Figure B4. Comparison of global carbon budget components released annually by GCP since 2006. $\mathrm{CO}_{2}$ emissions from (a) fossil $\mathrm{CO}_{2}$ emissions $\left(E_{\mathrm{FF}}\right)$ and $(\mathbf{b})$ land use change $\left(E_{\mathrm{LUC}}\right)$, as well as their partitioning among $(\mathbf{c})$ the atmosphere $\left(G_{\mathrm{ATM}}\right),(\mathbf{d})$ the land $\left(S_{\mathrm{LAND}}\right)$, and (e) the ocean $\left(S_{\text {OCEAN }}\right)$. See legend for the corresponding years and Tables 3 and A7 for references. The budget year corresponds to the year when the budget was first released. All values are in gigatonnes of carbon per year. Grey shading shows the uncertainty bounds representing $\pm 1 \sigma$ of the current global carbon budget. 
Author contributions. PF, MWJ, MOS, CLQ, RMA, JH, GPP, WP, JP, SS, DCEB, JGC, PC, and RBJ designed the study, conducted the analysis, and wrote the paper. RMA, GPP, and JIK produced the emissions and their uncertainties and 2019 emission projections, and analysed the emissions data. DG and GM provided emission data. PPT provided key atmospheric $\mathrm{CO}_{2}$ data. WP, PC, FC, CR, NN, and NS provided an updated atmospheric inversion, developed the protocol, and produced the evaluation. JP, AB, and RAH provided updated bookkeeping land use change emissions. LPC, GH, KKG, FNT, and GRvdW provided forcing data for land use change. PA, VB, DSG, VH, AKJ, EJ, EK, SL, DL, PCM, JRM, JEMSN, BP, HT, APW, AJW, and SZ provided an update of a DGVM. IH and JOK provided forcing data for the DGVMs. ER provided the evaluation of the DGVMs. JH, LaB, EB, NG, TI, AL, JS, and RS provided an update of a GOBM. MG, $\mathrm{PL}$, and $\mathrm{CR}$ provided an update of an ocean flux product. LeB, MB, KIC, RAF, TG, SG, NL, NM, DRM, SIN, CN, AMO, TO, $\mathrm{DP}, \mathrm{GR}$, and $\mathrm{BT}$ provided ocean $p \mathrm{CO}_{2}$ measurements for the year 2018, with synthesis by DCEB and SKL. LR provided an updated river flux estimate. AP contributed to setting up the GCB data set at http://globalcarbonatlas.org (last access: 4 December 2019). PF, MWJ, and MOS revised all figures, tables, text, and/or numbers to ensure the update is clear from the 2018 edition and in phase with the http://globalcarbonatlas.org.

Competing interests. The authors declare that they have no conflict of interest.

Acknowledgements. We thank all people and institutions who provided the data used in this carbon budget as well as Vivek Arora, Jinfeng Chang, Eunkyoung Choi, Julie Deshayes, Christian Ethé, Matthew Fortier, Tristan Quaife, Shijie Shu, Anthony Walker, and Ulrich Weber for their involvement in the development, use and analysis of the models and data products used here. We thank Ed Dlugokencky for providing atmospheric $\mathrm{CO}_{2}$ measurements. We thank Benjamin Pfeil and Steve Jones of the Bjerknes Climate Data Centre and the ICOS Ocean Thematic Centre of the EU Integrated Carbon Observation System (ICOS) at the University of Bergen as well as Karl Smith and Kevin O'Brien of NOAA's Pacific Marine Environmental Laboratory, who helped with SOCAT data management. We thank Alice Benoit-Cattin-Breton, Sólveig Ólafsdóttir, Frank Millero, and Geun-Ha Park, who contributed to the provision of ocean $p \mathrm{CO}_{2}$ observations (see Table A4). This is NOAA PMEL contribution number 4847 . We thank the institutions and funding agencies responsible for the collection and quality control of the data in SOCAT and the International Ocean Carbon Coordination Project (IOCCP) for its support. We thank FAO and its member countries for the collection and free dissemination of data relevant to this work. We thank data providers to ObsPack GLOBALVIEWplus v4.2 and NRT v4.40 for atmospheric $\mathrm{CO}_{2}$ observations. We thank Trang Chau, who produced the CMEMS $p \mathrm{CO}_{2}$-based ocean flux data and designed the system together with Marion Gehlen, Anna Denvil-Sommer, and Frédéric Chevallier. We thank the individuals and institutions that provided the databases used for the model evaluations introduced here and Nigel Hawtin for producing Figs. 2 and 9. We thank Fortunat Joos, Samar Khatiwala, and Timothy DeVries for providing historical data. We thank all people and institutions who provided the data used in this carbon budget and the Global Carbon Project members for their input throughout the development of this update. Finally, we thank all funders who have supported the individual and joint contributions to this work (see Table A5), as well as the reviewers of this paper and previous versions and the many researchers who have provided feedback.

Financial support. For a list of all funders that have supported this research, please refer to Table A5.

Review statement. This paper was edited by David Carlson and reviewed by Albertus J. (Han) Dolman, H. Damon Matthews, and one anonymous referee.

\section{References}

Adcroft, A., Anderson, W., Balaji, V., Blanton, C., Bushuk, M., Dufour, C. O., Dunne, J. P., Griffies, S. M., Hallberg, R., Harrison, M. J., Held, I. M., Jansen, M. F., John, J. G., Krasting, J. P., Langenhorst, A. R., Legg, S., Liang, Z., McHugh, C., Radhakrishnan, A., Reichl, B. G., Rosati, T., Samuels, B. L., Shao, A., Stouffer, R., Winton, M., Wittenberg, A. T., Xiang, B., Zadeh, N., and Zhang, R.: The GFDL Global Ocean and Sea Ice Model OM4.0: Model Description and Simulation Features, J. Adv. Model. Earth Sy., 2019MS001726, https://doi.org/10.1029/2019MS001726, accepted, 2019.

Alton, P. B.: Retrieval of seasonal Rubisco-limited photosynthetic capacity at global FLUXNET sites from hyperspectral satellite remote sensing: Impact on carbon modelling, Agr. Forest Meteorol., 232, 74-88, https://doi.org/10.1016/j.agrformet.2016.08.001, 2017.

Amante, C. and Eakins, B. W.: ETOPO1 1 Arc-Minute Global Relief Model: Procedures, Data Sources and Analysis, NOAA Technical Memorandum NESDIS NGDC-24, National Geophysical Data Center, NOAA, https://doi.org/10.7289/V5C8276M, 2009.

Andres, R. J., Boden, T. A., Bréon, F.-M., Ciais, P., Davis, S., Erickson, D., Gregg, J. S., Jacobson, A., Marland, G., Miller, J., Oda, T., Olivier, J. G. J., Raupach, M. R., Rayner, P., and Treanton, K.: A synthesis of carbon dioxide emissions from fossil-fuel combustion, Biogeosciences, 9, 1845-1871, https://doi.org/10.5194/bg-9-1845-2012, 2012.

Andres, R. J., Boden, T. A., and Higdon, D.: A new evaluation of the uncertainty associated with CDIAC estimates of fossil fuel carbon dioxide emission, Tellus Ser. B, 66, 23616, https://doi.org/10.3402/tellusb.v66.23616, 2014.

Andrew, R. M.: Global $\mathrm{CO}_{2}$ emissions from cement production, 1928-2017, Earth Syst. Sci. Data, 10, 2213-2239, https://doi.org/10.5194/essd-10-2213-2018, 2018.

Andrew, R. M.: Global $\mathrm{CO}_{2}$ emissions from cement production, 1928-2018, Earth Syst. Sci. Data, 11, 1675-1710, https://doi.org/10.5194/essd-11-1675-2019, 2019.

Andrew, R. M. and Peters, G. P.: A Multi-Region InputOutput Table Based on the Global Trade Analysis Project Database (Gtap-Mrio), Econ. Syst. Res., 25, 99-121, https://doi.org/10.1080/09535314.2012.761953, 2013. 
Archer, D., Eby, M., Brovkin, V., Ridgwell, A., Cao, L., Mikolajewicz, U., Caldeira, K., Matsumoto, K., Munhoven, G., Montenegro, A., and Tokos, K.: Atmospheric Lifetime of Fossil Fuel Carbon Dioxide, Annu. Rev. Earth Pl. Sc., 37, 117-134, https://doi.org/10.1146/annurev.earth.031208.100206, 2009.

Arneth, A., Sitch, S., Pongratz, J., Stocker, B. D., Ciais, P., Poulter, B., Bayer, A. D., Bondeau, A., Calle, L., Chini, L. P., Gasser, T., Fader, M., Friedlingstein, P., Kato, E., Li, W., Lindeskog, M., Nabel, J. E. M. S., Pugh, T. A. M., Robertson, E., Viovy, N., Yue, C., and Zaehle, S.: Historical carbon dioxide emissions caused by land-use changes are possibly larger than assumed, Nat. Geosci., 10, 79-84, https://doi.org/10.1038/ngeo2882, 2017.

Arora, V. K., Boer, G. J., Christian, J. R., Curry, C. L., Denman, K. L., Zahariev, K., Flato, G. M., Scinocca, J. F., Merryfield, W. J., and Lee, W. G.: The Effect of Terrestrial Photosynthesis Down Regulation on the Twentieth-Century Carbon Budget Simulated with the CCCma Earth System Model, J. Climate, 22, 6066-6088, https://doi.org/10.1175/2009jcli3037.1, 2009.

Aumont, O., Ethé, C., Tagliabue, A., Bopp, L., and Gehlen, M.: PISCES-v2: an ocean biogeochemical model for carbon and ecosystem studies, Geosci. Model Dev., 8, 2465-2513, https://doi.org/10.5194/gmd-8-2465-2015, 2015.

Avitabile, V., Herold, M., Heuvelink, G. B. M., Lewis, S. L., Phillips, O. L., Asner, G. P., Armston, J., Ashton, P. S., Banin, L., Bayol, N., Berry, N. J., Boeckx, P., de Jong, B. H. J., DeVries, B., Girardin, C. A. J., Kearsley, E., Lindsell, J. A., Lopez-Gonzalez, G., Lucas, R., Malhi, Y., Morel, A., Mitchard, E. T. A., Nagy, L., Qie, L., Quinones, M. J., Ryan, C. M., Ferry, S. J. W., Sunderland, T., Laurin, G. V., Gatti, R. C., Valentini, R., Verbeeck, H., Wijaya, A., and Willcock, S.: An integrated pan-tropical biomass map using multiple reference datasets, Glob. Chang. Biol., 22, 1406-1420, https://doi.org/10.1111/gcb.13139, 2016.

Baccini, A., Walker, W., Carvalho, L., Farina, M., Sulla-Menashe, D., and Houghton, R. A.: Tropical forests are a net carbon source based on aboveground measurements of gain and loss, Science, 358, 230-234, https://doi.org/10.1126/science.aam5962, 2017.

Bakker, D. C. E., Pfeil, B., Landa, C. S., Metzl, N., O’Brien, K. M., Olsen, A., Smith, K., Cosca, C., Harasawa, S., Jones, S. D., Nakaoka, S., Nojiri, Y., Schuster, U., Steinhoff, T., Sweeney, C., Takahashi, T., Tilbrook, B., Wada, C., Wanninkhof, R., Alin, S. R., Balestrini, C. F., Barbero, L., Bates, N. R., Bianchi, A. A., Bonou, F., Boutin, J., Bozec, Y., Burger, E. F., Cai, W.-J., Castle, R. D., Chen, L., Chierici, M., Currie, K., Evans, W., Featherstone, C., Feely, R. A., Fransson, A., Goyet, C., Greenwood, N., Gregor, L., Hankin, S., Hardman-Mountford, N. J., Harlay, J., Hauck, J., Hoppema, M., Humphreys, M. P., Hunt, C. W., Huss, B., Ibánhez, J. S. P., Johannessen, T., Keeling, R., Kitidis, V., Körtzinger, A., Kozyr, A., Krasakopoulou, E., Kuwata, A., Landschützer, P., Lauvset, S. K., Lefèvre, N., Lo Monaco, C., Manke, A., Mathis, J. T., Merlivat, L., Millero, F. J., Monteiro, P. M. S., Munro, D. R., Murata, A., Newberger, T., Omar, A. M., Ono, T., Paterson, K., Pearce, D., Pierrot, D., Robbins, L. L., Saito, S., Salisbury, J., Schlitzer, R., Schneider, B., Schweitzer, R., Sieger, R., Skjelvan, I., Sullivan, K. F., Sutherland, S. C., Sutton, A. J., Tadokoro, K., Telszewski, M., Tuma, M., van Heuven, S. M. A. C., Vandemark, D., Ward, B., Watson, A. J., and Xu, S.: A multidecade record of high-quality $f \mathrm{CO}_{2}$ data in version 3 of the Surface Ocean $\mathrm{CO}_{2}$ Atlas (SOCAT), Earth Syst. Sci. Data, 8, 383413, https://doi.org/10.5194/essd-8-383-2016, 2016.
Ballantyne, A. P., Alden, C. B., Miller, J. B., Tans, P. P., and White, J. W. C.: Increase in observed net carbon dioxide uptake by land and oceans during the past 50 years, Nature, 488, 70-72, https://doi.org/10.1038/nature11299, 2012.

Ballantyne, A. P., Andres, R., Houghton, R., Stocker, B. D., Wanninkhof, R., Anderegg, W., Cooper, L. A., DeGrandpre, M., Tans, P. P., Miller, J. B., Alden, C., and White, J. W. C.: Audit of the global carbon budget: estimate errors and their impact on uptake uncertainty, Biogeosciences, 12, 2565-2584, https://doi.org/10.5194/bg-12-2565-2015, 2015.

Bauer, J. E., Cai, W.-J., Raymond, P. A., Bianchi, T. S., Hopkinson, C. S., and Regnier, P. A. G.: The changing carbon cycle of the coastal ocean, Nature, 504, 61-70, https://doi.org/10.1038/nature12857, 2013.

Berthet, S., Séférian, R., Bricaud, C., Chevallier, M., Voldoire, A., and Ethé, C.: Evaluation of an Online Grid-Coarsening Algorithm in a Global Eddy-Admitting Ocean Biogeochemical Model, J. Adv. Model. Earth Sy., 11, 1759-1783, https://doi.org/10.1029/2019MS001644, 2019.

Best, M. J., Pryor, M., Clark, D. B., Rooney, G. G., Essery, R. L. H., Ménard, C. B., Edwards, J. M., Hendry, M. A., Porson, A., Gedney, N., Mercado, L. M., Sitch, S., Blyth, E., Boucher, O., Cox, P. M., Grimmond, C. S. B., and Harding, R. J.: The Joint UK Land Environment Simulator (JULES), model description Part 1: Energy and water fluxes, Geosci. Model Dev., 4, 677-699, https://doi.org/10.5194/gmd-4-677-2011, 2011.

BP: BP Statistical Review of World Energy June 2019, available at: https://www.bp.com/en/global/corporate/energy-economics/ statistical-review-of-world-energy.html, last access: June 2019.

Bruno, M. and Joos, F.: Terrestrial carbon storage during the past 200 years: A Monte Carlo Analysis of $\mathrm{CO}_{2}$ data from ice core and atmospheric measurements, Global Biogeochem. Cy., 11, 111-124, https://doi.org/10.1029/96GB03611, 1997.

Buitenhuis, E. T., Hashioka, T., and Le Quéré, C.: Combined constraints on global ocean primary production using observations and models, Global Biogeochem. Cy., 27, 847-858, https://doi.org/10.1002/gbc.20074, 2013.

Canadell, J. G., Le Quéré, C., Raupach, M. R., Field, C. B., Buitenhuis, E. T., Ciais, P., Conway, T. J., Gillett, N. P., Houghton, R. A., and Marland, G.: Contributions to accelerating atmospheric $\mathrm{CO}_{2}$ growth from economic activity, carbon intensity, and efficiency of natural sinks, P. Natl. Acad. Sci. USA, 104, 1886618870, https://doi.org/10.1073/pnas.0702737104, 2007.

Carbontracker Team: Compilation of near real time atmospheric carbon dioxide data provided by NOAA and EC; obspack_co2_1_NRT_v4.4.2_2019-06-10; NOAA Earth System Research Laboratory, Global Monitoring Division, https://doi.org/10.25925/20190610, 2019.

CEA: Central Electricity Authority (CEA): Daily Coal - Archive, Central Electricity Authority, available at: http://www.cea.nic.in/ dailyarchive.html, last access: 3 November 2019a.

CEA: Generation Overview Report September 2019: Summary All India, available at: http://cea.nic.in/reports/monthly/generation/ 2019/September/actual/actual.html, last access: 6 November 2019b.

CGADIP: Cooperative Global Atmospheric Data Integration Project: Multi-laboratory compilation of atmospheric carbon dioxide data for the period 1957-2017; 
obspack_co2_1_GLOBALVIEWplus_v4.2.2_2019-06-05, Earth System Research Laboratory, Global Monitoring Division, 2019. Chatfield, C.: The Holt-Winters Forecasting Procedure, Appl. Stat., 27, 264-279, https://doi.org/10.2307/2347162, 1978.

Chevallier, F., Fisher, M., Peylin, P., Serrar, S., Bousquet, P., Bréon, F.-M., Chédin, A., and Ciais, P.: Inferring $\mathrm{CO}_{2}$ sources and sinks from satellite observations: Method and application to TOVS data, J. Geophys. Res., 110, D24309, https://doi.org/10.1029/2005JD006390, 2005.

Ciais, P., Sabine, C., Govindasamy, B., Bopp, L., Brovkin, V., Canadell, J., Chhabra, A., DeFries, R., Galloway, J., Heimann, M., Jones, C., Le Quéré, C., Myneni, R., Piao, S., and Thornton, P.: Chapter 6: Carbon and Other Biogeochemical Cycles, in: Climate Change 2013 The Physical Science Basis, edited by: Stocker, T., Qin, D., and Platner, G.-K., Cambridge University Press, Cambridge, 2013.

CIL: Coal India Limited: Production and Offtake Performance of CIL and Subsidiary Companies, available at: https:// www.coalindia.in/en-us/performance/physical.aspx, last access: 1 November 2019.

Clark, D. B., Mercado, L. M., Sitch, S., Jones, C. D., Gedney, N., Best, M. J., Pryor, M., Rooney, G. G., Essery, R. L. H., Blyth, E., Boucher, O., Harding, R. J., Huntingford, C., and Cox, P. M.: The Joint UK Land Environment Simulator (JULES), model description - Part 2: Carbon fluxes and vegetation dynamics, Geosci. Model Dev., 4, 701-722, https://doi.org/10.5194/gmd-4701-2011, 2011.

Collier, N., Hoffman, F. M., Lawrence, D. M., Keppel-Aleks, G., Koven, C. D., Riley, W. J., Mu, M. Q., and Randerson, J. T.: The International Land Model Benchmarking (ILAMB) System: Design, Theory, and Implementation, J. Adv. Model. Earth Sy., 10, 2731-2754, https://doi.org/10.1029/2018ms001354, 2018.

Cox, P. M., Pearson, D., Booth, B. B., Friedlingstein, P., Huntingford, C., Jones, C. D., and Luke, C. M.: Sensitivity of tropical carbon to climate change constrained by carbon dioxide variability, Nature, 494, 341-344, https://doi.org/10.1038/nature11882, 2013.

Dai, A. and Trenberth, K. E.: Estimates of Freshwater Discharge from Continents: Latitudinal and Seasonal Variations, J. Hydrometeorol., 3, 660-687, https://doi.org/10.1175/15257541(2002)003<0660:EOFDFC>2.0.CO;2, 2002.

Davis, S. J. and Caldeira, K.: Consumption-based accounting of $\mathrm{CO}_{2}$ emissions, P. Natl. Acad. Sci. USA, 107, 5687-5692, https://doi.org/10.1073/pnas.0906974107, 2010.

Decharme, B., Delire, C., Minvielle, M., Colin, J., Vergnes, J., Alias, A., Saint-Martin, D., Séférian, R., Sénési, S., and Voldoire, A.: Recent Changes in the ISBA-CTRIP Land Surface System for Use in the CNRM-CM6 Climate Model and in Global OffLine Hydrological Applications, J. Adv. Model. Earth Sy., 11, 1207-1252, https://doi.org/10.1029/2018MS001545, 2019.

De Kauwe, M. G., Disney, M. I., Quaife, T., Lewis, P., and Williams, M.: An assessment of the MODIS collection 5 leaf area index product for a region of mixed coniferous forest, Remote Sens. Environ., 115, 767-780, https://doi.org/10.1016/j.rse.2010.11.004, 2011.

Delire, C., Séférian, R., Decharme, B., Alkama, R., Carrer, D., Joetzjer, E., Morel, X., and Rocher, M.: The global land carbon cycle simulated with ISBA, J. Adv. Model. Earth Sy., in review, 2019.
Denman, K. L., Brasseur, G., Chidthaisong, A., Ciais, P., Cox, P. M., Dickinson, R. E., Hauglustaine, D., Heinze, C., Holland, E., Jacob, D., Lohmann, U., Ramachandran, S., Leite da Silva Dias, P., Wofsy, S. C., and Zhang, X.: Couplings Between Changes in the Climate System and Biogeochemistry, in Climate Change 2007: The Physical Science Basis. Contribution of Working Group I to the Fourth Assessment Report of the Intergovernmental Panel on Climate Change, edited by: Solomon, S., Qin, D., Manning, M., Marquis, M., Averyt, K., Tignor, M. M. B., Miller, H. L., and Chen, Z. L., Cambridge University Press, Cambridge, UK and New York, USA, 499-587, 2007.

Denvil-Sommer, A., Gehlen, M., Vrac, M., and Mejia, C.: LSCEFFNN-v1: a two-step neural network model for the reconstruction of surface ocean $p \mathrm{CO}_{2}$ over the global ocean, Geosci. Model Dev., 12, 2091-2105, https://doi.org/10.5194/gmd-122091-2019, 2019.

DeVries, T.: The oceanic anthropogenic $\mathrm{CO}_{2}$ sink: Storage, air-sea fluxes, and transports over the industrial era, Global Biogeochem. Cy., 28, 631-647, https://doi.org/10.1002/2013gb004739, 2014.

DeVries, T., Holzer, M., and Primeau, F.: Recent increase in oceanic carbon uptake driven by weaker upper-ocean overturning, $\mathrm{Na}$ ture, 542, 215-218, https://doi.org/10.1038/nature21068, 2017.

DeVries, T., Le Quéré, C., Andrews, O., Berthet, S., Hauck, J., Ilyina, T., Landschützer, P., Lenton, A., Lima, I. D., Nowicki, M., Schwinger, J. and Séférian, R.: Decadal trends in the ocean carbon sink, P. Natl. Acad. Sci. USA, 116, 11646-11651, https://doi.org/10.1073/pnas.1900371116, 2019.

Dlugokencky, E. and Tans, P.: Trends in atmospheric carbon dioxide, National Oceanic \& Atmospheric Administration, Earth System Research Laboratory (NOAA/ESRL), available at: http:// www.esrl.noaa.gov/gmd/ccgg/trends/global.html, last access: 3 November 2019.

Doney, S. C., Lima, I., Feely, R. A., Glover, D. M., Lindsay, K., Mahowald, N., Moore, J. K., and Wanninkhof, R.: Mechanisms governing interannual variability in upper-ocean inorganic carbon system and air-sea $\mathrm{CO}_{2}$ fluxes: Physical climate and atmospheric dust, Deep.-Sea Res. Pt. II, 56, 640-655, https://doi.org/10.1016/j.dsr2.2008.12.006, 2009.

Duce, R. A., LaRoche, J., Altieri, K., Arrigo, K. R., Baker, A. R., Capone, D. G., Cornell, S., Dentener, F., Galloway, J., Ganeshram, R. S., Geider, R. J., Jickells, T., Kuypers, M. M., Langlois, R., Liss, P. S., Liu, S. M., Middelburg, J. J., Moore, C. M., Nickovic, S., Oschlies, A., Pedersen, T., Prospero, J., Schlitzer, R., Seitzinger, S., Sorensen, L. L., Uematsu, M., Ulloa, O., Voss, M., Ward, B., and Zamora, L.: Impacts of Atmospheric Anthropogenic Nitrogen on the Open Ocean, Science, 320, 893 897, https://doi.org/10.1126/science.1150369, 2008.

Dufour, C. O., Le Sommer, J., Gehlen, M., Orr, J. C., Molines, J. M., Simeon, J., and Barnier, B.: Eddy compensation and controls of the enhanced sea-to-air $\mathrm{CO}_{2}$ flux during positive phases of the Southern Annular Mode, Global Biogeochem. Cy., 27, 950-961, https://doi.org/10.1002/gbc.20090, 2013.

Durant, A. J., Le Quéré, C., Hope, C., and Friend, A. D.: Economic value of improved quantification in global sources and sinks of carbon dioxide, Philos. T. R. Soc. A, 369, 1967-1979, https://doi.org/10.1098/rsta.2011.0002, 2011.

Eakins, B. W. and Sharman, G. F.: Volumes of the World's Oceans from ETOPO1; NOAA National Geophysical Data Cen- 
ter, available at: http://www.ngdc.noaa.gov/mgg/global/etopo1_ ocean_volumes.html (last access: 27 September 2019), 2010.

EIA: U.S. Energy Information Administration, Short-Term Energy Outlook, available at: http://www.eia.gov/forecasts/steo/outlook. cfm, last access: 27 September 2019.

ENTSO-E: The European Network of Transmission System Operators Electricity Transparency Platform, available at: https: //transparency.entsoe.eu/, last access: 3 November 2019.

Erb, K. H., Kastner, T., Luyssaert, S., Houghton, R. A., Kuemmerle, T., Olofsson, P., and Haberl, H.: COMMENTARY: Bias in the attribution of forest carbon sinks, Nat. Clim. Change, 3, 854856, https://doi.org/10.1038/nclimate2004, 2013.

Etheridge, D. M., Steele, L. P., Langenfelds, R. L., Francey, R. J., Barnola, J. M., and Morgan, V. I.: Natural and anthropogenic changes in atmospheric $\mathrm{CO}_{2}$ over the last 1000 years from air in Antarctic ice and firn, J. Geophys. Res., 101, 4115-4128, https://doi.org/10.1029/95jd03410, 1996.

Eurostat: Supply and transformation of solid fuels - monthly data (nrg_101m), available at: https://ec.europa.eu/eurostat/data/ database, last access: 5 November 2019.

FAO: Food and Agriculture Organization of the United Nations: Global Forest Resources Assessment 2015, available at: http://www.fao.org/forest-resources-assessment/ past-assessments/fra-2015/en/ (last access: 27 September 2019), Rome, Italy, 2015.

FAOSTAT: Food and Agriculture Organization Statistics Division, available at: http://faostat.fao.org/ (last access: 27 September 2019), 2015.

Francey, R. J., Trudinger, C. M., van der Schoot, M., Law, R. M., Krummel, P. B., Langenfelds, R. L., Steele, L. P., Allison, C. E., Stavert, A. R., Andres, R. J., and Rödenbeck, C.: Reply to "Anthropogenic $\mathrm{CO}_{2}$ emissions", Nat. Clim. Change, 3, 604, https://doi.org/10.1038/nclimate1925, 2013.

Friedlingstein, P., Houghton, R. A., Marland, G., Hackler, J., Boden, T. A., Conway, T. J., Canadell, J. G., Raupach, M. R., Ciais, P., and Le Quéré, C.: Update on $\mathrm{CO}_{2}$ emissions, Nat. Geosci., 3, 811-812, https://doi.org/10.1038/ngeo1022, 2010.

Friedlingstein, P., Andrew, R. M., Rogelj, J., Peters, G. P., Canadell, J. G., Knutti, R., Luderer, G., Raupach, M. R., Schaeffer, M., van Vuuren, D. P., and Le Quéré, C.: Persistent growth of $\mathrm{CO}_{2}$ emissions and implications for reaching climate targets, Nat. Geosci., 7, 709-715, https://doi.org/10.1038/Ngeo2248, 2014.

Friedlingstein, P., Jones, M. W., O'Sullivan, M., Andrew, R. M., Hauck, J., Peters, G. P., Peters, W., Pongratz, J., Sitch, S., Le Quéré, C., Bakker, D. C. E., Canadell, J. G., Ciais, P., Jackson, R., Anthoni, P., Barbero, L., Bastos, A., Bastrikov, V., Becker, M., Bopp, L., Buitenhuis, E., Chandra, N., Chevallier, F., Chini, L. P., Currie, K. I., Feely, R. A., Gehlen, M., Gilfillan, D., Gkritzalis, T., Goll, D. S., Gruber, N., Gutekunst, S., Harris, I., Haverd, V., Houghton, R. A., Hurtt, G., Ilyina, T., Jain, A. K., Joetzjer, E., Kaplan, J. O., Kato, E., Goldewijk, K. K., Korsbakken, J. I., Landschützer, P., Lauvset, S. K., Lefèvre, N., Lenton, A., Lienert, S., Lombardozzi, D., Marland, G., McGuire, P. C., Melton, J. R., Metzl, N., Munro, D. R., Nabel, J. E. M. S., Nakaoka, S.-I., Neill, C., Omar, A. M., Ono, T., Peregon, A., Pierrot, D., Poulter, B., Rehder, G., Resplandy, L., Robertson, E., Rödenbeck, C., Séférian, R., Schwinger, J., Smith, N., Tans, P. P., Tian, H., Tilbrook, B., Tubiello, F. N., van der Werf, G. R., Wiltshire, A. J., and Zaehle, S.: Supplemental data of the Global Carbon Budget
2019: ICOS-ERIC Carbon Portal, https://doi.org/10.18160/gcp2019, 2019.

Gasser, T., Ciais, P., Boucher, O., Quilcaille, Y., Tortora, M., Bopp, L., and Hauglustaine, D.: The compact Earth system model OSCAR v2.2: description and first results, Geosci. Model Dev., 10, 271-319, https://doi.org/10.5194/gmd-10-271-2017, 2017.

Gaubert, B., Stephens, B. B., Basu, S., Chevallier, F., Deng, F., Kort, E. A., Patra, P. K., Peters, W., Rödenbeck, C., Saeki, T., Schimel, D., Van der Laan-Luijkx, I., Wofsy, S., and Yin, Y.: Global atmospheric $\mathrm{CO}_{2}$ inverse models converging on neutral tropical land exchange, but disagreeing on fossil fuel and atmospheric growth rate, Biogeosciences, 16, 117-134, https://doi.org/10.5194/bg16-117-2019, 2019.

GCP: The Global Carbon Budget 2007, available at: http://www. globalcarbonproject.org/carbonbudget/archive.htm (last access: 7 November 2016), 2007.

General Administration of Customs of the People's Republic of China: Monthly statistics reports, available at: http://www. customs.gov.cn/customs/302249/302274/302277/index.html, last access: 1 November 2019.

Giglio, L., Schroeder, W., and Justice, C. O.: The collection 6 MODIS active fire detection algorithm and fire products, Remote Sens. Environ., 178, 31-41, https://doi.org/10.1016/j.rse.2016.02.054, 2016.

Gilfillan, D., Marland, G., Boden, T., and Andres, R.: Global, Regional, and National Fossil-Fuel $\mathrm{CO}_{2}$ Emissions, available at: https://energy.appstate.edu/CDIAC, last access: 27 September 2019.

Gitz, V. and Ciais, P.: Amplifying effects of land-use change on future atmospheric $\mathrm{CO}_{2}$ levels, Global Biogeochem. Cy., 17, 1024, https://doi.org/10.1029/2002GB001963, 2003.

Goldewijk, K. K., Dekker, S. C., and van Zanden, J. L.: Percapita estimations of long-term historical land use and the consequences for global change research, J. Land Use Sci., 12, 313337, https://doi.org/10.1080/1747423x.2017.1354938, 2017.

Goll, D. S., Winkler, A. J., Raddatz, T., Dong, N., Prentice, I. C., Ciais, P., and Brovkin, V.: Carbon-nitrogen interactions in idealized simulations with JSBACH (version 3.10), Geosci. Model Dev., 10, 2009-2030, https://doi.org/10.5194/gmd-102009-2017, 2017.

Goll, D. S., Joetzjer, E., Huang, M., and Ciais, P.: Low Phosphorus Availability Decreases Susceptibility of Tropical Primary Productivity to Droughts, Geophys. Res. Lett., 45, 8231-8240, https://doi.org/10.1029/2018GL077736, 2018.

Gray, A. R., Johnson, K. S., Bushinsky, S. M., Riser, S. C., Russell, J. L., Talley, L. D., Wanninkhof, R., Williams, N. L., and Sarmiento, J. L.: Autonomous Biogeochemical Floats Detect Significant Carbon Dioxide Outgassing in the HighLatitude Southern Ocean, Geophys. Res. Lett., 45, 9049-9057, https://doi.org/10.1029/2018GL078013, 2018.

Gregg, J. S., Andres, R. J. and Marland, G.: China: Emissions pattern of the world leader in $\mathrm{CO}_{2}$ emissions from fossil fuel consumption and cement production, Geophys. Res. Lett., 35, L08806, https://doi.org/10.1029/2007g1032887, 2008.

Gruber, N., Clement, D., Carter, B. R., Feely, R. A., van Heuven, S., Hoppema, M., Ishii, M., Key, R. M., Kozyr, A., Lauvset, S. K., Lo Monaco, C., Mathis, J. T., Murata, A., Olsen, A., Perez, F. F., Sabine, C. L., Tanhua, T., and Wanninkhof, R.: The oceanic 
sink for anthropogenic $\mathrm{CO}_{2}$ from 1994 to 2007, Science, 363, 1193-1199, https://doi.org/10.1126/science.aau5153, 2019.

Hansen, M. C., Potapov, P. V., Moore, R., Hancher, M., Turubanova, S. A., Tyukavina, A., Thau, D., Stehman, S. V., Goetz, S. J., Loveland, T. R., Kommareddy, A., Egorov, A., Chini, L., Justice, C. O., and Townshend, J. R. G.: High-Resolution Global Maps of 21st-Century Forest Cover Change, Science, 342, 850-853, https://doi.org/10.1126/science.1244693, 2013.

Hansis, E., Davis, S. J., and Pongratz, J.: Relevance of methodological choices for accounting of land use change carbon fluxes, Global Biogeochem. Cy., 29, 1230-1246, https://doi.org/10.1002/2014GB004997, 2015.

Hauck, J., Lenton, A., Langlais, C., and Matear, R.: The Fate of Carbon and Nutrients Exported Out of the Southern Ocean, Global Biogeochem. Cy., 32, 1556-1573, https://doi.org/10.1029/2018GB005977, 2018.

Harris, I., Jones, P. D., Osborn, T. J., and Lister, D. H.: Updated high-resolution grids of monthly climatic observations - the CRU TS3.10 Dataset, Int. J. Climatol., 34, 623-642, https://doi.org/10.1002/joc.3711, 2014.

Haverd, V., Smith, B., Nieradzik, L., Briggs, P. R., Woodgate, W., Trudinger, C. M., Canadell, J. G., and Cuntz, M.: A new version of the CABLE land surface model (Subversion revision r4601) incorporating land use and land cover change, woody vegetation demography, and a novel optimisation-based approach to plant coordination of photosynthesis, Geosci. Model Dev., 11, 29953026, https://doi.org/10.5194/gmd-11-2995-2018, 2018.

Hertwich, E. G. and Peters, G. P.: Carbon footprint of nations: a global, trade-linked analysis, Environ. Sci Technol., 43, 64146420, https://doi.org/10.1021/es803496a, 2009.

Hooijer, A., Page, S., Canadell, J. G., Silvius, M., Kwadijk, J., Wösten, H., and Jauhiainen, J.: Current and future $\mathrm{CO}_{2}$ emissions from drained peatlands in Southeast Asia, Biogeosciences, 7, 1505-1514, https://doi.org/10.5194/bg-7-1505-2010, 2010.

Houghton, R. A.: Revised estimates of the annual net flux of carbon to the atmosphere from changes in land use and land management 1850-2000, Tellus Ser. B, 55, 378-390, https://doi.org/10.1034/j.1600-0889.2003.01450.x, 2003.

Houghton, R. A. and Nassikas, A. A.: Global and regional fluxes of carbon from land use and land cover change 1850-2015, Global Biogeochem. Cy., 31, 456-472, https://doi.org/10.1002/2016gb005546, 2017.

Houghton, R. A., House, J. I., Pongratz, J., van der Werf, G. R., DeFries, R. S., Hansen, M. C., Le Quéré, C., and Ramankutty, N.: Carbon emissions from land use and land-cover change, Biogeosciences, 9, 5125-5142, https://doi.org/10.5194/bg-9-51252012, 2012.

Houweling, S., Baker, D., Basu, S., Boesch, H., Butz, A., Chevallier, F., Deng, F., Dlugokencky, E. J., Feng, L., Ganshin, A., Hasekamp, O., Jones, D., Maksyutov, S., Marshall, J., Oda, T., O’Dell, C. W., Oshchepkov, S., Palmer, P. I., Peylin, P., Poussi, Z., Reum, F., Takagi, H., Yoshida, Y., and Zhuravlev, R.: An intercomparison of inverse models for estimating sources and sinks of $\mathrm{CO}_{2}$ using GOSAT measurements, J. Geophys. Res., 120, 5253-5266, https://doi.org/10.1002/2014jd022962, 2015.

Hugelius, G., Bockheim, J. G., Camill, P., Elberling, B., Grosse, G., Harden, J. W., Johnson, K., Jorgenson, T., Koven, C. D., Kuhry, P., Michaelson, G., Mishra, U., Palmtag, J., Ping, C.-L., O'Donnell, J., Schirrmeister, L., Schuur, E. A. G., Sheng, Y.,
Smith, L. C., Strauss, J., and Yu, Z.: A new data set for estimating organic carbon storage to $3 \mathrm{~m}$ depth in soils of the northern circumpolar permafrost region, Earth Syst. Sci. Data, 5, 393-402, https://doi.org/10.5194/essd-5-393-2013, 2013.

Huntzinger, D. N., Michalak, A. M., Schwalm, C., Ciais, P., King, A. W., Fang, Y., Schaefer, K., Wei, Y., Cook, R. B., Fisher, J. B., Hayes, D., Huang, M., Ito, A., Jain, A. K., Lei, H., Lu, C., Maignan, F., Mao, J., Parazoo, N., Peng, S., Poulter, B., Ricciuto, D., Shi, X., Tian, H., Wang, W., Zeng, N., and Zhao, F.: Uncertainty in the response of terrestrial carbon sink to environmental drivers undermines carbon-climate feedback predictions, Sci. Rep., 7, 4765, https://doi.org/10.1038/s41598-017-03818-2, 2017.

Hurtt, G., Chini, L., Sahajpal, R., Frolking, S., Calvin, K., Fujimori, S., Klein Goldewijk, K., Hasegawa, T., Havlik, P., and Heinemann, A.: Harmonization of global land-use change and management for the period 850-2100, Geosci. Model Dev. Discuss., in preparation, 2019.

Hurtt, G. C., Chini, L. P., Frolking, S., Betts, R. A., Feddema, J., Fischer, G., Fisk, J. P., Hibbard, K., Houghton, R. A., Janetos, A., Jones, C. D., Kindermann, G., Kinoshita, T., Goldewijk, K. K., Riahi, K., Shevliakova, E., Smith, S., Stehfest, E., Thomson, A., Thornton, P., van Vuuren, D. P., and Wang, Y. P.: Harmonization of land-use scenarios for the period 1500-2100: 600 years of global gridded annual land-use transitions, wood harvest, and resulting secondary lands, Climate Change, 109, 117161, https://doi.org/10.1007/s10584-011-0153-2, 2011.

IEA: World Energy Statistics: 2018 Edition, available at: http:// www.iea.org (last access: 28 November 2019), 2018.

IEA/OECD: International Energy Agency/Organisation for Economic Cooperation and Development: $\mathrm{CO}_{2}$ emissions from fuel combustion, available at: https://webstore.iea.org/ co2-emissions-from-fuel-combustion-2018-highlights (last access: 28 November 2019), Paris, 2018.

IMD: India Meteorological Department, Ministry of Earth Sciences (IMD): 2019 Southwest Monsoon Season Rainfall and IMD's Long Range Forecasts, available at: http://www.imd.gov. in/pages/press_release.php, last access: 6 November 2019.

IMF: World Economic Outlook Update, July 2019: Still Sluggish Global Growth, available at: http://www.imf.org, last access: 16 October 2019a.

IMF: World Economic Outlook: Global Manufacturing Downturn, Rising Trade Barriers. International Monetary Fund, available at: http://www.imf.org, last access: 30 October 2019b.

IPCC: 2006 IPCC Guidelines for National Greenhouse Gas Inventories, Prepared by the National Greenhouse Gas Inventories Programme, edited by: Eggleston, S., Buendia, L., Miwa, K., Ngara, T., and Tanabe, K., Intergovernmental Panel on Climate Change, Institute for Global Environmental Strategies, Japan, 2006.

Ito, A. and Inatomi, M.: Use of a process-based model for assessing the methane budgets of global terrestrial ecosystems and evaluation of uncertainty, Biogeosciences, 9, 759-773, https://doi.org/10.5194/bg-9-759-2012, 2012.

Jackson, R. B., Canadell, J. G., Le Quéré, C., Andrew, R. M., Korsbakken, J. I., Peters, G. P., and Nakicenovic, N.: Reaching peak emissions, Nat. Clim. Change, 6, 7-10, https://doi.org/10.1038/nclimate2892, 2016.

Jackson, R. B., Le Quéré, C., Andrew, R. M., Canadell, J. G., Korsbakken, J. I., Liu, Z., Peters, G. P., and Zheng, B.: Global en- 
ergy growth is outpacing decarbonization, Environ. Res. Lett., 13, 120401, https://doi.org/10.1088/1748-9326/aaf303, 2018.

Jacobson, A. R., Mikaloff Fletcher, S. E., Gruber, N., Sarmiento, J. L. and Gloor, M.: A joint atmosphereocean inversion for surface fluxes of carbon dioxide: 2 . Regional results, Global Biogeochem. Cy., 21, GB1020, https://doi.org/10.1029/2006GB002703, 2007.

JODI: Joint Organisations Data Initiative, available at: https://www. jodidata.org, last access: 3 November 2019.

Joetzjer, E., Delire, C., Douville, H., Ciais, P., Decharme, B., Carrer, D., Verbeeck, H., De Weirdt, M., and Bonal, D.: Improving the ISBACC land surface model simulation of water and carbon fluxes and stocks over the Amazon forest, Geosci. Model Dev., 8, 1709-1727, https://doi.org/10.5194/gmd-8-1709-2015, 2015.

Jones, M. W., Le Quéré, C., Andrew, R., Peters, G., Chevallier, F., Ciais, P., Janssens-Maenhout, G., van der Laan-Luijkx, I., Patra, P. Peters, W., and Rödenbeck, C.: Gridded fossil $\mathrm{CO}_{2}$ emissions and related $\mathrm{O}_{2}$ combustion consistent with national inventories 1959-2018, in preparation, 2019.

Joos, F. and Spahni, R.: Rates of change in natural and anthropogenic radiative forcing over the past 20,000 years, P. Natl. Acad. Sci. USA, 105, 1425-1430, https://doi.org/10.1073/pnas.0707386105, 2008.

Jung, M., Reichstein, M., Ciais, P., Seneviratne, S. I., Sheffield, J., Goulden, M. L., Bonan, G., Cescatti, A., Chen, J., de Jeu, R., Dolman, A. J., Eugster, W., Gerten, D., Gianelle, D., Gobron, N., Heinke, J., Kimball, J., Law, B. E., Montagnani, L., Mu, Q., Mueller, B., Oleson, K., Papale, D., Richardson, A. D., Roupsard, O., Running, S., Tomelleri, E., Viovy, N., Weber, U., Williams, C., Wood, E., Zaehle, S., and Zhang, K.: Recent decline in the global land evapotranspiration trend due to limited moisture supply, Nature, 467, 951-954, https://doi.org/10.1038/nature09396, 2010.

Kato, E., Kinoshita, T., Ito, A., Kawamiya, M., and Yamagata, Y.: Evaluation of spatially explicit emission scenario of land-use change and biomass burning using a processbased biogeochemical model, J. Land Use Sci., 8, 104-122, https://doi.org/10.1080/1747423x.2011.628705, 2013.

Keeling, C. D., Bacastow, R. B., Bainbridge, A. E., Ekdahl, C. A., Guenther, P. R., Waterman, L. S., and Chin, J. F. S.: Atmospheric Carbon-Dioxide Variations at Mauna-Loa Observatory, Hawaii, Tellus, 28, 538-551, https://doi.org/10.1111/j.21533490.1976.tb00701.x, 1976.

Keeling, R. F. and Manning, A. C.: Studies of Recent Changes in Atmospheric $\mathrm{O}_{2}$ Content, in Treatise on Geochemistry, vol. 5, edited by: Holland, H. D. and Turekian, K. K., Elsevier, Oxford, 385-404, 2014.

Khatiwala, S., Primeau, F., and Hall, T.: Reconstruction of the history of anthropogenic $\mathrm{CO}_{2}$ concentrations in the ocean, Nature, 462, 346-U110, https://doi.org/10.1038/nature08526, 2009.

Khatiwala, S., Tanhua, T., Mikaloff Fletcher, S., Gerber, M., Doney, S. C., Graven, H. D., Gruber, N., McKinley, G. A., Murata, A., Ríos, A. F., and Sabine, C. L.: Global ocean storage of anthropogenic carbon, Biogeosciences, 10, 2169-2191, https://doi.org/10.5194/bg-10-2169-2013, 2013.

Kirschke, S., Bousquet, P., Ciais, P., Saunois, M., Canadell, J. G., Dlugokencky, E. J., Bergamaschi, P., Bergmann, D., Blake, D. R., Bruhwiler, L., Cameron-Smith, P., Castaldi, S., Chevallier, F., Feng, L., Fraser, A., Heimann, M., Hodson, E. L., Houwel- ing, S., Josse, B., Fraser, P. J., Krummel, P. B., Lamarque, J. F., Langenfelds, R. L., Le Quéré, C., Naik, V., O’Doherty, S., Palmer, P. I., Pison, I., Plummer, D., Poulter, B., Prinn, R. G., Rigby, M., Ringeval, B., Santini, M., Schmidt, M., Shindell, D. T., Simpson, I. J., Spahni, R., Steele, L. P., Strode, S. A., Sudo, K., Szopa, S., van der Werf, G. R., Voulgarakis, A., van Weele, M., Weiss, R. F., Williams, J. E., and Zeng, G.: Three decades of global methane sources and sinks, Nat. Geosci., 6, 813-823, https://doi.org/10.1038/Ngeo1955, 2013.

Klein Goldewijk, K., Beusen, A., Doelman, J., and Stehfest, E.: Anthropogenic land use estimates for the Holocene - HYDE 3.2, Earth Syst. Sci. Data, 9, 927-953, https://doi.org/10.5194/essd9-927-2017, 2017.

Kobayashi, S., Ota, Y., Harada, Y., Ebita, A., Moriya, M., Onoda, H., Onogi, K., Kamahori, H., Kobayashi, C., Endo, H., Miyaoka, K., and Takahashi, K.: The JRA-55 Reanalysis: General Specifications and Basic Characteristics, J. Meteorol. Soc. Jpn., 93, 5-48, https://doi.org/10.2151/jmsj.2015-001, 2015.

Korsbakken, J. I., Peters, G. P., and Andrew, R. M.: Uncertainties around reductions in China's coal use and $\mathrm{CO}_{2}$ emissions, Nat. Clim. Change, 6, 687-690, https://doi.org/10.1038/nclimate2963, 2016.

Krinner, G., Viovy, N., de Noblet-Ducoudré, N., Ogée, J., Polcher, J., Friedlingstein, P., Ciais, P., Sitch, S., and Prentice, I. C.: A dynamic global vegetation model for studies of the coupled atmosphere-biosphere system, Global Biogeochem. Cy., 19, 133, https://doi.org/10.1029/2003GB002199, 2005.

Landschützer, P., Gruber, N., Bakker, D. C. E., and Schuster, U.: Recent variability of the global ocean carbon sink, Global Biogeochem. Cy., 28, 927-949, https://doi.org/10.1002/2014GB004853, 2014.

Landschützer, P., Gruber, N., Haumann, F. A., Rödenbeck, C., Bakker, D. C. E., van Heuven, S., Hoppema, M., Metzl, N., Sweeney, C., Takahashi, T., Tilbrook, B., and Wanninkhof, R.: The reinvigoration of the Southern Ocean carbon sink, Science, 349, 1221-1224, https://doi.org/10.1126/science.aab2620, 2015.

Landschützer, P., Gruber, N., and Bakker, D. C. E.: Decadal variations and trends of the global ocean carbon sink, Global Biogeochem. Cy., 30, 1396-1417, https://doi.org/10.1002/2015gb005359, 2016.

Landschützer, P., Gruber, N., Bakker, D. C. E., Stemmler, I., and Six, K. D.: Strengthening seasonal marine $\mathrm{CO}_{2}$ variations due to increasing atmospheric $\mathrm{CO}_{2}$, Nat. Clim. Change, 8, 146-150, https://doi.org/10.1038/s41558-017-0057-x, 2018.

Lasslop, G., Reichstein, M., Papale, D., Richardson, A. D., Arneth, A., Barr, A., Stoy, P., and Wohlfahrt, G.: Separation of net ecosystem exchange into assimilation and respiration using a light response curve approach: critical issues and global evaluation, Glob. Change Biol., 16, 187-208, https://doi.org/10.1111/j.1365-2486.2009.02041.x, 2010.

Law, R. M., Ziehn, T., Matear, R. J., Lenton, A., Chamberlain, M. A., Stevens, L. E., Wang, Y.-P., Srbinovsky, J., Bi, D., Yan, H., and Vohralik, P. F.: The carbon cycle in the Australian Community Climate and Earth System Simulator (ACCESS-ESM1) Part 1: Model description and pre-industrial simulation, Geosci. Model Dev., 10, 2567-2590, https://doi.org/10.5194/gmd-102567-2017, 2017.

Lawrence, D. M., Fisher, R. A., Koven, C. D., Oleson, K. W., Swenson, S. C., Bonan, G., Collier, N., Ghimire, B., Kamp- 
enhout, L., Kennedy, D., Kluzek, E., Lawrence, P. J., Li, F., Li, H., Lombardozzi, D., Riley, W. J., Sacks, W. J., Shi, M., Vertenstein, M., Wieder, W. R., Xu, C., Ali, A. A., Badger, A. M., Bisht, G., Broeke, M., Brunke, M. A., Burns, S. P., Buzan, J., Clark, M., Craig, A., Dahlin, K., Drewniak, B., Fisher, J. B., Flanner, M., Fox, A. M., Gentine, P., Hoffman, F., KeppelAleks, G., Knox, R., Kumar, S., Lenaerts, J., Leung, L. R., Lipscomb, W. H., Lu, Y., Pandey, A., Pelletier, J. D., Perket, J., Randerson, J. T., Ricciuto, D. M., Sanderson, B. M., Slater, A., Subin, Z. M., Tang, J., Thomas, R. Q., Val Martin, M., and Zeng, X.: The Community Land Model version 5: Description of new features, benchmarking, and impact of forcing uncertainty, J. Adv. Model. Earth Sy., 2018MS001583, https://doi.org/10.1029/2018MS001583, accepted, 2019.

Lee, T. J. and Pielke, R. A.: Estimating the Soil Surface Specific Humidity, J. Appl. Meteorol., 31, 480-484, https://doi.org/10.1175/15200450(1992)031<0480:ETSSSH>2.0.CO;2, 1992.

Le Quéré, C., Raupach, M. R., Canadell, J. G., Marland, G., Bopp, L., Ciais, P., Conway, T. J., Doney, S. C., Feely, R. A., Foster, P., Friedlingstein, P., Gurney, K., Houghton, R. A., House, J. I., Huntingford, C., Levy, P. E., Lomas, M. R., Majkut, J., Metzl, N., Ometto, J. P., Peters, G. P., Prentice, I. C., Randerson, J. T., Running, S. W., Sarmiento, J. L., Schuster, U., Sitch, S., Takahashi, T., Viovy, N., Van Der Werf, G. R., and Woodward, F. I.: Trends in the sources and sinks of carbon dioxide, Nat. Geosci., 2, 831-836, https://doi.org/10.1038/ngeo689, 2009.

Le Quéré, C., Andres, R. J., Boden, T., Conway, T., Houghton, R. A., House, J. I., Marland, G., Peters, G. P., van der Werf, G. R., Ahlström, A., Andrew, R. M., Bopp, L., Canadell, J. G., Ciais, P., Doney, S. C., Enright, C., Friedlingstein, P., Huntingford, C., Jain, A. K., Jourdain, C., Kato, E., Keeling, R. F., Klein Goldewijk, K., Levis, S., Levy, P., Lomas, M., Poulter, B., Raupach, M. R., Schwinger, J., Sitch, S., Stocker, B. D., Viovy, N., Zaehle, S., and Zeng, N.: The global carbon budget 1959-2011, Earth Syst. Sci. Data, 5, 165-185, https://doi.org/10.5194/essd-5-1652013, 2013.

Le Quéré, C., Peters, G. P., Andres, R. J., Andrew, R. M., Boden, T. A., Ciais, P., Friedlingstein, P., Houghton, R. A., Marland, G., Moriarty, R., Sitch, S., Tans, P., Arneth, A., Arvanitis, A., Bakker, D. C. E., Bopp, L., Canadell, J. G., Chini, L. P., Doney, S. C., Harper, A., Harris, I., House, J. I., Jain, A. K., Jones, S. D., Kato, E., Keeling, R. F., Klein Goldewijk, K., Körtzinger, A., Koven, C., Lefèvre, N., Maignan, F., Omar, A., Ono, T., Park, G.-H., Pfeil, B., Poulter, B., Raupach, M. R., Regnier, P., Rödenbeck, C., Saito, S., Schwinger, J., Segschneider, J., Stocker, B. D., Takahashi, T., Tilbrook, B., van Heuven, S., Viovy, N., Wanninkhof, R., Wiltshire, A., and Zaehle, S.: Global carbon budget 2013, Earth Syst. Sci. Data, 6, 235-263, https://doi.org/10.5194/essd6-235-2014, 2014.

Le Quéré, C., Moriarty, R., Andrew, R. M., Peters, G. P., Ciais, P., Friedlingstein, P., Jones, S. D., Sitch, S., Tans, P., Arneth, A., Boden, T. A., Bopp, L., Bozec, Y., Canadell, J. G., Chini, L. P., Chevallier, F., Cosca, C. E., Harris, I., Hoppema, M., Houghton, R. A., House, J. I., Jain, A. K., Johannessen, T., Kato, E., Keeling, R. F., Kitidis, V., Klein Goldewijk, K., Koven, C., Landa, C. S., Landschützer, P., Lenton, A., Lima, I. D., Marland, G., Mathis, J. T., Metzl, N., Nojiri, Y., Olsen, A., Ono, T., Peng, S., Peters, W., Pfeil, B., Poulter, B., Raupach, M. R., Regnier, P., Rö- denbeck, C., Saito, S., Salisbury, J. E., Schuster, U., Schwinger, J., Séférian, R., Segschneider, J., Steinhoff, T., Stocker, B. D., Sutton, A. J., Takahashi, T., Tilbrook, B., van der Werf, G. R., Viovy, N., Wang, Y.-P., Wanninkhof, R., Wiltshire, A., and Zeng, N.: Global carbon budget 2014, Earth Syst. Sci. Data, 7, 47-85, https://doi.org/10.5194/essd-7-47-2015, 2015a.

Le Quéré, C., Moriarty, R., Andrew, R. M., Canadell, J. G., Sitch, S., Korsbakken, J. I., Friedlingstein, P., Peters, G. P., Andres, R. J., Boden, T. A., Houghton, R. A., House, J. I., Keeling, R. F., Tans, P., Arneth, A., Bakker, D. C. E., Barbero, L., Bopp, L., Chang, J., Chevallier, F., Chini, L. P., Ciais, P., Fader, M., Feely, R. A., Gkritzalis, T., Harris, I., Hauck, J., Ilyina, T., Jain, A. K., Kato, E., Kitidis, V., Klein Goldewijk, K., Koven, C., Landschützer, P., Lauvset, S. K., Lefèvre, N., Lenton, A., Lima, I. D., Metzl, N., Millero, F., Munro, D. R., Murata, A., Nabel, J. E. M. S., Nakaoka, S., Nojiri, Y., O’Brien, K., Olsen, A., Ono, T., Pérez, F. F., Pfeil, B., Pierrot, D., Poulter, B., Rehder, G., Rödenbeck, C., Saito, S., Schuster, U., Schwinger, J., Séférian, R., Steinhoff, T., Stocker, B. D., Sutton, A. J., Takahashi, T., Tilbrook, B., van der Laan-Luijkx, I. T., van der Werf, G. R., van Heuven, S., Vandemark, D., Viovy, N., Wiltshire, A., Zaehle, S., and Zeng, N.: Global Carbon Budget 2015, Earth Syst. Sci. Data, 7, 349-396, https://doi.org/10.5194/essd-7-349-2015, 2015b.

Le Quéré, C., Andrew, R. M., Canadell, J. G., Sitch, S., Korsbakken, J. I., Peters, G. P., Manning, A. C., Boden, T. A., Tans, P. P., Houghton, R. A., Keeling, R. F., Alin, S., Andrews, O. D., Anthoni, P., Barbero, L., Bopp, L., Chevallier, F., Chini, L. P., Ciais, P., Currie, K., Delire, C., Doney, S. C., Friedlingstein, P., Gkritzalis, T., Harris, I., Hauck, J., Haverd, V., Hoppema, M., Klein Goldewijk, K., Jain, A. K., Kato, E., Körtzinger, A., Landschützer, P., Lefèvre, N., Lenton, A., Lienert, S., Lombardozzi, D., Melton, J. R., Metzl, N., Millero, F., Monteiro, P. M. S., Munro, D. R., Nabel, J. E. M. S., Nakaoka, S., O’Brien, K., Olsen, A., Omar, A. M., Ono, T., Pierrot, D., Poulter, B., Rödenbeck, C., Salisbury, J., Schuster, U., Schwinger, J., Séférian, R., Skjelvan, I., Stocker, B. D., Sutton, A. J., Takahashi, T., Tian, H., Tilbrook, B., van der Laan-Luijkx, I. T., van der Werf, G. R., Viovy, N., Walker, A. P., Wiltshire, A. J., and Zaehle, S.: Global Carbon Budget 2016, Earth Syst. Sci. Data, 8, 605-649, https://doi.org/10.5194/essd-8-605-2016, 2016.

Le Quéré, C., Andrew, R. M., Friedlingstein, P., Sitch, S., Pongratz, J., Manning, A. C., Korsbakken, J. I., Peters, G. P., Canadell, J. G., Jackson, R. B., Boden, T. A., Tans, P. P., Andrews, O. D., Arora, V. K., Bakker, D. C. E., Barbero, L., Becker, M., Betts, R. A., Bopp, L., Chevallier, F., Chini, L. P., Ciais, P., Cosca, C. E., Cross, J., Currie, K., Gasser, T., Harris, I., Hauck, J., Haverd, V., Houghton, R. A., Hunt, C. W., Hurtt, G., Ilyina, T., Jain, A. K., Kato, E., Kautz, M., Keeling, R. F., Klein Goldewijk, K., Körtzinger, A., Landschützer, P., Lefèvre, N., Lenton, A., Lienert, S., Lima, I., Lombardozzi, D., Metzl, N., Millero, F., Monteiro, P. M. S., Munro, D. R., Nabel, J. E. M. S., Nakaoka, S., Nojiri, Y., Padin, X. A., Peregon, A., Pfeil, B., Pierrot, D., Poulter, B., Rehder, G., Reimer, J., Rödenbeck, C., Schwinger, J., Séférian, R., Skjelvan, I., Stocker, B. D., Tian, H., Tilbrook, B., Tubiello, F. N., van der Laan-Luijkx, I. T., van der Werf, G. R., van Heuven, S., Viovy, N., Vuichard, N., Walker, A. P., Watson, A. J., Wiltshire, A. J., Zaehle, S., and Zhu, D.: Global Carbon Budget 2017, Earth Syst. Sci. Data, 10, 405-448, https://doi.org/10.5194/essd-10-405-2018, 2018a. 
Le Quéré, C., Andrew, R. M., Friedlingstein, P., Sitch, S., Hauck, J., Pongratz, J., Pickers, P. A., Korsbakken, J. I., Peters, G. P., Canadell, J. G., Arneth, A., Arora, V. K., Barbero, L., Bastos, A., Bopp, L., Chevallier, F., Chini, L. P., Ciais, P., Doney, S. C., Gkritzalis, T., Goll, D. S., Harris, I., Haverd, V., Hoffman, F. M., Hoppema, M., Houghton, R. A., Hurtt, G., Ilyina, T., Jain, A. K., Johannessen, T., Jones, C. D., Kato, E., Keeling, R. F., Goldewijk, K. K., Landschützer, P., Lefèvre, N., Lienert, S., Liu, Z., Lombardozzi, D., Metzl, N., Munro, D. R., Nabel, J. E. M. S., Nakaoka, S., Neill, C., Olsen, A., Ono, T., Patra, P., Peregon, A., Peters, W., Peylin, P., Pfeil, B., Pierrot, D., Poulter, B., Rehder, G., Resplandy, L., Robertson, E., Rocher, M., Rödenbeck, C., Schuster, U., Schwinger, J., Séférian, R., Skjelvan, I., Steinhoff, T., Sutton, A., Tans, P. P., Tian, H., Tilbrook, B., Tubiello, F. N., van der Laan-Luijkx, I. T., van der Werf, G. R., Viovy, N., Walker, A. P., Wiltshire, A. J., Wright, R., Zaehle, S., and Zheng, B.: Global Carbon Budget 2018, Earth Syst. Sci. Data, 10, 21412194, https://doi.org/10.5194/essd-10-2141-2018, 2018 b.

Le Quéré, C., Korsbakken, J. I., Wilson, C., Tosun, J., Andrew, R., Andres, R. J., Canadell, J. G., Jordan, A., Peters, G. P., and van Vuuren, D. P.: Drivers of declining $\mathrm{CO}_{2}$ emissions in 18 developed economies, Nat. Clim. Change, 9, 213-217, https://doi.org/10.1038/s41558-019-0419-7, 2019.

Li, H. and Ilyina, T.: Current and Future Decadal Trends in the Oceanic Carbon Uptake Are Dominated by Internal Variability, Geophys. Res. Lett., 45, 916-925, https://doi.org/10.1002/2017gl075370, 2018.

Li, W., Ciais, P., Peng, S., Yue, C., Wang, Y., Thurner, M., Saatchi, S. S., Arneth, A., Avitabile, V., Carvalhais, N., Harper, A. B., Kato, E., Koven, C., Liu, Y. Y., Nabel, J. E. M. S., Pan, Y., Pongratz, J., Poulter, B., Pugh, T. A. M., Santoro, M., Sitch, S., Stocker, B. D., Viovy, N., Wiltshire, A., Yousefpour, R., and Zaehle, S.: Land-use and land-cover change carbon emissions between 1901 and 2012 constrained by biomass observations, Biogeosciences, 14, 5053-5067, https://doi.org/10.5194/bg-145053-2017, 2017.

Lienert, S. and Joos, F.: A Bayesian ensemble data assimilation to constrain model parameters and land-use carbon emissions, Biogeosciences, 15, 2909-2930, https://doi.org/10.5194/bg-152909-2018, 2018.

Liu, Z., Guan, D., Wei, W., Davis, S. J., Ciais, P., Bai, J., Peng, S., Zhang, Q., Hubacek, K., Marland, G., Andres, R. J., CrawfordBrown, D., Lin, J., Zhao, H., Hong, C., Boden, T. A., Feng, K., Peters, G. P., Xi, F., Liu, J., Li, Y., Zhao, Y., Zeng, N. and He, K.: Reduced carbon emission estimates from fossil fuel combustion and cement production in China, Nature, 524, 335-338, https://doi.org/10.1038/nature14677, 2015.

Manning, A. C. and Keeling, R. F.: Global oceanic and land biotic carbon sinks from the scripps atmospheric oxygen flask sampling network, Tellus, Ser. B., 58, 95-116, https://doi.org/10.1111/j.1600-0889.2006.00175.x, 2006.

Marland, G.: Uncertainties in Accounting for $\mathrm{CO}_{2}$ From Fossil Fuels, J. Ind. Ecol., 12, 136-139, https://doi.org/10.1111/j.15309290.2008.00014.x, 2008.

Marland, G. and Rotty, R. M.: Carbon-Dioxide Emissions from Fossil-Fuels - a Procedure for Estimation and Results for 19501982, Tellus Ser. B, 36, 232-261, https://doi.org/10.1111/j.16000889.1984.tb00245.x, 1984.
Marland, G., Hamal, K., and Jonas, M.: How Uncertain Are Estimates of $\mathrm{CO}_{2}$ Emissions?, J. Ind. Ecol., 13, 4-7, https://doi.org/10.1111/j.1530-9290.2009.00108.x, 2009.

Masarie, K. A. and Tans, P. P.: Extension and Integration of Atmospheric Carbon-Dioxide Data into a Globally Consistent Measurement Record, J. Geophys. Res., 100, 11593-11610, https://doi.org/10.1029/95jd00859, 1995.

Mauritsen, T., Bader, J., Becker, T., Behrens, J., Bittner, M., Brokopf, R., Brovkin, V., Claussen, M., Crueger, T., Esch, M., Fast, I., Fiedler, S., Fläschner, D., Gayler, V., Giorgetta, M., Goll, D. S., Haak, H., Hagemann, S., Hedemann, C., Hohenegger, C., Ilyina, T., Jahns, T., Jimenéz-de-la-Cuesta, D., Jungclaus, J., Kleinen, T., Kloster, S., Kracher, D., Kinne, S., Kleberg, D., Lasslop, G., Kornblueh, L., Marotzke, J., Matei, D., Meraner, K., Mikolajewicz, U., Modali, K., Möbis, B., Müller, W. A., Nabel, J. E. M. S., Nam, C. C. W., Notz, D., Nyawira, S., Paulsen, H., Peters, K., Pincus, R., Pohlmann, H., Pongratz, J., Popp, M., Raddatz, T. J., Rast, S., Redler, R., Reick, C. H., Rohrschneider, T., Schemann, V., Schmidt, H., Schnur, R., Schulzweida, U., Six, K. D., Stein, L., Stemmler, I., Stevens, B., Storch, J., Tian, F., Voigt, A., Vrese, P., Wieners, K., Wilkenskjeld, S., Winkler, A., and Roeckner, E.: Developments in the MPI-M Earth System Model version 1.2 (MPI-ESM1.2) and Its Response to Increasing $\mathrm{CO}_{2}$, J. Adv. Model. Earth Sy., 11, 9981038, https://doi.org/10.1029/2018MS001400, 2019.

MCI: Ministry of Commerce and Industry: Foreign Trade Data Dissemination Portal, available at: http://14.98.253.4/, last access: 3 November 2019.

McKinley, G. A., Pilcher, D. J., Fay, A. R., Lindsay, K., Long, M. C., and Lovenduski, N. S.: Timescales for detection of trends in the ocean carbon sink, Nature, 530, 469-472, https://doi.org/10.1038/nature16958, 2016.

McNeil, B. I., Matear, R. J., Key, R. M., Bullister, J. L., and Sarmiento, J. L.: Anthropogenic $\mathrm{CO}_{2}$ uptake by the ocean based on the global chlorofluorocarbon data set, Science, 299, 235239, https://doi.org/10.1126/science.1077429, 2003.

Meiyappan, P., Jain, A. K., and House, J. I.: Increased influence of nitrogen limitation on $\mathrm{CO}_{2}$ emissions from future land use and land use change, Global Biogeochem. Cy., 29, 1524-1548, https://doi.org/10.1002/2015gb005086, 2015.

Melton, J. R. and Arora, V. K.: Competition between plant functional types in the Canadian Terrestrial Ecosystem Model (CTEM) v. 2.0, Geosci. Model Dev., 9, 323-361, https://doi.org/10.5194/gmd-9-323-2016, 2016.

Mercado, L. M., Bellouin, N., Sitch, S., Boucher, O., Huntingford, C., Wild, M., and Cox, P. M.: Impact of changes in diffuse radiation on the global land carbon sink, Nature, 458, 1014-1017, https://doi.org/10.1038/nature07949, 2009.

Merlin, O., Al Bitar, A., Rivalland, V., Béziat, P., Ceschia, E., and Dedieu, G.: An Analytical Model of Evaporation Efficiency for Unsaturated Soil Surfaces with an Arbitrary Thickness, J. Appl. Meteorol. Clim., 50, 457-471, https://doi.org/10.1175/2010JAMC2418.1, 2011.

Mikaloff Fletcher, S. E., Gruber, N., Jacobson, A. R., Doney, S. C., Dutkiewicz, S., Gerber, M., Follows, M., Joos, F., Lindsay, K., Menemenlis, D., Mouchet, A., Müller, S. A., and Sarmiento, J. L.: Inverse estimates of anthropogenic $\mathrm{CO}_{2}$ uptake, transport, and storage by the ocean, Global Biogeochem. Cy., 20, GB2002, https://doi.org/10.1029/2005GB002530, 2006. 
Millar, R. J., Fuglestvedt, J. S., Friedlingstein, P., Rogelj, J., Grubb, M. J., Matthews, H. D., Skeie, R. B., Forster, P. M., Frame, D. J., and Allen, M. R.: Emission budgets and pathways consistent with limiting warming to $1.5^{\circ} \mathrm{C}$, Nat. Geosci., 10, 741-747, https://doi.org/10.1038/ngeo3031, 2017.

Ministry of Mines: Ministry of Mines: Mineral Production, available at: http://ibm.nic.in/index.php?c=pages\&m=index\&id=497, last access: 18 September 2019.

Myhre, G., Alterskjær, K., and Lowe, D.: A fast method for updating global fossil fuel carbon dioxide emissions, Environ. Res. Lett., 4, 034012, https://doi.org/10.1088/1748-9326/4/3/034012, 2009.

Myneni, R. B., Ramakrishna, R., Nemani, R., and Running, S. W.: Estimation of global leaf area index and absorbed par using radiative transfer models, IEEE T. Geosci. Remote, 35, 1380-1393, https://doi.org/10.1109/36.649788, 1997.

Narayanan, B., Aguiar, A., and McDougall, R.: Global Trade, Assistance, and Production: The GTAP 9 Data Base, Cent. Glob. Trade Anal. Purdue Univ., available at: https://www.gtap.agecon. purdue.edu/databases/v9/default.asp, September 2015.

NBS: Energy supply growth is speeding up, and the share of clean energy is continuously increasing, The department director interprets the half-yearly report, National Bureau of Statistics, available at: http://www.stats.gov.cn/tjsj/sjjd/201907/ t20190717_1676924.html, last access 23 September 2019a.

NBS: National Bureau of Statistics, 2019, Statistical Communiqué of the People's Republic of China on the 2018 National Economic and Social Development, available at: http://www.stats. gov.cn/english/PressRelease/201902/t20190228_1651335.html, last access: 23 September 2019b.

NBS: National Bureau of Statistics (NBS): National Data (online database), National Bureau of Statistics, available at: http://data. stats.gov.cn/, last access: 1 November 2019c.

NOAA/ESRL: NOAA Greenhouse Gas Marine Boundary Layer Reference, available at: https://www.esrl.noaa.gov/gmd/ccgg/ $\mathrm{mbl} / \mathrm{mbl} . \mathrm{html}$, last access: 27 September 2019.

OEA: Index of Eight Core Industries, available at: http://eaindustry. nic.in/home.asp, last access: 5 November 2019.

Paulsen, H., Ilyina, T., Six, K. D., and Stemmler, I.: Incorporating a prognostic representation of marine nitrogen fixers into the global ocean biogeochemical model HAMOCC, J. Adv. Model. Earth Sy., 9, 438-464, https://doi.org/10.1002/2016MS000737, 2017.

Peters, G. P., Andrew, R., and Lennox, J.: Constructing an environmentally-extended multi-regional input-output table using the GTAP database, Econ. Syst. Res., 23, 131-152, https://doi.org/10.1080/09535314.2011.563234, 2011a.

Peters, G. P., Minx, J. C., Weber, C. L., and Edenhofer, O.: Growth in emission transfers via international trade from 1990 to 2008, P. Natl. Acad. Sci. USA, 108, 8903-8908, https://doi.org/10.1073/pnas.1006388108, $2011 \mathrm{~b}$.

Peters, G. P., Davis, S. J., and Andrew, R.: A synthesis of carbon in international trade, Biogeosciences, 9, 3247-3276, https://doi.org/10.5194/bg-9-3247-2012, 2012a.

Peters, G. P., Marland, G., Le Quéré, C., Boden, T., Canadell, J. G., and Raupach, M. R.: Rapid growth in $\mathrm{CO}_{2}$ emissions after the 2008-2009 global financial crisis, Nat. Clim. Change, 2, 2-4, https://doi.org/10.1038/nclimate1332, 2012b.
Peters, G. P., Andrew, R. M., Boden, T., Canadell, J. G., Ciais, P., Le Quéré, C., Marland, G., Raupach, M. R., and Wilson, C.: The challenge to keep global warming below $2{ }^{\circ} \mathrm{C}$, Nat. Clim. Change, 3, 4-6, https://doi.org/10.1038/nclimate1783, 2013.

Peters, G. P., Le Quéré, C., Andrew, R. M., Canadell, J. G., Friedlingstein, P., Ilyina, T., Jackson, R. B., Joos, F., Korsbakken, J. I., McKinley, G. A., Sitch, S., and Tans, P.: Towards real-time verification of $\mathrm{CO}_{2}$ emissions, Nat. Clim. Change, 7, 848-850, https://doi.org/10.1038/s41558-017-0013-9, 2017.

Peylin, P., Law, R. M., Gurney, K. R., Chevallier, F., Jacobson, A. R., Maki, T., Niwa, Y., Patra, P. K., Peters, W., Rayner, P. J., Rödenbeck, C., van der Laan-Luijkx, I. T., and Zhang, X.: Global atmospheric carbon budget: results from an ensemble of atmospheric $\mathrm{CO}_{2}$ inversions, Biogeosciences, 10, 6699-6720, https://doi.org/10.5194/bg-10-6699-2013, 2013.

Pfeil, B., Olsen, A., Bakker, D. C. E., Hankin, S., Koyuk, H., Kozyr, A., Malczyk, J., Manke, A., Metzl, N., Sabine, C. L., Akl, J., Alin, S. R., Bates, N., Bellerby, R. G. J., Borges, A., Boutin, J., Brown, P. J., Cai, W.-J., Chavez, F. P., Chen, A., Cosca, C., Fassbender, A. J., Feely, R. A., González-Dávila, M., Goyet, C., Hales, B., Hardman-Mountford, N., Heinze, C., Hood, M., Hoppema, M., Hunt, C. W., Hydes, D., Ishii, M., Johannessen, T., Jones, S. D., Key, R. M., Körtzinger, A., Landschützer, P., Lauvset, S. K., Lefèvre, N., Lenton, A., Lourantou, A., Merlivat, L., Midorikawa, T., Mintrop, L., Miyazaki, C., Murata, A., Nakadate, A., Nakano, Y., Nakaoka, S., Nojiri, Y., Omar, A. M., Padin, X. A., Park, G.-H., Paterson, K., Perez, F. F., Pierrot, D., Poisson, A., Ríos, A. F., Santana-Casiano, J. M., Salisbury, J., Sarma, V. V. S. S., Schlitzer, R., Schneider, B., Schuster, U., Sieger, R., Skjelvan, I., Steinhoff, T., Suzuki, T., Takahashi, T., Tedesco, K., Telszewski, M., Thomas, H., Tilbrook, B., Tjiputra, J., Vandemark, D., Veness, T., Wanninkhof, R., Watson, A. J., Weiss, R., Wong, C. S., and Yoshikawa-Inoue, H.: A uniform, quality controlled Surface Ocean $\mathrm{CO}_{2}$ Atlas (SOCAT), Earth Syst. Sci. Data, 5, 125-143, https://doi.org/10.5194/essd-5-125-2013, 2013.

Piao, S., Huang, M., Liu, Z., Wang, X. H., Ciais, P., Canadell, J. G., Wang, K., Bastos, A., Friedlingstein, P., Houghton, R. A., Le Quéré, C., Liu, Y. W., Myneni, R. B., Peng, S. S., Pongratz, J., Sitch, S., Yan, T., Wang, Y. L., Zhu, Z. C., Wu, D. H., and Wang, T.: Lower land-use emissions responsible for increased net land carbon sink during the slow warming period, Nat. Geosci., 11, 739-743, https://doi.org/10.1038/s41561-018-0204-7, 2018.

Pongratz, J., Reick, C. H., Raddatz, T., and Claussen, M.: Effects of anthropogenic land cover change on the carbon cycle of the last millennium, Global Biogeochem. Cy., 23, GB4001, https://doi.org/10.1029/2009GB003488, 2009.

Pongratz, J., Reick, C. H., Houghton, R. A., and House, J. I.: Terminology as a key uncertainty in net land use and land cover change carbon flux estimates, Earth Syst. Dynam., 5, 177-195, https://doi.org/10.5194/esd-5-177-2014, 2014.

Poulter, B., Frank, D. C., Hodson, E. L., and Zimmermann, N. E.: Impacts of land cover and climate data selection on understanding terrestrial carbon dynamics and the $\mathrm{CO}_{2}$ airborne fraction, Biogeosciences, 8, 2027-2036, https://doi.org/10.5194/bg8-2027-2011, 2011.

PPAC: Natural Gas, Petroleum Planning and Analysis Cell, Ministry of Petroleum and Natural Gas, available at: http:// eaindustry.nic.in/home.asp, last access: 5 November 2019a. 
PPAC: Petroleum, Petroleum Planning and Analysis Cell, Ministry of Petroleum and Natural Gas, available at: http://eaindustry.nic. in/home.asp, last access: 17 October 2019b.

Prentice, I. C., Farquhar, G. D., Fasham, M. J. R., Goulden, M. L., Heimann, M., Jaramillo, V. J., Kheshgi, H. S., Le Quéré, C., Scholes, R. J., Wallace, D. W. R., and Press, C. U.: The Carbon Cycle and Atmospheric Carbon Dioxide, in Climate Change 2001: The Scientific Basis, Contribution of Working Group I to the Third Assessment Report of the Intergovernmental Panel on Climate Change, edited by: Houghton, J. T., Ding, Y., Griggs, D. J., Noguer, M., van der Linden, P. J., Dai, X., Maskell, K., and Johnson, C. A., Cambridge University Press, Cambridge, United Kingdom and New York, NY, USA, 183-237, 2001.

Price, J. T. and Warren, R.: Review of the Potential of "Blue Carbon" Activities to Reduce Emissions; available at: http://avoid-net-uk.cc.ic.ac.uk/wpcontent/uploads/delightfuldownloads/2016/03/Literature-review-of-the-potential-ofbluecarbon-activities-to-reduce-emissions-AVOID2-WPE2.pdf (last access: 25 July 2018), 2016.

Raupach, M. R., Marland, G., Ciais, P., Le Quéré, C., Canadell, J. G., Klepper, G., and Field, C. B.: Global and regional drivers of accelerating $\mathrm{CO}_{2}$ emissions, P. Natl. Acad. Sci. USA, 104, 10288-10293, https://doi.org/10.1073/pnas.0700609104, 2007.

Regnier, P., Friedlingstein, P., Ciais, P., Mackenzie, F. T., Gruber, N., Janssens, I. A., Laruelle, G. G., Lauerwald, R., Luyssaert, S., Andersson, A. J., Arndt, S., Arnosti, C., Borges, A. V., Dale, A. W., Gallego-Sala, A., Goddéris, Y., Goossens, N., Hartmann, J., Heinze, C., Ilyina, T., Joos, F., LaRowe, D. E., Leifeld, J., Meysman, F. J. R., Munhoven, G., Raymond, P. A., Spahni, R., Suntharalingam, P., and Thullner, M.: Anthropogenic perturbation of the carbon fluxes from land to ocean, Nat. Geosci., 6, 597-607, https://doi.org/10.1038/ngeo1830, 2013.

Remaud, M., Chevallier, F., Cozic, A., Lin, X., and Bousquet, P.: On the impact of recent developments of the $\mathrm{LMDz}$ atmospheric general circulation model on the simulation of $\mathrm{CO}_{2}$ transport, Geosci. Model Dev., 11, 4489-4513, https://doi.org/10.5194/gmd-11-4489-2018, 2018.

Resplandy, L., Keeling, R. F., Rödenbeck, C., Stephens, B. B., Khatiwala, S., Rodgers, K. B., Long, M. C., Bopp, L., and Tans, P. P.: Revision of global carbon fluxes based on a reassessment of oceanic and riverine carbon transport, Nat. Geosci., 11, 504-509, https://doi.org/10.1038/s41561-018-0151-3, 2018.

Rhein, M., Rintoul, S. R., Aoki, S., Campos, E., Chambers, D., Feely, R. A., Gulev, S., Johnson, G. C., Josey, S. A., Kostianoy, A., Mauritzen, C., Roemmich, D., Talley, L. D., Wang, F., Stocker, T., Qin, D., and Platner, G.-K.: Chapter 3: Observations: Ocean, in: Climate Change 2013 The Physical Science Basis, Cambridge University Press, 2013.

Rödenbeck, C.: Estimating $\mathrm{CO}_{2}$ sources and sinks from atmospheric mixing ratio measurements using a global inversion of atmospheric transport, Technical Report 6, available at: http: //www.bgc-jena.mpg.de/CarboScope/s/tech_report6.pdf (last accessed: 1 November 2019), Max Planck Institute for Biogeochemistry, Jena, 2005.

Rödenbeck, C., Houweling, S., Gloor, M., and Heimann, M.: $\mathrm{CO}_{2}$ flux history 1982-2001 inferred from atmospheric data using a global inversion of atmospheric transport, Atmos. Chem. Phys., 3, 1919-1964, https://doi.org/10.5194/acp-3-1919-2003, 2003.
Rödenbeck, C., Keeling, R. F., Bakker, D. C. E., Metzl, N., Olsen, A., Sabine, C., and Heimann, M.: Global surface-ocean $p \mathrm{CO}_{2}$ and sea-air $\mathrm{CO}_{2}$ flux variability from an observationdriven ocean mixed-layer scheme, Ocean Sci., 9, 193-216, https://doi.org/10.5194/os-9-193-2013, 2013.

Rödenbeck, C., Bakker, D. C. E., Metzl, N., Olsen, A., Sabine, C., Cassar, N., Reum, F., Keeling, R. F., and Heimann, M.: Interannual sea-air $\mathrm{CO}_{2}$ flux variability from an observationdriven ocean mixed-layer scheme, Biogeosciences, 11, 45994613, https://doi.org/10.5194/bg-11-4599-2014, 2014.

Rödenbeck, C., Bakker, D. C. E., Gruber, N., Iida, Y., Jacobson, A. R., Jones, S., Landschützer, P., Metzl, N., Nakaoka, S., Olsen, A., Park, G.-H., Peylin, P., Rodgers, K. B., Sasse, T. P., Schuster, U., Shutler, J. D., Valsala, V., Wanninkhof, R., and Zeng, J.: Data-based estimates of the ocean carbon sink variability - first results of the Surface Ocean $p \mathrm{CO}_{2}$ Mapping intercomparison (SOCOM), Biogeosciences, 12, 72517278, https://doi.org/10.5194/bg-12-7251-2015, 2015.

Rödenbeck, C., Zaehle, S., Keeling, R., and Heimann, M.: How does the terrestrial carbon exchange respond to interannual climatic variations? A quantification based on atmospheric $\mathrm{CO}_{2}$ data, Biogeosciences, 15, 2481-2498, https://doi.org/10.5194/bg-15-2481-2018, 2018.

Rogelj, J., Schaeffer, M., Friedlingstein, P., Gillett, N. P., van Vuuren, D. P., Riahi, K., Allen, M., and Knutti, R.: Differences between carbon budget estimates unravelled, Nat. Clim. Change, 6 , 245-252, https://doi.org/10.1038/Nclimate2868, 2016.

Rogelj, J., Forster, P. M., Kriegler, E., Smith, C. J., and Séférian, R.: Estimating and tracking the remaining carbon budget for stringent climate targets, Nature, 571, 335-342, https://doi.org/10.1038/s41586-019-1368-z, 2019.

Rypdal, K., Paciomik, N., Eggleston, S., Goodwin, J., Irving, W., Penman, J., and Woodfield, M.: Chapter 1 Introduction to the 2006 Guidelines, in 2006 IPCC Guidelines for National Greenhouse Gas Inventories, edited by: Eggleston, S., Buendia, L., Miwa, K., Ngara, T., and Tanabe, K., Institute for Global Environmental Strategies (IGES), Hayama, Kanagawa, Japan, 2006.

Saatchi, S. S., Harris, N. L., Brown, S., Lefsky, M., Mitchard, E. T. A., Salas, W., Zutta, B. R., Buermann, W., Lewis, S. L., Hagen, S., Petrova, S., White, L., Silman, M., and Morel, A.: Benchmark map of forest carbon stocks in tropical regions across three continents, P. Natl. Acad. Sci. USA, 108, 98999904, https://doi.org/10.1073/pnas.1019576108, 2011.

Sabine, C. L., Feely, R. A., Gruber, N., Key, R. M., Lee, K., Bullister, J. L., Wanninkhof, R., Wong, C. S., Wallace, D. W. R., Tilbrook, B., Millero, F. J., Peng, T.-H., Kozyr, A., Ono, T., and Rio, A. F.: The Oceanic Sink for Anthropogenic $\mathrm{CO}_{2}$, Science, 305, 367-371, https://doi.org/10.1126/science.1097403, 2004.

Saunois, M., Bousquet, P., Poulter, B., Peregon, A., Ciais, P., Canadell, J. G., Dlugokencky, E. J., Etiope, G., Bastviken, D., Houweling, S., Janssens-Maenhout, G., Tubiello, F. N., Castaldi, S., Jackson, R. B., Alexe, M., Arora, V. K., Beerling, D. J., Bergamaschi, P., Blake, D. R., Brailsford, G., Brovkin, V., Bruhwiler, L., Crevoisier, C., Crill, P., Covey, K., Curry, C., Frankenberg, C., Gedney, N., Höglund-Isaksson, L., Ishizawa, M., Ito, A., Joos, F., Kim, H.-S., Kleinen, T., Krummel, P., Lamarque, J.-F., Langenfelds, R., Locatelli, R., Machida, T., Maksyutov, S., McDonald, K. C., Marshall, J., Melton, J. R., Morino, I., Naik, V., O’Doherty, S., Parmentier, F.-J. W., Patra, P. K., Peng, C., Peng, S., Peters, 
G. P., Pison, I., Prigent, C., Prinn, R., Ramonet, M., Riley, W. J., Saito, M., Santini, M., Schroeder, R., Simpson, I. J., Spahni, R., Steele, P., Takizawa, A., Thornton, B. F., Tian, H., Tohjima, Y., Viovy, N., Voulgarakis, A., van Weele, M., van der Werf, G. R., Weiss, R., Wiedinmyer, C., Wilton, D. J., Wiltshire, A., Worthy, D., Wunch, D., Xu, X., Yoshida, Y., Zhang, B., Zhang, Z., and Zhu, Q.: The global methane budget 2000-2012, Earth Syst. Sci. Data, 8, 697-751, https://doi.org/10.5194/essd-8-697-2016, 2016.

SCCL: Singareni Collieries Company Limited (SCCL): Provisional Production and Dispatches Performance. Singareni Collieries Company Limited, available at: https://scclmines.com/scclnew/ performance_production.asp, last access: 3 September 2019.

Schimel, D., Alves, D., Enting, I., Heimann, M., Joos, F., Raynaud, D., Wigley, T., Prater, M., Derwent, R., Ehhalt, D., Fraser, P., Sanhueza, E., Zhou, X., Jonas, P., Charlson, R., Rodhe, H., Sadasivan, S., Shine, K. P., Fouquart, Y., Ramaswamy, V., Solomon, S., Srinivasan, J., Albritton, D., Derwent, R., Isaksen, I., Lal, M., Wuebbles, D., and Press, C. U.: Radiative Forcing of Climate Change, in: Climate Change 1995 The Science of Climate Change. Contribution of Working Group I to the Second Assessment Report of the Intergovernmental Panel on Climate Change, edited by: Houghton, J. T., Meira Rilho, L. G., Callander, B. A., Harris, N., Kattenberg, A., and Maskell, K., Cambridge University Press, Cambridge, United Kingdom and New York, NY, USA, 1995.

Schimel, D., Stephens, B. B., and Fisher, J. B.: Effect of increasing $\mathrm{CO}_{2}$ on the terrestrial carbon cycle, P. Natl. Acad. Sci. USA, 112, 436-441, https://doi.org/10.1073/pnas.1407302112, 2015.

Schwietzke, S., Sherwood, O. A., Bruhwiler, L. M., Miller, J. B., Etiope, G., Dlugokencky, E. J., Michel, S. E., Arling, V. A., Vaughn, B. H., White, J. W., and Tans, P. P.: Upward revision of global fossil fuel methane emissions based on isotope database, Nature, 538, 88-91, https://doi.org/10.1038/nature19797, 2016.

Schwinger, J., Goris, N., Tjiputra, J. F., Kriest, I., Bentsen, M., Bethke, I., Ilicak, M., Assmann, K. M., and Heinze, C.: Evaluation of NorESM-OC (versions 1 and 1.2), the ocean carboncycle stand-alone configuration of the Norwegian Earth System Model (NorESM1), Geosci. Model Dev., 9, 2589-2622, https://doi.org/10.5194/gmd-9-2589-2016, 2016.

Séférian, R., Delire, C., Decharme, B., Voldoire, A., Salas y Melia, D., Chevallier, M., Saint-Martin, D., Aumont, O., Calvet, J.C., Carrer, D., Douville, H., Franchistéguy, L., Joetzjer, E., and Sénési, S.: Development and evaluation of CNRM Earth system model - CNRM-ESM1, Geosci. Model Dev., 9, 1423-1453, https://doi.org/10.5194/gmd-9-1423-2016, 2016.

Sellar, A. A., Jones, C. G., Mulcahy, J., Tang, Y., Yool, A., Wiltshire, A., O’Connor, F. M., Stringer, M., Hill, R., Palmieri, J., Woodward, S., Mora, L., Kuhlbrodt, T., Rumbold, S., Kelley, D. I., Ellis, R., Johnson, C. E., Walton, J., Abraham, N. L., Andrews, M. B., Andrews, T., Archibald, A. T., Berthou, S., Burke, E., Blockley, E., Carslaw, K., Dalvi, M., Edwards, J., Folberth, G. A., Gedney, N., Griffiths, P. T., Harper, A. B., Hendry, M. A., Hewitt, A. J., Johnson, B., Jones, A., Jones, C. D., Keeble, J., Liddicoat, S., Morgenstern, O., Parker, R. J., Predoi, V., Robertson, E., Siahaan, A., Smith, R. S., Swaminathan, R., Woodhouse, M. T., Zeng, G., and Zerroukat, M.: UKESM1: Description and evaluation of the UK Earth
System Model, J. Adv. Model. Earth Sy., 2019MS001739, https://doi.org/10.1029/2019MS001739, accepted, 2019.

Shangguan, W., Hengl, T., Mendes de Jesus, J., Yuan, H., and Dai, Y.: Mapping the global depth to bedrock for land surface modeling, J. Adv. Model. Earth Sy., 9, 65-88, https://doi.org/10.1002/2016MS000686, 2017.

Shevliakova, E., Pacala, S. W., Malyshev, S., Hurtt, G. C., Milly, P. C. D., Caspersen, J. P., Sentman, L. T., Fisk, J. P., Wirth, C., and Crevoisier, C.: Carbon cycling under 300 years of land use change: Importance of the secondary vegetation sink, Global Biogeochem. Cy., 23, GB2022, https://doi.org/10.1029/2007GB003176, 2009.

Sitch, S., Huntingford, C., Gedney, N., Levy, P. E., Lomas, M., Piao, S. L., Betts, R., Ciais, P., Cox, P., Friedlingstein, P., Jones, C. D., Prentice, I. C., and Woodward, F. I.: Evaluation of the terrestrial carbon cycle, future plant geography and climate-carbon cycle feedbacks using five Dynamic Global Vegetation Models (DGVMs), Glob. Change Biol., 14, 2015-2039, https://doi.org/10.1111/j.1365-2486.2008.01626.x, 2008.

Smith, B., Wårlind, D., Arneth, A., Hickler, T., Leadley, P., Siltberg, J., and Zaehle, S.: Implications of incorporating $\mathrm{N}$ cycling and $\mathrm{N}$ limitations on primary production in an individualbased dynamic vegetation model, Biogeosciences, 11, 20272054, https://doi.org/10.5194/bg-11-2027-2014, 2014.

Stephens, B. B., Gurney, K. R., Tans, P. P., Sweeney, C., Peters, W., Bruhwiler, L., Ciais, P., Ramonet, M., Bousquet, P., Nakazawa, T., Aoki, S., Machida, T., Inoue, G., Vinnichenko, N., Lloyd, J., Jordan, A., Heimann, M., Shibistova, O., Langenfelds, R. L., Steele, L. P., Francey, R. J., and Denning, A. S.: Weak northern and strong tropical land carbon uptake from vertical profiles of atmospheric $\mathrm{CO}_{2}$, Science, 316, 1732-1735, https://doi.org/10.1126/science.1137004, 2007.

Stocker, T., Qin, D., and Platner, G.-K.: Climate Change 2013 The Physical Science Basis, Cambridge University Press, 2013.

Swart, N. C., Fyfe, J. C., Saenko, O. A., and Eby, M.: Wind-driven changes in the ocean carbon sink, Biogeosciences, 11, 61076117, https://doi.org/10.5194/bg-11-6107-2014, 2014.

Tian, H., Xu, X., Lu, C., Liu, M., Ren, W., Chen, G., Melillo, J., and Liu, J.: Net exchanges of $\mathrm{CO}_{2}, \mathrm{CH}_{4}$, and $\mathrm{N}_{2} \mathrm{O}$ between China's terrestrial ecosystems and the atmosphere and their contributions to global climate warming, J. Geophys. Res., 116, G02011, https://doi.org/10.1029/2010jg001393, 2011.

Tian, H., Chen, G., Lu, C., Xu, X., Hayes, D. J., Ren, W., Pan, S., Huntzinger, D. N., and Wofsy, S. C.: North American terrestrial $\mathrm{CO}_{2}$ uptake largely offset by $\mathrm{CH}_{4}$ and $\mathrm{N}_{2} \mathrm{O}$ emissions: toward a full accounting of the greenhouse gas budget, Climatic Change, 129, 413-426, https://doi.org/10.1007/s10584014-1072-9, 2015.

Todd-Brown, K. E. O., Randerson, J. T., Post, W. M., Hoffman, F. M., Tarnocai, C., Schuur, E. A. G., and Allison, S. D.: Causes of variation in soil carbon simulations from CMIP5 Earth system models and comparison with observations, Biogeosciences, 10, 1717-1736, https://doi.org/10.5194/bg-10-1717-2013, 2013.

UN: United Nations Statistics Division: National Accounts Main Aggregates Database, available at: http://unstats.un.org/unsd/ snaama/Introduction.asp (last access: 2 January 2018), 2017.

UN: United Nations Statistics Division: Energy Statistics, available at: http://unstats.un.org/unsd/energy/ (last access: 27 September 2019), 2018. 
UNFCCC: National Inventory Submissions, available at: https: //unfccc.int/process-and-meetings/transparency-and-reporting/ reporting-and-review-under-the-convention/ greenhouse-gas-inventories-annex-i-parties/ national-inventory-submissions-2019, last access: 20 June 2019. van der Laan-Luijkx, I. T., van der Velde, I. R., van der Veen, E., Tsuruta, A., Stanislawska, K., Babenhauserheide, A., Zhang, H. F., Liu, Y., He, W., Chen, H., Masarie, K. A., Krol, M. C., and Peters, W.: The CarbonTracker Data Assimilation Shell (CTDAS) v1.0: implementation and global carbon balance 2001-2015, Geosci. Model Dev., 10, 2785-2800, https://doi.org/10.5194/gmd-10-2785-2017, 2017.

van der Velde, I. R., Miller, J. B., Schaefer, K., van der Werf, G. R., Krol, M. C., and Peters, W.: Terrestrial cycling of ${ }^{13} \mathrm{CO}_{2}$ by photosynthesis, respiration, and biomass burning in SiBCASA, Biogeosciences, 11, 6553-6571, https://doi.org/10.5194/bg-116553-2014, 2014.

van der Werf, G. R., Randerson, J. T., Giglio, L., Collatz, G. J., Mu, M., Kasibhatla, P. S., Morton, D. C., DeFries, R. S., Jin, Y., and van Leeuwen, T. T.: Global fire emissions and the contribution of deforestation, savanna, forest, agricultural, and peat fires (1997-2009), Atmos. Chem. Phys., 10, 11707-11735, https://doi.org/10.5194/acp-10-11707-2010, 2010.

van der Werf, G. R., Randerson, J. T., Giglio, L., van Leeuwen, T. T., Chen, Y., Rogers, B. M., Mu, M., van Marle, M. J. E., Morton, D. C., Collatz, G. J., Yokelson, R. J., and Kasibhatla, P. S.: Global fire emissions estimates during 1997-2016, Earth Syst. Sci. Data, 9, 697-720, https://doi.org/10.5194/essd-9-697-2017, 2017.

Van Minnen, J. G., Klein Goldewijk, K., Stehfest, E., Eickhout, B., van Drecht, G., and Leemans, R.: The importance of three centuries of land-use change for the global and regional terrestrial carbon cycle, Climatic Change, 97, 123-144, https://doi.org/10.1007/s10584-009-9596-0, 2009.

Varadhan, S.: Coal India expects to resume a third of output 5 at flooded Dipka mine within 10 days, Reuters, available at: https://www.reuters.com/article/coal-indiamine-floods/coalindia-expects-to-resume-a-third-of-output-at-flooded-dipkamine-within-10-days-idINKBN1WI1IT, last access: 15 October 2019.

Viovy, N.: CRUNCEP data set, available at: ftp://nacp.ornl.gov/ synthesis/2009/frescati/temp/land_use_change/original/readme. htm, last access: June 2016.

Walker, A. P., Quaife, T., van Bodegom, P. M., De Kauwe, M. G., Keenan, T. F., Joiner, J., Lomas, M. R., MacBean, N., Xu, C. G., Yang, X. J., and Woodward, F. I.: The impact of alternative traitscaling hypotheses for the maximum photosynthetic carboxylation rate (V-cmax) on global gross primary production, New Phytol., 215, 1370-1386, https://doi.org/10.1111/nph.14623, 2017.

Wanninkhof, R., Park, G.-H., Takahashi, T., Sweeney, C., Feely, R., Nojiri, Y., Gruber, N., Doney, S. C., McKinley, G. A., Lenton, A., Le Quéré, C., Heinze, C., Schwinger, J., Graven, H., and Khatiwala, S.: Global ocean carbon uptake: magnitude, variability and trends, Biogeosciences, 10, 1983-2000, https://doi.org/10.5194/bg-10-1983-2013, 2013.
Watson, R. T., Rodhe, H., Oeschger, H., Siegenthaler, U., and Press, C. U.: Greenhouse Gases and Aerosols, in Climate Change: The IPCC Scientific Assessment. Intergovernmental Panel on Climate Change (IPCC), edited by: Houghton, J. T., Jenkins, G. J., and Ephraums, J. J., Cambridge University Press, Cambridge, 140, 1990.

Wenzel, S., Cox, P. M., Eyring, V., and Friedlingstein, P.: Projected land photosynthesis constrained by changes in the seasonal cycle of atmospheric $\mathrm{CO}_{2}$, Nature, 538, 499-501, https://doi.org/10.1038/nature19772, 2016.

Wilkenskjeld, S., Kloster, S., Pongratz, J., Raddatz, T., and Reick, C. H.: Comparing the influence of net and gross anthropogenic land-use and land-cover changes on the carbon cycle in the MPI-ESM, Biogeosciences, 11, 4817-4828, https://doi.org/10.5194/bg-11-4817-2014, 2014.

Woodward, F. I. and Lomas, M. R.: Vegetation dynamics - simulating responses to climatic change, Biol. Rev., 79, 643-670, https://doi.org/10.1017/S1464793103006419, 2004.

Xi, F., Davis, S. J., Ciais, P., Crawford-Brown, D., Guan, D., Pade, C., Shi, T., Syddall, M., Lv, J., Ji, L., Bing, L., Wang, J., Wei, W., Yang, K.-H., Lagerblad, B., Galan, I., Andrade, C., Zhang, Y., and Liu, Z.: Substantial global carbon uptake by cement carbonation, Nat. Geosci., 9, 880-883, https://doi.org/10.1038/ngeo2840, 2016.

Yin, X. W.: Responses of leaf nitrogen concentration and specific leaf area to atmospheric $\mathrm{CO}_{2}$ enrichment: a retrospective synthesis across 62 species, Glob. Change Biol., 8, 631-642, https://doi.org/10.1046/j.1365-2486.2002.00497.x, 2002.

Zaehle, S. and Friend, A. D.: Carbon and nitrogen cycle dynamics in the $\mathrm{O}-\mathrm{CN}$ land surface model: 1. Model description, site-scale evaluation, and sensitivity to parameter estimates, Global Biogeochem. Cy., 24, GB1005, https://doi.org/10.1029/2009GB003521, 2010.

Zaehle, S., Ciais, P., Friend, A. D., and Prieur, V.: Carbon benefits of anthropogenic reactive nitrogen offset by nitrous oxide emissions, Nat. Geosci., 4, 601-605, https://doi.org/10.1038/ngeo1207, 2011.

Zheng, B., Chevallier, F., Yin, Y., Ciais, P., Fortems-Cheiney, A., Deeter, M. N., Parker, R. J., Wang, Y., Worden, H. M., and Zhao, Y.: Global atmospheric carbon monoxide budget 2000 2017 inferred from multi-species atmospheric inversions, Earth Syst. Sci. Data, 11, 1411-1436, https://doi.org/10.5194/essd-111411-2019, 2019.

Zscheischler, J., Mahecha, M. D., Avitabile, V., Calle, L., Carvalhais, N., Ciais, P., Gans, F., Gruber, N., Hartmann, J., Herold, M., Ichii, K., Jung, M., Landschützer, P., Laruelle, G. G., Lauerwald, R., Papale, D., Peylin, P., Poulter, B., Ray, D., Regnier, P., Rödenbeck, C., Roman-Cuesta, R. M., Schwalm, C., Tramontana, G., Tyukavina, A., Valentini, R., van der Werf, G., West, T. O., Wolf, J. E., and Reichstein, M.: Reviews and syntheses: An empirical spatiotemporal description of the global surface-atmosphere carbon fluxes: opportunities and data limitations, Biogeosciences, 14, 3685-3703, https://doi.org/10.5194/bg-14-3685-2017, 2017. 